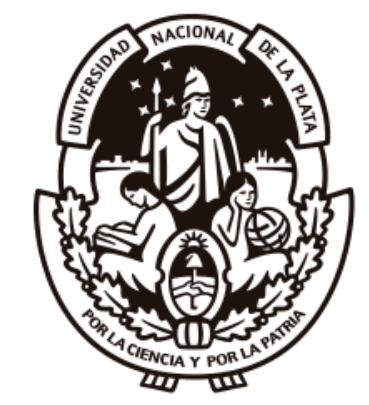

UNIVERSIDAD NACIONAL DE LA PLATA

FACULTAD DE CIENCIAS VETERINARIAS

Trabajo de Tesis realizado como requisito para optar al título de DOCTOR EN CIENCIAS VETERINARIAS

\title{
ESTUDIO CUANTITATIVO Y MOLECULAR DE LA EDAD DE ARRIBO A LA PUBERTAD EN LA HEMBRA BOVINA
}

\author{
Autor: Med. Vet. Martín Bonamy \\ Director: Dr. Guillermo Giovambattista \\ Codirector: Med. Vet. Andrés Baldo
}

Lugar de trabajo:

Cátedra de Producción de Bovinos

Instituto de Genética Veterinaria Ing. Fernando Noel Dolout.

IGEVET. FCV-CONICET

Miembros del Jurado:

Ing. Agr. M. Sc. Lilia M. Melucci

Dr. Darío Colombatto

Dr. Sebastián Picco 
A mis padres Silvana y Alejandro. 
"El conocimiento no es una vasija que se llena, sino un fuego que se enciende" Plutarco. 


\section{AGRADECIMIENTOS}

Quiero agradecer a la Universidad Nacional de La Plata, quién me permitió completar mis estudios secundarios donde comencé a interesarme por los sistemas productivos en la Escuela Inchausti, posteriormente mis estudios universitarios, y finalmente becó mis estudios de posgrado.

A mis directores Guille y Andrés por dirigir esta tesis, por su apoyo, aporte y conocimientos aportados durante el curso de estos años. Por la oportunidad de pertenecer un grupo de trabajo con ambición constante de crecimiento y superación.

Al grupo de bovinos Alberto, Roberto, Enrique, Fede, Nico, Lisa, Adri, Juli, Mari, Jorge y Chucho, por el aprendizaje, la colaboración, el empuje y el compañerismo durante este tiempo.

A Alicia, Santiago, Pía y Luzbel quienes me acompañaron en mis primeros pasos en la investigación científica, cuando todavía era un estudiante.

Al grupo del IGEVET, en especial a Andrés, Moni, Mari, Nadia y Gisella por la colaboración y la paciencia cuando me encontraba perdido en el laboratorio.

A todo grupo de mejoramiento genético de FAUBA, en especial a Andrés y Seba, por compartir sus conocimientos, por darme una mano, palabras de aliento y algún que otro empujón cuando fue necesario.

A Ramiro, Seba y Andrés por la colaboración en el diseño de los modelos de análisis.

Al personal de campo de la "Cabaña El Amanecer - UNLP”, a la "Cabaña Don Alejandro - TAESA", a la familia Larsen de "Cabaña El Refugio", a Beto Stancovich de "Cabaña Océano Chico", a Alberto Areco de "Cabaña Flores 
Chicas", a Pochin Aguirregabiria y a Jorge Ferrario quienes hicieron posible todos los muestreos que se cristalizaron en este trabajo.

A la gente de la Mejoramiento Genético de la UNESP y la ANCP, en especial a Fernando Baldi, por la oportunidad de trabajar junto a ellos y por hacer tan agradable mi estadía.

A mi familia y a Natali, por el apoyo y el cariño de siempre y por acompañarme en todas las decisiones que he tomado. A mis amigos de siempre, los de allá y los de acá por ser el cable a tierra cada vez que los necesito, por tener la palabra justa, por los consejos la complicidad y la gran compañía para los momentos de ocio. Sin duda sin el apoyo de los afectos no estaría hoy escribiendo estas líneas. 


\section{LISTADO DE PUBLICACIONES RELATIVAS AL PRESENTE PLAN DE TESIS}

- Bonamy M, Prando AJ, de Iraola JJ, Vaca R, Antonini A, Giovambattista G, Baldo A. Relación entre crecimiento y pubertad en vaquillonas en sistemas pastoriles de Buenos Aires. 2014. $37^{\circ}$ Congreso Argentino de Producción Animal. CABA. Argentina.

- Bonamy M, Prando AJ, de Iraola JJ, Baldo A, Rogberg-Muñoz A. Influencia de la recría pastoril sobre la pubertad al momento del servicio en hembras bovinas. 2016. Segunda Jornada de Divulgación Científica del IGEVET. La Plata. Argentina.

- Bonamy M, de Iraola JJ, Prando AJ, Pofcher EJ, Giovambattista G, Baldo A, Munilla-Leguizamon S. Correlación genética entre la circunferencia escrotal a los 300 días de edad y la edad al primer parto en vaquillonas Angus. 2017. $40^{\circ}$ Congreso Argentino de Producción Animal. Córdoba. Argentina.

- Bonamy M, de Iraola JJ, Prando AJ, Baldo A, Giovambattista G, RogbergMuñoz A. Longitudinal data analysis detects differences in pre-breeding growing curves of 24-month calving Angus heifers under two pasture-based system. Journal of the science of food and agriculture. ENVIADO.

- Bonamy M, de Iraola JJ, Baldo A, Prando A, Giovambattista G, Munilla S. Early scrotal circumference measurements better reflects female precocity in beef cattle. Livestock Science. ENVIADO. 
INDICE DE CONTENIDOS.

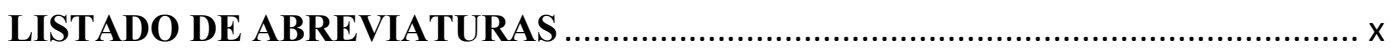

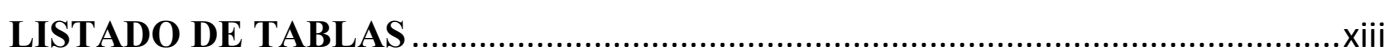

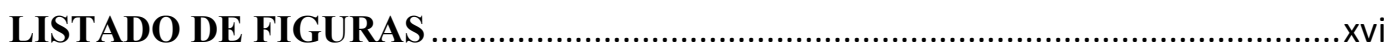

TITULO: Estudio cuantitativo y molecular de la edad de arribo a la pubertad en la

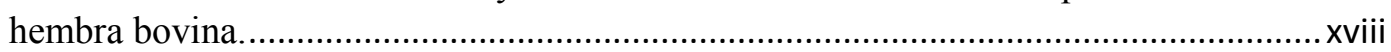

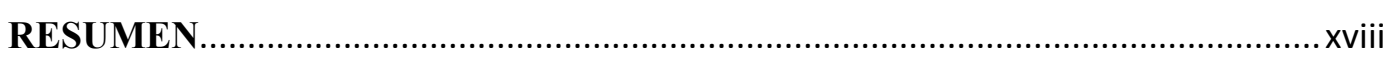

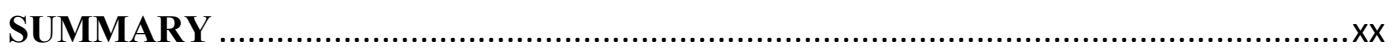

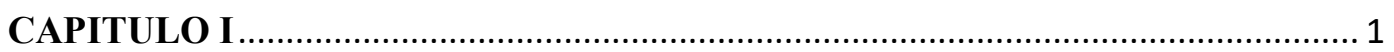

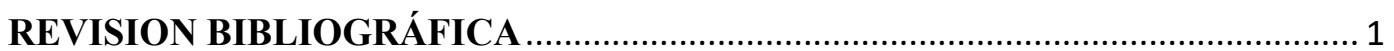

1.1 EL SISTEMA PRODUCTOR DE CARNE EN ARGENTINA Y LA IMPORTANCIA DE LA FERTILIDAD......................................................... 1

1.2 LA PRECOCIDAD SEXUAL Y EL USO DE CATEGORÍAS JÓVENES....... 4 1.3 DESARROLLO DE LA HEMBRA BOVINA.................................................. 6

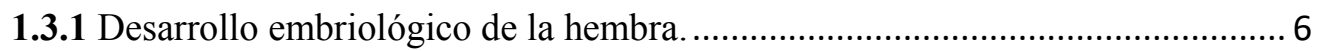

1.3.2 Consideraciones fisiológicas sobre el ciclo estral bovino.................................. 7

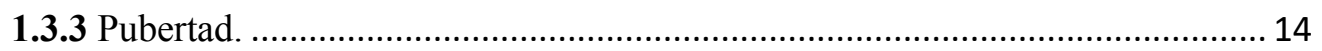

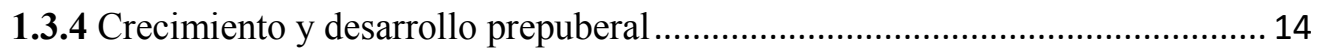

1.3.4.1 Crecimiento del aparato reproductivo.................................................... 15

1.3.4.2 Función ovárica en terneras prepúberes.................................................. 16

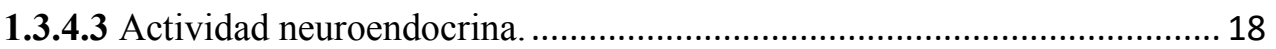

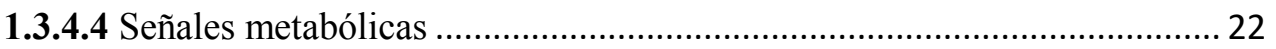

1.4 RELACION DE LA PUBERTAD CON LA NUTRICIÓN ............................ 26

1.5 INICIO DE LA PUBERTAD EN VAQUILLONAS ..................................... 26

1.6 SELECCIÓN GENÉTICA POR PRECOCIDAD SEXUAL. ............................ 28

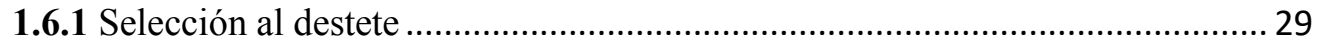

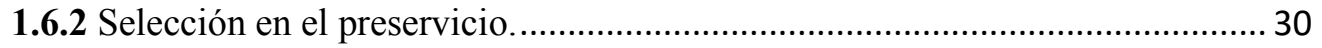

1.6.3 Selección por características correlacionadas ................................................... 32

1.6.4 Selección a través de información de marcadores genéticos. …….................... 33

1.6.5 Selección a través de evaluaciones genéticas............................................... 33

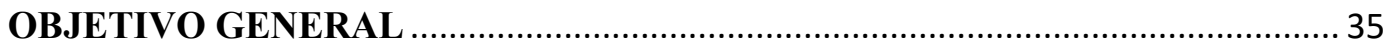

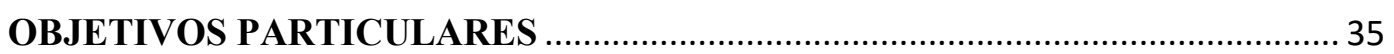

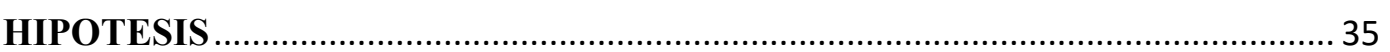

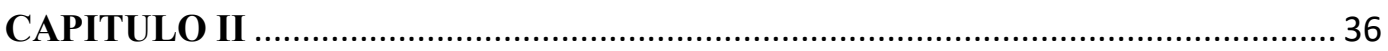


ANÁLISIS LONGITUDINAL DE LAS DIFERENCIAS EN CURVAS DE CRECIMIENTO PRESERVICIO EN VAQUILLONAS ANGUS PARA ENTORE A 15 MESES BAJO DOS TRATAMIENTOS NUTRICIONALES BASADOS EN

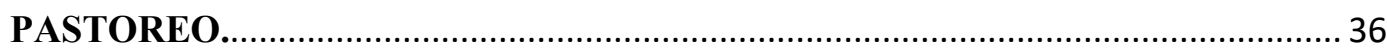

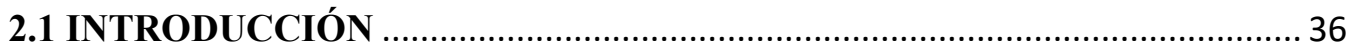

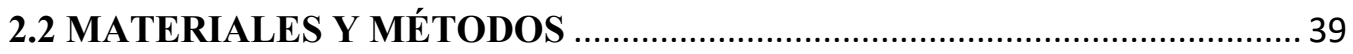

2.2.1 Animales, condiciones alimenticias y datos fenotípicos................................ 39

2.2.2 Estimación del balance energético durante el estudio..................................... 41

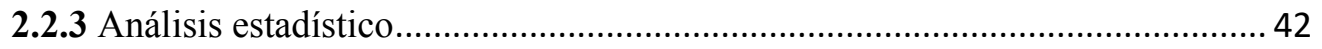

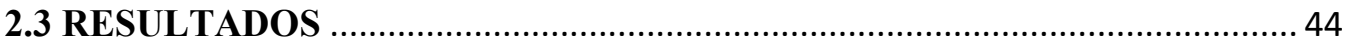

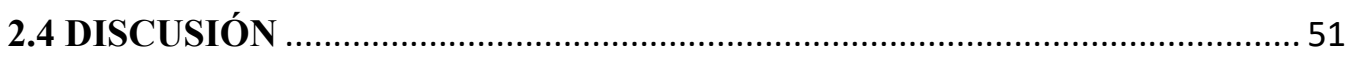

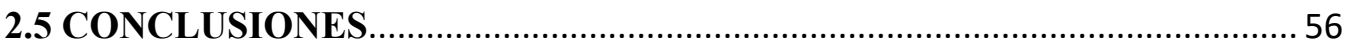

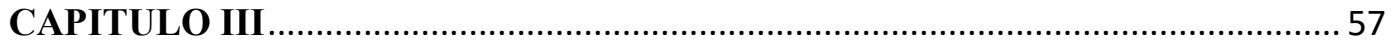

RIESGO DE PUBERTAD ASOCIADO A LA PRESENCIA DE POLIMORFISMOS EN GENES CANDIDATOS. UN ENFOQUE UTILIZANDO

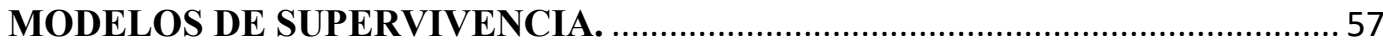

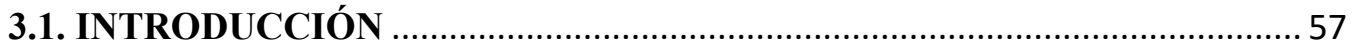

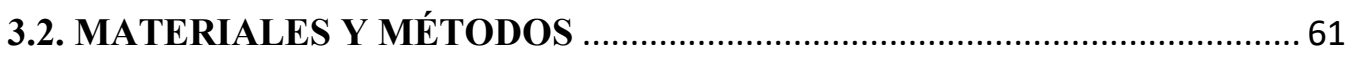

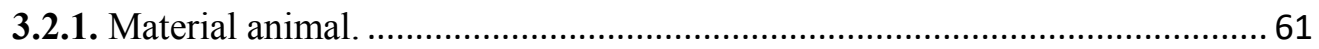

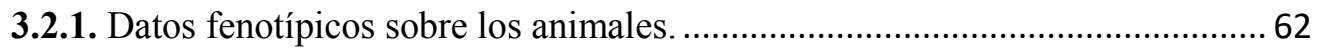

3.2.3. Obtención, procesamiento de muestras, determinación de genotipos.............. 63

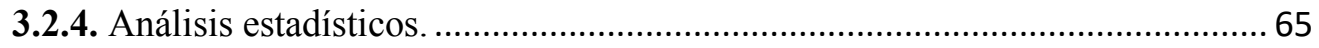

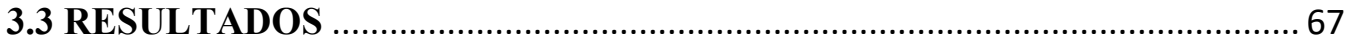

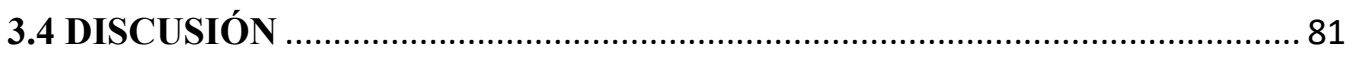

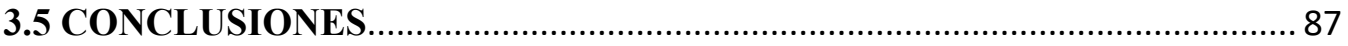

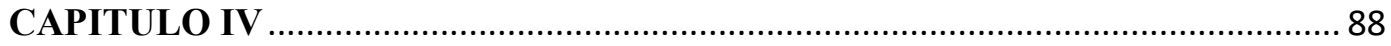

CORRELACIONES GENÉTICAS ENTRE LA PRECOCIDAD SEXUAL EN LAS HEMBRAS Y LA CIRCUNFERENCIA ESCROTAL EN LOS MACHOS A

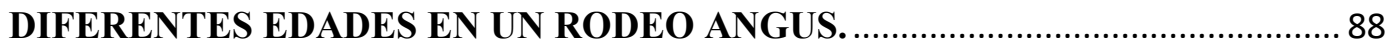

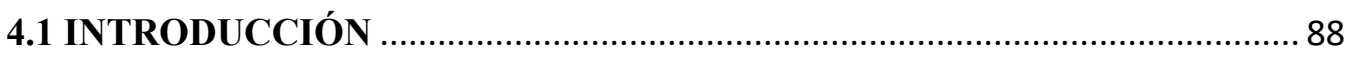

4.2.2 Mediciones y armado de archivos de datos...................................................... 95

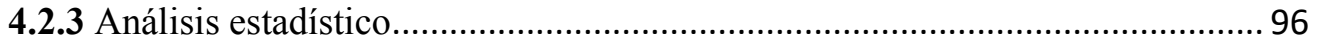

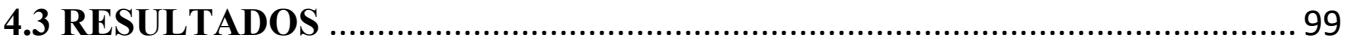

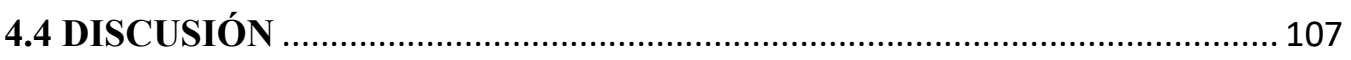

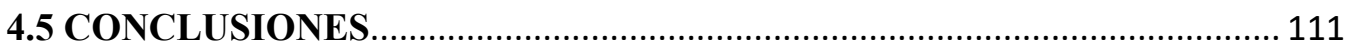

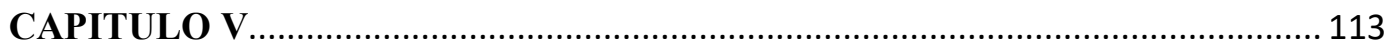




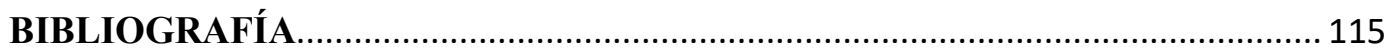

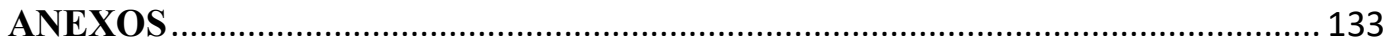

Anexo 1. Datos utilizados en la ecuación de predicción de los requerimientos energéticos de las vaquillonas. National Research Council. NRC. 2012 .................... 133

Anexo 2. Extracción orgánica de ADN total de sangre periférica. 134

Anexo 4. Amplificación de IGF-SnaBI y GnRHR-SNP6 por reacción en cadena de la polimerasa (PCR) para pirosecuenciación. 135

Anexo 5. Descripción de la técnica de pirosecuenciación. 136 


\section{LISTADO DE ABREVIATURAS}

AD Ad-libitum

ADN Ácido desoxirribonucleico

ADP Aumento diario de peso vivo

AGNEs Ácidos grasos no esterificados

Asociación nacional de criadores e investigadores

ANCP

(Brasil)

APd Aumento de peso derivado

ARC Núcleo arcuato

BE Balance energético

BLUP Mejor predicción lineal insesgada

CE Circunferencia escrotal

CE300 Circunferencia escrotal a los 300 días de edad

CE400 Circunferencia escrotal a los 400 días de edad

CE630 Circunferencia escrotal a los 630 días de edad

CICUAL

Comité institucional para el cuidado y uso de los

animales de laboratorio

CL Cuerpo lúteo

DAP Días al parto

DEP Desvió esperado de progenie

EBV Valor de cría esperado

EDTA Ácido etilendiaminotetraacético

EGF Factor de crecimiento epidérmico

EPP Edad al primer parto 
ES Error estándar

FGF Factor de crecimiento de fibroblastos

FPA Fracción de pubertad acumulada

FPP Fecha de primer parto

FSH Hormona folículo estimulante

GABA Acido gamma aminobutírico

GDR Grado de desarrollo reproductivo

GnIH Factor inhibidor de la liberación de gonadotrofinas

GnRH Hormona liberadora de gonadotrofinas

GnRHR Receptor de la hormona liberadora de gonadotrofinas

GWAS Estudio de asociación de genoma completo

h2 Heredabilidad

IA Inseminación Artificial

IATF Inseminación Artificial a tiempo Fijo

IC Intervalo de confianza

IGF-1 Factor de crecimiento similar a insulina tipo 1

INS Insulina

IPP Intervalo parto parto

KISS Kisspeptina

KISS1R Receptor 1 de kisspeptina

LD Desequilibrio de ligamiento

LE Equilibrio de ligamiento

LEP Leptina

LEPR Receptor de leptina 
MPOA Área preoptica medial

MSH Hormona melanocito estimulante

NKB Neurokinina B

NPY Neuropéptido Y

P4 Progesterona

PC Pastoreo controlado

PE Peso estimado

PGE2 Prostaglandina E2

PGF2 $\alpha$ Prostaglandina F2 $\alpha$

POMC Proopiomelanocortina

QTL Locus de caracteres cuantitativos

REML Máxima verisimilitud restricta

Req Requerimientos

RFRP Péptido similar a RFamida

SAM Selección asistida por marcadores

SNP Polimorfismo de nucleótido simple

TBE Buffer tris-borato-EDTA

TGF $\beta \quad$ Factor de crecimiento transformante $\beta$

VMN Núcleo ventromedial 


\section{LISTADO DE TABLAS}

Tabla 1.1. Escala de grado de desarrollo reproductivo (GDR). Adaptado de Casaro y Mihura (1999)

Tabla 2.1. Peso, edad y aumento diario de peso de vaquillonas bajo pastoreo ad libitum (AD) y pastoreo controlado (PC).

Tabla 2.2. Peso, edad y aumento diario de peso de vaquillonas púberes y no púberes bajo pastoreo ad libitum (AD) y pastoreo controlado (PC)....

Tabla 2.3. Estimación de los parámetros de las curvas de crecimiento entre tratamientos y entre estados puberales.

Tabla 3.1 Listado de los polimorfismos evaluados y su ubicación en el genoma bovino. .64

Tabla 3.2. Frecuencias genotípicas para los SNPs IGF-SnaBI y SNP6-GnRHR. Datos por establecimiento y totales. .68

Tabla 3.3. Distribución de los animales entre los genotipos, animales púberes y censurados (cens.) utilizados para el análisis de supervivencia .68

Tabla 3.4. Estimadores de riesgo asociado al polimorfismo en el marcador IGFSnaBI y el peso sin considerar al rodeo como un factor de estratificación .73

Tabla 3.5. Estimadores de riesgo asociado al polimorfismo en el marcador IGFSnaBI y el peso considerando al rodeo como un factor de estratificación .74 
Tabla 3.6. Estimación del riesgo relativo de pubertad entre alelos de IGF1-Sna-BI para los modelos sin estratificación por rodeo y con estratificación por rodeo .74

Tabla 3.7. Modelo de sensibilidad de censura S1 para el análisis de riesgo asociado al marcador IGF-SnaBI. A. Sin considerar el efecto rodeo; B. Considerando el efecto rodeo. .75

Tabla 3.8. Análisis de sensibilidad de censura S1 para el análisis de riesgo asociado al marcador IGF-SnaBI. A. Sin considerar el efecto rodeo; B. Considerando el efecto rodeo. .76

Tabla 3.9. Análisis de riesgo asociado al polimorfismo en el marcador IGF-SnaBI y el peso para $\mathrm{R} 1$ .76

Tabla 3.10. Análisis de riesgo asociado al polimorfismo en el marcador IGF-SnaBI y el peso para $\mathrm{R} 2$. . .76

Tabla 3.11. Estimadores de riesgo asociado al polimorfismo en el marcador GnRHR - SNP6 y el peso sin considerar al rodeo como un factor de estratificación y considerando al rodeo como un factor de estratificación para toda la población evaluada.

Tabla 3.12. Estimadores de riesgo de pubertad asociado al SNP GnRHR - SNP6 y el peso para los dos rodeos evaluados. .78

Tabla 3.13. Análisis de sensibilidad de censura para el análisis de riesgo asociado al marcador GnRHR-SNP6. .78 
Tabla 3.14. Estimación de parámetros de las curvas de crecimiento entre los distintos genotipos de IGF-SnaBI

Tabla 4.1. Medias fenotípicas para las características evaluadas en machos y hembras. .100

Tabla 4.2. Descomposición de la varianza total para Edad al primer parto (EPP), fecha de primer parto (FPP) y Circunferencia escrotal (CE) a los 300, 400 y 630 días de edad. 103

Tabla 4.3. Correlaciones genéticas (encima de la diagonal), fenotípicas (debajo de la diagonal) y heredabilidad para para Edad al primer parto (EPP; A), fecha de primer parto (FPP; B) y Circunferencia escrotal (CE) a los 300, 400 y 630 días de edad. .104

Tabla 4.4. Soluciones de los efectos fijos para cada las estimaciones de los valores de cría para edad al primer parto (EPP), fecha de primer parto (FPP) y Circunferencia escrotal (CE) a los 300, 400 y 630 días de edad......105

Tabla 4.5. Extracto del ranking de toros para las características evaluadas......106

Tabla 4.6. Correlaciones de orden entre los rankings de toros para edad al primer parto (EPP), fecha de primer parto (FPP) y Circunferencia escrotal (CE) a los 300, 400 y 630 días de edad 


\section{LISTADO DE FIGURAS}

Figura 1.1. Cambios endocrinos en la vaquillona desde los 6 meses hasta la pubertad (Adaptado de Day y Nogueira, 2013)

Figura 2.1. Balance Energético (BE), aumento de peso derivado (APd) y fracción de pubertad acumulada (FPA) para cada tratamiento durante el ensayo .45

Figura 2.2: Fracción acumulada de vaquillonas púberes (FPA), peso estimado (PE) por el modelo y aumento de peso derivado (APd) para cada tratamiento durante el ensayo.

Figura 2.3: Peso medio estimado por el modelo (PE) y aumento de peso derivado (APd) en vaquillonas púberes $(\mathrm{P})$ y no púberes $(\mathrm{NP})$

Figura 2.4. Aumento diario de peso (ADP) predestete y durante la recría en vaquillonas púberes $(\mathrm{P})$ y no púberes $(\mathrm{NP})$ para cada tratamiento.....50

Figura 3.1.A. Curvas de supervivencia de Kaplan - Meier para los distintos genotipos del SNP IGF-SnaBI, para toda la población evaluada

Figura 3.1.B. Curvas de supervivencia de Kaplan - Meier para los distintos genotipos del SNP IGF-SnaBI, para R1 .70

Figura 3.1.C. Curvas de supervivencia de Kaplan - Meier para los distintos genotipos del SNP IGF-Sna-BI, para R2 . .70

Figura 3.2.A. Curvas de supervivencia de Kaplan - Meier para los distintos genotipos del SNP GnRHR-SNP6, para toda la población evaluada. . .71 
Figura 3.2.B. Curvas de supervivencia de Kaplan - Meier para los distintos genotipos del SNP GnRHR-SNP6, para R1

Figura 3.2.C. Curvas de supervivencia de Kaplan - Meier para los distintos genotipos del SNP GnRHR-SNP6, para R2 .....................72

Figura 3.3 Curva de crecimiento y aumento de peso derivado (APd) para los distintos polimorfismos del marcador IFG-SnaBI en el rodeo R1 .....80

Figura 3.4. Curva de crecimiento y aumento de peso derivado (APd) para los distintos polimorfismos del marcador IFG-SnaBI en el rodeo R2 ....80

Figura 4.1. Mediciones y edad a la medición de la circunferencia escrotal en el establecimiento 101

Figura 4.2. Gráficos de caja y bigotes describiendo las medidas de circunferencia escrotal ajustada por edad (encima) y los registros de parto de las hembras (debajo) en los distintos grupos de contemporáneos.......102 
TITULO: Estudio cuantitativo y molecular de la edad de arribo a la pubertad en la hembra bovina.

PLABRAS CLAVE: Pubertad, Precocidad sexual, Mejoramiento, Genética, Angus.

\section{RESUMEN}

Adelantar los servicios de las vaquillonas, implementando sistemas de entore a 15 meses de edad es una forma de mejorar la productividad de los rodeos de cría. Para lograr un planteo exitoso es necesario que las vaquillonas hayan alcanzado la pubertad antes de iniciar la temporada de servicios donde la genética y la alimentación juegan un papel central. En este trabajo se evaluó el impacto de una recría pastoril en el crecimiento de las vaquillonas y en la proporción de vaquillonas ciclando al momento del servicio. Se encontraron diferencias en la forma de las curvas de crecimiento, con diferencias en las pendientes de las curvas hasta los 289 días de edad y una menor proporción de vaquillonas ciclando, en hembras alimentadas en un sistema de pastoreo controlado con un aumento diario de peso de $0,58 \mathrm{~kg} / \mathrm{d}$ comparada con una recría ad-libitum. La diferencia en el número de vaquillonas ciclando podría originarse en restricciones puntuales de la alimentación durante la recría. En otro ensayo se encontró, mediante el uso de modelos de supervivencia, un mayor riesgo de pubertad asociado al genotipo TT del marcador IGF-SnaBI, si bien el efecto más importante como factor de riesgo asociado a la pubertad resultó el peso. Por último, se determinó la correlación genética entre la precocidad sexual en hembras, medida a través de la edad al primer parto (EPP) y fecha de primer parto (FPP), con la circunferencia escrotal (CE) medida a diferentes edades en un rodeo comercial. La correlación genética entre 
EPP y CE resultó mayor a edades de medición más temprana, constituyendo un carácter para seleccionar a los machos y mejorar la precocidad sexual en las hembras. Por otra parte, EPP permitiría a través de una mayor heredabilidad un progreso genético más rápido respecto a FPP. 
TITLE: Quantitative and molecular study of age at puberty in heifers

KEYWORDS Puberty, Sexual precocious, Animal breeding, Genetics, Angus.

\section{SUMMARY}

Calving at 24 months improve profitability pf cow calf production systems. For this purpose, heifers must be puberal before breeding season. Puberty attainment is conditioned by nutrition and genetics, where the first enhance the effects of genetics, allowing productive potential expression. In this work an 0.5 $\mathrm{kg} / \mathrm{d}$ average daily gain rearing was evaluated. Growing pattern and slope of growing curve until 289 days of age differences was found. Furthermore, fewer heifers was pubertal during rearing compared with an ad-libitum forage-based rearing, but weight did not differ during rearing. Differences in proportion of pubertal heifers in at begin of breeding season could be related with a nutritional restriction at moment that first heifers attain puberty. In other trial effect of two genetic markers in puberty risk were evaluated. Results demonstrate a greater puberty risk in animals with TT genotype of IGF-SnaBI, while weight is the principal risk factor of puberty attainment. Survival models used in this analysis allows a better handling of censored data, providing best estimates than linear models. Finally, genetic correlation between sexual precocity in females, evaluated through age at first calving (AFC) and date of first calving (DFC), and scrotal circumference (SC) at different ages in a commercial herd. Early SC measurements are a better proxy to improve female precocity. Furthermore, AFC provides a better tool to select female precocity because their higher heritability. 


\section{CAPITULO I}

\section{REVISION BIBLIOGRÁFICA}

\subsection{EL SISTEMA PRODUCTOR DE CARNE EN ARGENTINA Y LA IMPORTANCIA DE LA FERTILIDAD.}

La ganadería bovina en la República Argentina resulta una actividad prioritaria debido a su aporte al PBI nacional, a la generación de empleo en la cadena productiva y a la importancia de las proteínas de origen bovino en la dieta. Actualmente y desde hace algunos años esta actividad enfrenta cambios coyunturales y estructurales, debido al aumento de la demanda de carne por el mundo, al desplazamiento a zonas más marginales y a un estancamiento productivo en términos de volumen (Rearte, 2010; Lozano, 2011; Rearte, 2011).

Regionalmente, la producción de carne argentina tiene un gran potencial de acceso a mercados debido a la calidad de la carne producida, a diferencia de países vecinos como Brasil y Paraguay. Sin embargo, las exportaciones de carne se ven limitadas debido a un alto consumo interno de producto (lo que genera históricamente no más de un $10 \%$ de saldo exportable) y a un estancamiento en el aumento de la producción a nivel nacional. Este último está limitado por dos factores, el bajo peso de faena por un lado y a la baja tasa de destete nacional, la cual apenas supera el $60 \%$, donde sin dudas la fertilidad en los rodeos de cría es la llave para generar un cambio.

Los sistemas de cría en la Argentina, al igual que en los grandes países productores de carne, se realizan sobre sistemas pastoriles (naturales o implantados) con distintos niveles de suplementación. La región con mayor concentración de 
vacas es la región pampeana, con alrededor del 40\% de los casi 23.000 .000 de vientres del país (SENASA, http://www.senasa.gob.ar/cadena-animal/bovinos-ybubalinos/informacion/informes-y-estadisticas), destinando las regiones con mayores limitantes edafoclimáticas a los sistemas de cría y el engorde en suelos con mayor aptitud muchas veces en rotaciones con sistemas agrícolas.

En los últimos años, las regiones extra pampeanas, como el NOA y el NEA, han ido aumentando la superficie ganadera a través de la liberación de suelos a partir del desmonte o la incorporación de bovinos a sistemas silvopastoriles, actualmente participan con poco más del $6 \%$ y $20 \%$ respectivamente del stock de vientres del país. En estas regiones la principal actividad ganadera es la cría bovina, para luego trasladar los terneros a zonas de engorde, o bien recriarlos y terminarlos en sistemas que integran periodos de encierre a corral con concentrados.

El manejo de los sistemas de cría suele ser estacional, con una temporada de servicios de alrededor de 90 días en los meses de mayor disponibilidad forrajera (Carrillo, 1997). Por lo tanto, todas las actividades que se realizan están definidas en principio por esta práctica, siendo su principal producto los terneros que suelen ser comercializados o transferidos al destete (alrededor del otoño) hacia sistemas de engorde.

Es por esta razón que la rentabilidad esta mayormente influenciada por dos factores: la cantidad de terneros producidos y su peso al destete (Carrillo, 1997). Este tipo de sistemas aprovechan la capacidad de los bovinos de producir un producto de alto valor biológico para el consumo humano utilizando como recurso el forraje, volviéndose altamente dependiente de las condiciones agroecológicas. 
En la región pampeana la productividad secundaria de la cría ronda entre los 70 y $80 \mathrm{~kg}$ de carne/ha/año, pudiendo alcanzar en los sistemas más eficientes productividades de entre 150 y $200 \mathrm{~kg} / \mathrm{ha} /$ año (Rearte, 2011). Uno de los factores que más impacta en estas diferencias es el porcentaje de destete en sistemas que además maximizan el aprovechamiento de los forrajes.

La importancia relativa de la fertilidad en los sistemas productores de carne es conocida hace ya varios años. Esta variable tiene el doble de importancia que las características de crecimiento, y es 10 veces más importante que la calidad de la carne producida (Trenkle y Willham, 1977). De modo que el principal objetivo del sistema es lograr un ternero transable al momento de la zafra. En este sentido la ampliación de la frontera ganadera presenta un nuevo desafío, mantener e incrementar la producción regional de carne, en zonas con mayores limitantes para la producción de pasto. Sumado a esto la búsqueda de mayores productividades conlleva a una intensificación de los sistemas, con un consecuente aumento de la carga y concentración de hembras, exigiendo a las mismas en términos de adaptación.

La reposición de los machos en la mayoría de los casos suele realizarse a través de la compra de toros, principalmente de 2 años, a establecimientos especializados en la producción de esta categoría. En cambio, las hembras suelen reponerse con terneras de la propia producción que son recriadas para servicio (Carrillo, 1997). De modo que la mejora genética suele realizarse a través de los machos, ya sea por compra de toros o por inseminación artificial (IA), y luego perpetuarse a través de la selección de hembras producidas en el propio establecimiento. 
En términos productivos, la fertilidad debe ser pensada no solo como la capacidad de la hembra de preñarse, sino también de hacerlo lo antes posible en la estación reproductiva en sistemas con cargas desafiantes. De esta manera, se lograrán más detestes y más pesados, y se alargarán los intervalos parto servicio, de modo que será más probable que la hembra vuelva a preñarse en el primer mes de servicio, formando parte de la cabeza de parición del año próximo. En un servicio estacionado de 90 días, una vaca que pare el último día de la estación de partos sería expuesta nuevamente a los toros a unos pocos días de haber parido o incluso estando preñada.

\subsection{LA PRECOCIDAD SEXUAL Y EL USO DE CATEGORÍAS JÓVENES}

El uso de categorías jóvenes en el rodeo es una forma de mejorar los resultados productivos. Esta tecnología consiste en comenzar a utilizar los reproductores a los 15 meses de edad de manera de acortar las recrías, reduciendo sus costos y liberando superficie para su aprovechamiento por categorías productivas (Carrillo, 1997; Pereira Gomes de Freitas, 2005). De esta forma se logra un aumento de la carga útil en los sistemas, mejorando la productividad (Martin y col., 1992).

Otras ventajas de esta práctica tienen que ver con aumentar el número de terneros obtenidos por vaca de modo de aumentar el retorno al capital (Carrillo, 1997; Albuquerque y Baldi, 2011), además, este retorno es más rápido debido a que los animales comienzan a producir antes (Morris y col., 2000). 
Por otro lado, en programas de mejoramiento genético posibilita acortar el intervalo generacional acelerando los procesos de mejora. En el caso de los machos, las ventajas para los rodeos comerciales tienen que ver con un menor precio de compra, y en el caso de las cabañas un menor costo de recría (Kassari y col., 1996).

El uso de categorías jóvenes ha sido mucho más difundido en las hembras que en los machos si bien existen reportes de uso exitoso de toritos en el país (Prando, 2015). Las mayores exigencias nutricionales de las vaquillonas en crecimiento y desarrollo durante su recría, y más importantes aún durante su segundo servicio (simultáneamente a su primera lactancia), dificultan su aplicación en sistemas con limitantes en la producción de forraje.

Para lograr un uso exitoso de categorías jóvenes es necesario que los animales hayan alcanzado la pubertad durante la recría. Idealmente, las hembras deberían ser púberes unos 45 días antes del inicio del servicio, ya que la fertilidad va en aumento a medida que los ciclos estrales se suceden. Se ha reportado que la fertilidad del tercer ciclo estral es un 20\% superior a la del primero (Byerley y col., 1987; Holm y col., 2015). De esta manera, es más probable lograr un mayor número de partos de vaquillonas en cabeza de parición, siendo más fácil que estas se mantengan en cabeza de parición durante toda su vida, volviéndose más productivas. Es así como la edad al primer parto de la hembra es el cuello de botella en la eficiencia de la vaquillona ( Day y Nogueira, 2013). 


\subsection{DESARROLLO DE LA HEMBRA BOVINA.}

\subsubsection{Desarrollo embriológico de la hembra.}

En los mamíferos, el sexo es determinado en el momento de la fertilización, a través de la constitución cromosómica diferencial entre machos y hembras. A partir de este punto, una serie de cambios morfofisiológicos se sucederán para pasar de un embrión indiferenciado a un individuo sexualmente dimórfico. El sexo primordial en los mamíferos euterios es el femenino, siendo la presencia del cromosoma $\mathrm{Y}$ en el par sexual quien determina la diferenciación temprana de la gónada hacia un testículo.

El sexo fenotípico queda constituido alrededor del día 60 de gestación pasando previamente por un estado indiferenciado, siguiendo con el desarrollo anatómico de los órganos sexuales y el desarrollo del eje endocrino gonadal que regulará su funcionamiento (Russo, 2011). Según la siguiente descripción:

Estadio gonadal indiferenciado: El esbozo gonadal está constituido por la cresta genital, un engrosamiento de la cara ventral del mesonefros. Este tejido es colonizado por las células germinales primordiales originadas en el endodermo del saco vitelino, las que migran a través del intestino medio (Russo, 2011).

Diferenciación del sistema de conductos: En los estadios de gónada indiferenciada existen dos pares de conductos, los de Wolff y los de Müller. Estos últimos están situados paralela y externamente a los anteriores y dan origen al oviducto, el útero y la porción craneal de la vagina, mientras que los primeros se atresian (Russo, 2011). 
Diferenciación de los genitales externos: Los genitales externos se originan principalmente a través del seno urogenital y tejidos relacionados, que está limitado por los pliegues cloacales, que luego de diferenciarse darán origen a la uretra y los labios vulvares y un engrosamiento de este dará origen al clítoris (Russo, 2011).

Diferenciación del sistema nervioso central: Una diferencia importante entre los machos y hembras bovinas es la capacidad de estas últimas de liberar en forma cíclica gonadotrofinas [hormona folículo estimulante (FSH) y hormona luteinizante $(\mathrm{LH})$ ], además de hacerlo en forma tónica como en el macho. Se cree que el estrógeno y la testosterona podrían estar modulando la actividad de los circuitos neuronales, provocando cambios estructurales y funcionales en las neuronas (Russo, 2011).

Ovogénesis: Una vez determinado el sexo gonadal se dan dos procesos íntimamente relacionados, la ovogénesis y la foliculogénesis. Durante la ovogénesis, las ovogonias (células totipotenciales) se multiplican y dan origen a los ovocitos quienes quedan detenidos en diploteno de la profase meiótica. Este proceso se inicia alrededor de los 70 días de gestación, de modo que al momento del nacimiento la hembra tendrá determinado su pool folicular que ira decreciendo a medida que envejece (Russo, 2011).

\subsubsection{Consideraciones fisiológicas sobre el ciclo estral bovino.}

La hembra bovina es poliéstrica continua. Esto significa que mientras ningún evento (fisiológico o patológico) lo impida, los ciclos estrales se suceden desde la pubertad durante toda la vida del animal. Previo a la pubertad algunas fases del 
ciclo irán teniendo lugar para ser detenidas, ya sea por falta de estimulación o presencia de inhibición.

Cada ciclo tiene una duración de 17 a 23 días (21 días en promedio) y su duración depende en gran medida de cuantas ondas foliculares tengan lugar durante el mismo. El celo dura entre 6 y 18 hs y la ovulación sucede posterior a su finalización. Post ovulación se desarrolla un cuerpo lúteo que elevará los niveles de progesterona plasmática (P4) desde el día 4 hasta el día 16 a 20, donde se produce la luteólisis.

El proceso descripto anteriormente es regulado por el hipotálamo, la hipófisis, las gónadas y el útero, que funcionalmente se constituyen como un eje de regulación endocrina, paracrina y autocrina.

El hipotálamo produce hormona liberadora de gonadotrofinas (GnRH en las neuronas de la porción mediobasal y anterior, particularmente en el núcleo arcuato y es liberada a los vasos portales hipofisiarios, para así dirigirse a la adenohipófisis. La GnRH se libera de manera pulsátil y cada pulso induce un pico de LH y FSH.

En la oveja se ha visto que cada pulso de LH induce un pico de estradiol folicular, que en presencia de progesterona ejerce una retroalimentación negativa sobre la secreción hipotalámica de GnRH.

Después de la luteólisis, cuando la progesterona vuelve a niveles basales, el mecanismo se invierte eliminando la retroalimentación negativa y aumentando la pulsatilidad de $\mathrm{LH}$, induciendo la producción de estradiol folicular, para que eventualmente desarrolle un folículo dominante y la alta producción de estradiol induzca un pico preovulatorio de gonadotrofinas. De esta manera el estradiol ejerce 
un control negativo o positivo sobre la secreción de LH, dependiendo de la presencia o ausencia de niveles umbrales de progesterona (Bo y col., 2007; Russo, 2011).

El ciclo estral de la hembra bovina puede dividirse en dos fases según la estructura anatómica ovárica y estado funcional que predomine: fase folicular y fase lútea, además se podría considerar una fase intermedia periovulatoria (Bo y col., 2007; Russo, 2011).

Fase folicular: El inicio de la fase folicular tiene lugar con la luteólisis, durante esta fase los niveles de P4 decaen por debajo de $1 \mathrm{ng} / \mathrm{ml}$. Esta baja en los niveles de P4 elimina la retroalimentación negativa ejercida sobre la secreción de gonadotrofinas. Como consecuencia, se produce un aumento de la frecuencia de pulsos de LH (1 pulso cada $60 \mathrm{~min}$ ) y en menor medida de FSH (Schams, 1987; Bo y col., 2007). Este aumento de LH estimula el desarrollo del folículo dominante, que secreta cantidades crecientes de estradiol. La duración de este periodo dependerá del grado de desarrollo del folículo dominante al momento de iniciar la luteólisis, ya que dependerá de cuanto tarde el folículo en desarrollarse lo suficiente como para secretar el estradiol necesario como para desencadenar la descarga preovulatoria de LH.

Durante la fase periovulatoria se inicia el celo, y se desencadena el pico preovulatorio de gonadotrofinas y la ovulación. El celo ocurrirá entre 58 y 60 hs desde la luteólisis (Dieleman y col., 1986), los niveles de estradiol durante este periodo irán en aumento hasta inducir el comportamiento de celo (Hurnik, 1987) y un pico preovulatorio de LH. 
El aumento de estradiol estimula la síntesis de receptores de GnRH en la hipófisis (Schoenemann y col., 1985; Kinder y col., 1991), aumentando la sensibilidad hipofisaria a esta hormona (Kesner y col., 1981). Este proceso culmina con la liberación de una descarga de GnRH que induce el pico preovulatorio de gonadotrofinas (Bo y col., 2007).

La LH, secretada en respuesta al pico de GnRH, estimula la maduración final del folículo, la activación del ovocito para reiniciar la meiosis y el mantenimiento del cuerpo lúteo. La ovulación ocurre unas 24 a 30 hs del inicio de las descargas de LH. Además, este aumento de LH provoca un aumento de la irrigación ovárica, se disocia el cumulus oophurus, por lo que se reinicia la meiosis, eliminando el primer corpúsculo polar.

Se produce además un aumento y cambio en la producción de esteroides, aumentando la producción de progesterona, produciendo edema y estimulando la colagenasa de la teca que degrada el tejido conectivo, e iniciando la formación del estigma folicular, donde se romperá el folículo al momento de la ovulación.

Por otra parte, aumenta la producción de prostaglandina-E2 (PGE2) y prostaglandina-F2 $\alpha$ (PGF2 $\alpha)$, la primera a través del activador del plasminógeno colaborará en la formación del estigma, y las contracciones provocadas por PGF2 $\alpha$ producen la rotura del folículo (Russo, 2011).

Luego de la descarga preovulatoria de LH no se registran pulsos de secreción de esta hormona durante 6 a 12 hs (Walters y Schallenberger, 1984), aparentemente por el agotamiento del contenido de LH en la hipófisis. Sin embargo, la secreción de FSH continúa y se produce un segundo pico, por la eliminación del efecto de 
retroalimentación negativa de la inhibina, que era producida por el folículo preovulatorio (Fortune, 1994; Bo y col., 2007)

Fase lútea: La fase lútea comienza después de la ovulación y se caracteriza por la presencia de un cuerpo lúteo funcional con secreción de P4, la concentración de esta hormona comienza a aumentar hacia el día 3 o 4, para alcanzar un pico entre el día 8 y 12 .

Luego de la ovulación, la cavidad del folículo es invadida por células de la granulosa y de la teca, que se diferenciaran a células tecales grandes y pequeñas respectivamente (Fitz y col., 1982). Si bien ambos tipos de células producen progesterona, las células pequeñas poseen casi todos los receptores de LH y tienen una respuesta 6 veces más alta a LH, y contribuyen en un 15\% de la secreción de progesterona.

Las células luteales grandes, quienes aportan el $85 \%$ de la progesterona circulante, poseen casi todos los receptores de PGE2 y PGF2 $\alpha$ (Bo y col., 2007). Estas células también producen neurofisina y oxitocina, que cumplen un importante rol en la luteólisis.

Pasados alrededor de 14 días bajo efectos de la progesterona, el endometrio secreta pulsos de PGF2 $\alpha$, que llega al ovario a través de una difusión local arteriovenosa o mecanismo de contracorriente y da comienzo a la luteólisis. En la luteólisis intervienen hormonas secretadas por el folículo dominante (estradiol), el propio Cuerpo Lúteo (CL) (oxitocina) y el endometrio (PGF2a) (Bo y col., 2007).

El estradiol induce en el endometrio la síntesis de receptores, donde actuará la oxitocina proveniente de la neurohipófisis en primera medida y posteriormente 
del CL, lo cual induce la cascada que termina en la producción de PGF2a, la que es descargada en la vena utero-ovarica y pasa a la arteria ovárica en íntima relación con esta. PGF2a induce la liberación por parte del CL de más oxitocina, la que estimula la secreción de más PGF2a, estableciéndose un feedback positivo (Knickerbocker y col., 1988).

Durante la fase lútea se dan ondas de desarrollo folicular y cada onda es precedida por un aumento de la FSH, a medida que la P4 aumenta la frecuencia de liberación de LH disminuye y sólo cuando una onda folicular se da en ausencia de P4 podrá eventualmente llegar a la ovulación (Bo y col., 2007; Russo, 2011).

Dinámica folicular: El desarrollo folicular de la hembra bovina sigue un patrón de ondas, durante un ciclo estral se dan 2 o 3 ondas de crecimiento folicular. Cada onda involucra el desarrollo sincrónico de un grupo de folículos desde los $4 \mathrm{~mm}$, que se da en simultáneo en los dos ovarios (Ginther y col., 1989). Después de dos o tres días de crecimiento un folículo ejercerá su dominancia sobre los demás, que se atresiarán, volviéndose el folículo dominante (Adams y col., 1993). La primera onda de crecimiento folicular comienza el día 0 del ciclo estral (día de la ovulación), la segunda onda se inicia el día 8 o 9, o 9 o 10, según el ciclo estral sea de dos o tres ondas de crecimiento folicular (Ginther y col., 1989). En los ciclos de 3 ondas, la tercera onda emerge el día 15 o 16.

Previo a cada onda folicular existe un aumento en la concentración de FSH (Bo y col., 2007; Russo, 2011). Esta hormona es la responsable del reclutamiento de un grupo de folículos y este aumento comienza dos días antes de la emergencia de la onda, para alcanzar la máxima concentración el día antes o el mismo día de la 
emergencia de la onda. Luego del reclutamiento folicular, la concentración de FSH comienza a descender alcanzando su mínimo al momento de la desviación (día 2,5 aproximadamente), en el cual el folículo dominante posee la capacidad de seguir creciendo con bajos niveles de FSH, y no así los folículos subordinados (Ginther, 2000; Ginther, 2016).

El folículo dominante produce estradiol e inhibina que actúan suprimiendo los niveles circulantes de FSH (Martin y col., 1991; Gibbons y col., 1997; Ginther, 2016). La inhibina es secretada por todos los folículos en desarrollo, mientras que el estradiol se produce principalmente en el dominante (Bo y col., 2007).

El folículo dominante posee receptores para LH en las células de la granulosa y en las células de la teca, mientras que los folículos subordinados solo los tienen en las células de la teca, permitiéndole crecer en un ambiente con baja concentración de FSH (Ginther, 2016). La LH estimula en las células de la granulosa del folículo dominante la producción de estradiol, de aquí que el folículo dominante es LH dependiente. Los niveles altos de progesterona no suprimen la liberación de FSH, pero si inhiben los pulsos de LH (Ginther, 2016).

Este fenómeno es responsable de que un folículo no pueda ovular una vez ejercida su dominancia, y comience a atresiarse. Previo a la regresión morfológica cesa la producción de estradiol y de inhibina, liberando el freno a la secreción de FSH, quien iniciará una nueva onda de reclutamiento. En caso de no existir un cuerpo lúteo funcional, ya en la fase folicular del ciclo estral, permitirá el aumento de la frecuencia de pulsos de $\mathrm{LH}$, lo que estimulará el mayor crecimiento del 
folículo dominante, aumentando las concentraciones de estradiol, ocurriendo el comportamiento de celo y la ovulación.

\subsubsection{Pubertad.}

La pubertad puede definirse como el momento en que las hembras adquieren capacidad de reproducirse, es decir, de dejar descendencia (Estill, 2014). En términos fisiológicos esto implica que la vaquillona ovule y esta ovulación se continúe con una fase lútea normal (Moran y col., 1989), logrando aumentos en los niveles de P4 sérica por encima de $1 \mathrm{ng} / \mathrm{ml}$ (Jones y col., 2014). Este momento es el final de una serie de cambios madurativos que va sufriendo el animal, y es desencadenada por una pérdida de sensibilidad del eje hipotalámico-hipofisariogonadal a una retroalimentación negativa ejercida por el 17- $\beta$ estradiol, lo que permite que se desencadene un pico preovulatorio de LH (Day y col., 1984; Moran y col., 1989). Se considera que los bovinos pueden ser enmarcados dentro de la teoría gonadostática, que considera que es la propia gónada la que de alguna manera detiene su propio desarrollo.

\subsubsection{Crecimiento y desarrollo prepuberal}

Durante la vida prepuberal el aparato reproductivo va creciendo y alterando sus estructuras y su fisiología hasta volverse completamente funcional al momento de la pubertad (figura 1.1). Este proceso está coordinado y regulado por centros cerebrales (el hipotálamo, la hipófisis) y los ovarios en el caso de la hembra. Además, está influenciado fuertemente por señales metabólicas, principalmente 
nutricionales, que van inhibiendo o estimulando el desarrollo. Por lo tanto, la pubertad se da cuando las aferencias estimuladoras superan a las inhibidoras. Se ha demostrado que algunas fases de este proceso son decisivas y determinantes de la edad a la pubertad de las hembras. En este sentido no solo es importante la nutrición de la hembra, sino también la nutrición de su madre, que la afectará directamente ya sea en la etapa de desarrollo embrionario, como también en lactancia.

\subsubsection{Crecimiento del aparato reproductivo.}

El crecimiento de los ovarios en terneras prepúberes ocurre entre las 2 y 14 semanas y luego entre las 30 a 60 semanas de vida (Honaramooz y col., 2004) a una tasa casi 4 veces mayor a la del cuerpo en el primer periodo y a una tasa similar que el resto del cuerpo en el último (Desjardins y Hafs, 1969).

El número de folículos antrales aumenta significativamente entre las 6 y 60 semanas de vida (Desjardins y Hafs, 1969; Honaramooz y col., 2004). El diámetro máximo folicular aumenta entre las 8 y 14 semanas, de las 38 a las 42 y luego de las 52 a las 60 semanas de vida, este aumento de diámetros esta correlacionado con el diámetro de las estructuras tubulares (Honaramooz y col., 2004). El mismo autor reporta una correlación entre el número de folículos mayores a $3 \mathrm{~mm}$ con el diámetro uterino, siendo esta última menor que en el caso anterior, esto demuestra una muy coordinada sucesión de eventos relacionados entre sí.

El desarrollo tubular por su parte muestra un rápido crecimiento hacia las 10 semanas de vida, para luego desacelerarse y luego volver a incrementarse entre las 12 a 24 semanas y entre las 32 y 40 semanas de vida (Honaramooz y col., 2004). 


\subsubsection{Función ovárica en terneras prepúberes}

Existe una muy estrecha relación regulatoria entre la función endocrina en un nivel superior y la función ovárica con mecanismos de retroalimentación, donde participan además los centros cerebrales y las señales del ovario interactúan con señales metabólicas y ambientales.

Se han reportado dos aumentos de LH entre el nacimiento y la pubertad, el primero entre las 12 y 20 semanas de edad (pico temprano de gonadotrofinas), seguido por una declinación de los niveles séricos de hormona y el próximo aumento gradual será inmediatamente anterior a la pubertad.

Se ha encontrado también un aumento de FSH coincidente con el pico temprano de LH (Schams y col., 1981; Evans y col., 1992; Evans y col., 1994), este pico fue asociado con un aumento del diámetro máximo folicular como con el número máximo de folículos en crecimiento (Evans y col., 1994). Existen evidencias de que este aumento temprano de las gonadotrofinas juega un papel crítico para el posterior desarrollo reproductivo, el arribo a la pubertad y la posterior vida productiva de la hembra (Evans y col., 1992).

En un experimento realizado en vaquillonas Hereford, la supresión de este pico temprano resultó en una pubertad retardada y baja fertilidad (Bo y col., 2007). Experimentos realizados sobre vacas ovariectomizadas (Dodson y col., 1988) sugieren que el control de este aumento en los niveles de LH es ejercido por el ovario, Day y col., (1984) sostienen que el decrecimiento en la secreción de LH se debe al establecimiento de un feedback negativo ejercido por el estradiol sobre la 
secreción de GnRH (Figura 1.1). Observaciones similares han sido realizadas en machos, pudiendo indicar que las vías metabólicas que determinan una pubertad más temprana pueden ser similares en ambos sexos.

Figura 1.1. Cambios endocrinos en la vaquillona desde los 6 meses hasta la pubertad (Adaptado de Day y Nogueira, 2013).

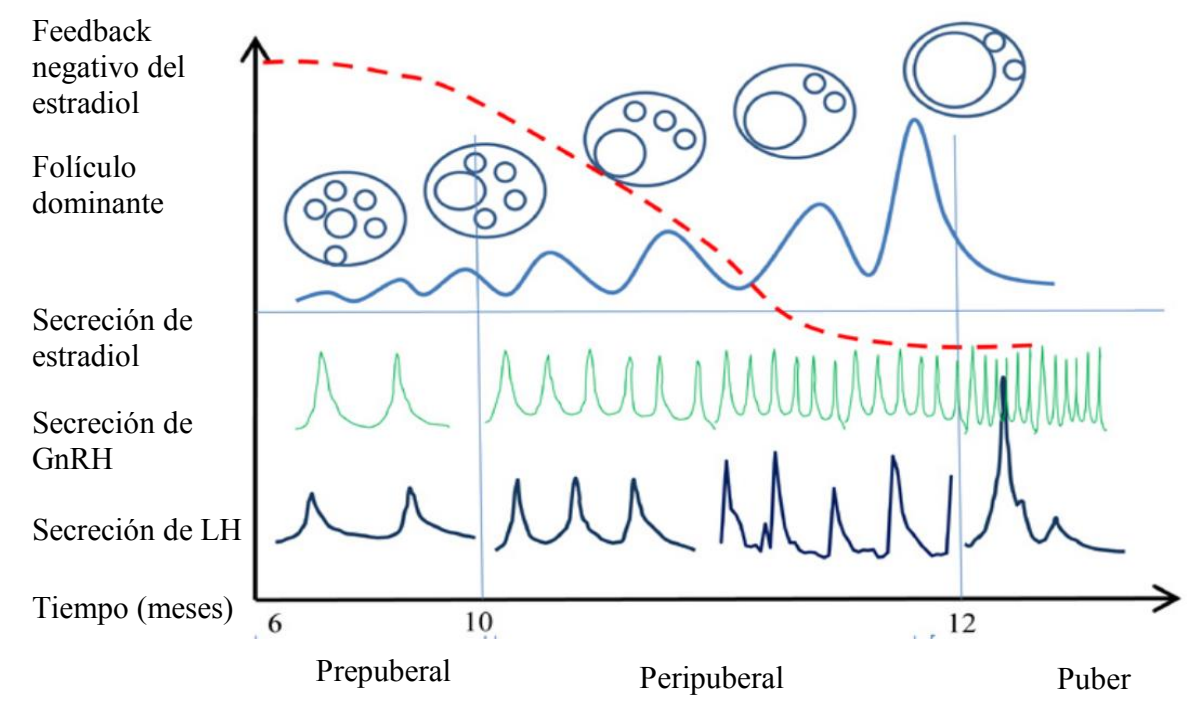

Nota: El período peripuperal incluye unos 60 días previos a la puebrtad. Este período se caracteriza por una disminución del feedback negativo ejercido por el estradiol sobre la secreción de gonadotrofinas. Resultando en aumento del diámetro de los folículos y una mayor producción de estradiol. Eventualmente la secreción de estradiol se vuelve suficiente para inducir el pico preovulatorio de LH.

El crecimiento folicular en las vaquillonas prepúberes sigue un patrón de ondas, con un intervalo promedio entre el inicio de estas de 8,1 días. Cada onda folicular, al igual que en ondas anovulatorias de un animal adulto, tiene 3 fases de desarrollo (crecimiento, estática y regresión) y cada onda folicular es precedida de un pico de concentración de FSH, indicando que los mecanismos que controlan el fenómeno de emergencia, selección y regresión de una onda folicular son los mismos en hembras maduras que prepúberes (Adams y col., 1994). 
El desarrollo folicular en hembras prepúberes se ve truncado al momento de la ovulación, ya que no existe un pico de gonadotrofinas que la induzca,. Existen reportes que indican que la relación entre el diámetro máximo del mayor folículo subordinado y el diámetro del folículo dominante tiende a decrecer entre las 2 y 34 semanas de edad, lo que sugiere que la dominancia ejercida por el folículo dominante se va haciendo más importante a medida que la hembra madura (Evans y col., 1994).

\subsubsection{Actividad neuroendocrina.}

En el proceso regulatorio del desarrollo reproductivo de una hembra intervienen muchos elementos. Sin dudas, el aparato reproductor cumple un rol fundamental, pero sumado a este intervienen muchos órganos reguladores o sensores del metabolismo, desde el hígado hasta las células grasas. Todas las señales confluyen en los centros regulatorios cerebrales quienes son al final de cuentas quienes reprimen o inducen la liberación de GnRH, hacia el sistema porta hipotálamo hipofisiario, para inducir la secreción de LH que dará inicio a la vida reproductiva de la hembra.

El hipotálamo de las vaquillonas prepúberes tiene la capacidad de secretar GnRH si recibe el estímulo adecuado, la hipófisis puede responder a la GnRH, sintetizar y liberar FSH y LH de manera pulsátil o bien produciendo un pico al igual que en las hembras adultas (Kinder y col., 1987; Day y Anderson, 1998) y los ovarios ante la secreción de gonadotrofinas consiguen ovular (Kinder y col., 1995; Day y Anderson, 1998). Es decir que todos los órganos que componen el eje 
reproductor están individualmente preparados para funcionar, pero para que el proceso de la ovulación ocurra todos deben trabajar de manera sinérgica.

Estudios realizados en vacas ovariectomizadas determinaron que la inhibición de la ovulación es ejercida por el ovario sobre el hipotálamo a través de estradiol (Day y col., 1984; Kinder y col., 1995). Esta inhibición sobre el hipotálamo comienza a declinar unos 50 días previos a la pubertad (Day y col., 1984; Kinder y col., 1987). La naturaleza de este proceso de retroalimentación negativa es indirecta, a través de centros cerebrales, donde se superponen cambios funcionales como también remodelaciones estructurales de algunos tejidos implicados.

Durante la vida prepuberal las neuronas secretoras de GnRH van sufriendo remodelaciones morfológicas, y se sabe que tratamientos que retardan la pubertad posponen este proceso de remodelación, esto ha sido observado en conejas, ratas, y un proceso similar ha sido observado al comparar vacas en anestro y vacas ciclando (Day and Anderson, 1998).

Se ha demostrado que el estradiol aumenta el número de sinapsis en el núcleo arcuato (ARC) y el núcleo ventromedial (VMN) en ratas, dos núcleos que tienen una función principal en la regulación de la secreción de GnRH. Todo este proceso de remodelación es necesario previo a la pubertad.

La administración de antagonistas del estradiol durante el período prepuberal retarda la pubertad, e inhibe esta remodelación de las neuronas GnRH. De modo que, si bien el estradiol ejerce un efecto inhibitorio sobre la secreción de GnRH, también ejerce un efecto putativo positivo regulando el proceso de remodelación 
neural. La administración de estradiol exógeno a vaquillonas prepúberes resultó en una pubertad más temprana, acelerando la desrepresión ejercida sobre la GnRH, sin embargo, sugieren que la administración exógena de estradiol solo aceleraría el inicio de la ciclicidad en vaquillonas subnutridas (Day y Anderson, 1998).

El efecto del estradiol sobre el hipotálamo no es directo, ya que las neuronas GnRH no contiene receptores de estradiol, los que se encuentran en el área preóptica medial (MPOA), en el septum ventrolateral, en la estría terminal, en el NVM, y en el ARC (Anderson y col., 1986; Day y Anderson, 1998).

La regulación de la secreción de GnRH es ejercida a través de GABA, dopamina, endorfinas, opioides y el neuropéptido Y (NPY) (Day y Anderson, 1998; Amstalden y col., 2014). En un estudio realizado por Day y col. (1984) se demostró que días previos a la pubertad en algunas de estas regiones regulatorias disminuye el número de receptores de estradiol, asociándose con un aumento de la pulsatilidad de LH.

El proceso madurativo consiste un juego de señales excitatorias e inhibitorias de la secreción de GnRH, y el balance entre estas determinan la primera ovulación de la hembra. Dentro de este proceso las neuronas productoras de NPY, proopiomelanocortina (POMC) y la kisspeptina (KISS o GPR54) tienen un rol fundamental (Amstalden y col., 2014). Existen evidencias que cambios funcionales en neuronas NPY y POMC contribuyen en el efecto acelerador de la pubertad en vaquillonas con altas tasas de ganancias de peso (Allen y col., 2012).

KISS ha sido propuesta como el mayor estimulador de la secreción de GnRH (Ojeda y col., 2010). De hecho, se sabe que en ausencia de esta o de su receptor 
(KISS1R) la pubertad no ocurre. La acción de KISS ha sido estudiada en ratones y primates, concluyendo que las neuronas productoras de KISS, ubicadas en el ARC, son fundamentales para la secreción pulsátil de GnRH (Lomniczi y col., 2013b; Ojeda y Lomniczi, 2014).

Estas células también producen Nurokinina B (NKB) y Dinorfina. La primera es un estimulador de la secreción de KISS y la segunda es un opioide inhibidor. Es por esta razón, que se cree que estas células podrían autorregularse paracrinamente.

Se ha propuesto que las neuronas KISS son las principales efectoras del efecto del estradiol sobre la secreción de GnRH (Allen y col., 2012), estimulando la secreción de GnRH a través de la estimulación de receptores KISS1R. Se ha descripto que una mutación de estos receptores retrasa la pubertad en ratones y humanos (Amstalden y col., 2014). Además, el efecto de KISS sobre la secreción de GnRH se basa en el hecho de que las neuronas que la producen se proyectan hacia las neuronas GnRH y en que las neuronas GnRH presentan receptores KISS (Amstalden y col., 2014).

Por otra parte, se ha demostrado que KISS tiene un efecto directo sobre la secreción de LH (Suzuki y col., 2008). Las neuronas KISS se ubican principalmente en el área preóptica (POA) y en el ARC, y en esas neuronas hay receptores de estradiol (Franceschini y col., 2006). El número de neuronas inmunorreactivas a KISS aumenta en corderos púberes respecto a prepúberes. El número de células KISS1 en ARC aumentó con la administración de estradiol en corderas ovariectomizadas, mientras que en la región MPOA aumentan con la edad, de manera que en el proceso regulatorio de la pubertad la edad juega un rol importante. 
Estos últimos afectan menos la pulsatilidad de la LH, pero tienen importancia en la secreción tónica de LH (Amstalden y col., 2014).

\subsubsection{Señales metabólicas}

La importancia de la nutrición en el desarrollo y el arribo a la pubertad es bien conocida. Existen muchas evidencias del retraso en la pubertad producido por las restricciones alimentarias agudas o crónicas, a través de un retraso en la pulsatilidad de LH (Garcia y col., 2002; Chelikani y col., 2003; Zieba, 2004; Gasser y col., 2006a; Duittoz y col., 2016).

El efecto observado en la pulsatilidad de LH responde a una menor secreción de GnRH (I'Anson y col., 2000). En varios estudios realizados por Gasser y col., (2006a; 2006b; 2006c) se demostró que en grupos de vaquillonas que exhibían altas ADP, la ocurrencia de pubertad precoz, definida como pubertad antes de los 300 días, se daba en una mayor proporción de vaquillonas . Estos mecanismos de aceleración de la pubertad parecen estar mediados por neuronas NPY y POMC (Amstalden y col., 2014).

La leptina (LEP) es una hormona proteica secretada por el tejido adiposo, su concentración aumenta en respuesta a la reserva adiposa, regulando la ingesta y el gasto energético. Además, LEP tiene un efecto importante en el desencadenamiento de la función reproductiva, aunque es insuficiente para desencadenarla por si sola (Houseknecht y col., 1998; Zieba, 2004).

Hoy se sostiene que su función es más bien permisiva para el progreso de la pubertad (Amstalden y col., 2014), afectando la secreción de GnRH (Garcia y col., 
2002; Williams y col., 2002; Amstalden y col., 2014). Es así como se propone que la LEP es una de las señales metabólicas que más influyen en la transición hacia la pubertad, indicando la presencia de un ambiente propicio para la reproducción.

Las neuronas GnRH no contienen receptores de leptina (LEPR), su efecto parece estar mediado por neuronas NPY y POMC e interneuronas localizadas en ARC. Estudios en ratones indican que otro posible sitio de acción importante es el área premamilar del hipotálamo (Roa y col., 2010; Amstalden y col., 2014; Duittoz y col., 2016). Además, se considera que las neuronas KISS son un blanco LEP (Messager, 2005; Ojeda y col., 2006; Estill, 2014), y podrían mediar los efectos de la misma.

En los últimos años, se han estudiado los efectos epigenéticos ejercidos por la nutrición en el útero del feto, y han concluido que la secreción tanto de KISS como de NPY y POMC pueden ser afectadas por la LEP durante la vida fetal (Amstalden y col., 2014).

El efecto del NPY sobre la secreción de LH no es afectado por la LEP, de manera que el efecto de la LEP está más arriba que el del NPY, de hecho, el hipotálamo no tiene receptores de LEP, pero si tiene receptores de NPY. Se ha demostrado un retardo en la pubertad en ratas a las que se le administró NPY, mientras que la administración de antagonistas de este acelera la pubertad (Allen y col., 2012). Todas estas observaciones sostienen la hipótesis de que la disminución del efecto inhibidor del NPY es crítico en el inicio de la ciclicidad de la hembra.

La proteína relacionada con el gen Agutí actúa sinérgicamente con el NPY, esta es un antagonista endógeno del receptor de melanocortina, y si bien tiene un 
efecto menos marcado que NPY como orexígeno, su efecto es más perdurable en el tiempo. Esta proteína también tiene un efecto inhibidor sobre la secreción de GnRH (Lomniczi y col., 2013a; Amstalden y col., 2014; Lomniczi y col., 2015).

La hormona alfa melanocito estimulante (MSH) es uno de los productos de POMC, y tiene un efecto regulador en el balance energético. Existen reportes sobre el efecto estimulador de la MSH sobre la secreción de GnRH, como así también del efecto estimulador de LEP sobre las neuronas POMC (Amstalden y col., 2014).

El cambio en la pulsatilidad de la GnRH es el último término de una serie de modificaciones trasinápticas y gliales que regulan los impulsos aferentes a las neuronas GnRH. Estos cambios incluyen un aumento de las señales excitatorias (a través de KISS principalmente, pero también mediante el glutamato) y una disminución de las señales inhibitorias, mientras que los efectos de la neuroglía son más bien facilitadores a través de factores de crecimiento o moléculas pequeñas (Ojeda y col., 2006; Ojeda y col., 2010; Ojeda y Lomniczi, 2014; Lomniczi y col., 2015).

Actualmente, se ha encontrado en mamíferos la presencia de un factor inhibidor de la secreción de GnRH ortólogo al GnIH existente en las aves llamado péptido similar a RFamida (RFRP, por su sigla en inglés). Este factor se suma a los efectos inhibidores de la secreción de GnRH inducido por neuronas GABA érgicas, pero a diferencia de estas, la primera inhibe de manera directa la secreción de GnRH (Ojeda y col., 2006).

Además de todo esto, las células de la glía (principalmente astrocitos y tanicitos) producen moléculas de señalización que contribuyen a determinar el 
tiempo de la pubertad, básicamente a través de 4 factores: factor de crecimiento transformante beta (TGF $\beta$ ), factor de crecimiento epidérmico (EGF), factor de crecimiento de fibroblastos (FGF), y factor de crecimiento similar a insulina (IGFI), sumado a un efecto ejercido a través de cambios en la organización celular (Ojeda y col., 2010; Lomniczi y col., 2015).

Ninguno de todos los factores mencionados actúa de forma aislada, más bien entre ellos contribuyen a la formación de una red de regulación, que tiene además vías de escape que garantiza el éxito reproductivo de la pubertad.

También se ha reportado que al suprimir la secreción de KISS se pone en funcionamiento una vía de alternativa que reestablece la función reproductiva, aunque más tardíamente. De aquí que la regulación del momento de la pubertad está coordinada por una red génica, donde interactúan muchos elementos (Lomniczi y col., 2013b), algunos de ellos actúan como portales que reciben y procesan información del ambiente, otros solo funcionan dentro de la propia red. Estas redes tienen nodos centrales, fuertemente conectados con toda la red, y nodos subordinados en distintas posiciones jerárquicas que responden a los nodos centrales.

En general se piensa en una regulación compleja, pero de pocos genes, donde la complejidad está dada por las conexiones que se dan dentro de la red. La idea de una red génica ha sido ampliamente estudiada en roedores y primates. Sin embargo, aún son escasos los reportes en bovinos, pero el concepto se extiende en todos los mamíferos. Sumado a este concepto de red génica hay que sumar los efectos 
epigenéticos ejercidos principalmente a partir de metilación y modificación de histonas (Ojeda y col., 2010; Lomniczi y col., 2015).

\subsection{RELACION DE LA PUBERTAD CON LA NUTRICIÓN}

La nutrición juega un papel central en el proceso de crecimiento y maduración de cualquier animal, de hecho, se propone que la pubertad se alcanza cuando un bovino logra alrededor del 55\% del peso adulto (Patterson y col., 1992; Morris y Wilson, 1997; Morris y col., 2000; Freetly y col., 2011) y cerca del $90 \%$ de la talla adulta (Freetly y col., 2011). Estos valores presentan alguna variación según los autores, generalmente explicadas por las razas o biotipos utilizados en los diversos estudios (Short y Bellows, 1971; Honaramooz y col., 2004a; Gasser y col., 2006a; Roberts y col., 2009).

El efecto de la nutrición sobre el arribo a la pubertad es ejercido a través de mecanismos citados previamente en este trabajo. Se sabe que hormonas como LEP, la hormona de crecimiento $(\mathrm{GH})$, el factor de crecimiento tipo insulina 1 (IGF-1), la Insulina (INS) y algunos metabolitos como los ácidos grasos no esterificados (AGNEs) en sangre son las aferencias de los altos centros cerebrales reguladores de la actividad reproductiva (Yelich y col., 1996).

\subsection{INICIO DE LA PUBERTAD EN VAQUILLONAS}

El evento central para alcanzar la pubertad es la secreción de GnRH, que induce la liberación de LH (Rawlings y col., 2005; Duittoz y col., 2016). Esto solo 
será posible una vez que la retroalimentación negativa ejercida por el estradiol sobre la GnRH decline (Day y Anderson, 1998).

En la primera ovulación de una hembra, el folículo ovula estando en fase estática, o sea que es relativamente más viejo que en hembras adultas donde el folículo ovula desde la fase de crecimiento. Además, el cuerpo lúteo de ese ciclo estral es más pequeño y tiene una vida más corta, por lo que el intervalo interovulatorio es menor y el ciclo estral infértil, mientras que el segundo intervalo interovulatorio es de duración normal (Evans, 2003; Evans y Rawlings, 2010).

Los dos elementos que condicionan la pubertad son el peso y la edad (Nelsen y col., 1985). Según estos autores la edad a la pubertad en la raza Angus fluctúa entre los 340 y 420 días (Ferrell, 1982; Freetly y Cundiff, 1997; Freetly y col., 2001; Larson y col., 2016), el peso a la pubertad en general se establece entre un 50 y $65 \%$ del peso adulto (Patterson y col., 1992; Funston y col., 2012; Patterson y col., 2013). Sin embargo, tanto el peso como la edad a la pubertad pueden variar dependiendo de las condiciones nutricionales en las que se manejó a las vaquillonas.

Se plantea que tanto el peso como la edad tienen una suerte de umbrales relativamente independientes, de modo que, a tasas de crecimiento altas, la limitante para el arribo a la pubertad será la edad, por lo que la vaquillona alcanzara la pubertad a una edad temprana con un peso más alto, ya que excedió ampliamente el umbral de peso. Sin embargo, si las tasas de crecimiento son bajas, la vaquillona alcanzará la pubertad a una edad más tardía y a un peso menor, ya que el umbral de edad habría sido sobrepasado, siendo limitada solo por el peso (Arije y Wiltbank, 1971; Short y Bellows, 1971; Barcellos y col., 2014). 
Varios trabajos remarcan la importancia no solo del crecimiento durante la recría, sino también del crecimiento predestete (Patterson y col., 1992; Mialon y col., 2000; Gasser y col., 2006a; Gasser y col., 2006d). Gasser y col., (2006a) encontraron que un alto plano nutricional entre los 4 y 7 meses es suficiente para lograr una pubertad precoz en un $67 \%$ de las vaquillonas evaluadas.

\subsubsection{Inducción de la pubertad de las vaquillonas}

Existen reportes de tratamientos hormonales para la inducción de celo en vaquillonas prepúberes a través de implantes de progestágenos y sales de estradiol (Gonzalez-Padilla y col., 1975; Short y col., 1976; Rodrigues y col., 2013). Algunos tratamientos basados en este tipo de hormonas se ofrecen comercialmente y si bien esta clase de tecnologías pueden ser de gran impacto inmediato, ya que permiten preñar precozmente vaquillonas que probablemente se preñarían tarde en el servicio o bien no lo harían. Sin embargo, la inducción de la pubertad podría llevar a retener hembras en el establecimiento que de otra manera hubiesen sido rechazadas, y estar seleccionando en contra de las características reproductivas con un efecto negativo sobre el rodeo.

\subsection{SELECCIÓN GENÉTICA POR PRECOCIDAD SEXUAL.}

Los reportes de heredabilidad $\left(\mathrm{h}^{2}\right)$ de la edad a la pubertad varían según los autores, si bien la mayoría de los valores estimados se sitúan entre el 30 y $40 \%$ (Martin y col., 1992; Morris y col., 2000), existen reportes que van desde un 10\% 
hasta un 60\% (Cammack y col., 2009), lo cual lo convierte en un carácter capaz de ser seleccionado.

En términos productivos la selección por edad a la pubertad resulta compleja, ya que la naturaleza binaria del carácter y la censura que la misma sufre en el intervalo obligan a realizar mediciones a intervalos cortos para detectar a las hembras púberes. En un programa de mejora genética se debería de trabajar con caracteres de media a alta $\mathrm{h}^{2}$, fáciles y económicos de medir, seleccionando indirectamente por pubertad (Johnston y col., 2009).

\subsubsection{Selección al destete}

En rodeos tanto comerciales como de cabaña, la primera intervención donde se realiza una selección de vaquillonas es al momento del destete, donde se define cuantas y cuales terneras son retenidas para recría como vientres futuros y cuales son vendidas o transferidas a sistemas de engorde. En este momento hay dos aspectos fundamentales y fáciles de evaluar, el peso corporal y el biotipo.

El primero de ellos es importante ya que la posibilidad de alcanzar un peso objetivo futuro depende del peso que tengan las vaquillonas al destete. Este valor depende de dos elementos, el primero y más importante es la edad (dada por la fecha de parición), de manera que debemos pensar en la reposición en el momento que damos servicio a las madres de las futuras vaquillonas (18 meses antes).

El segundo elemento es la ganancia diaria al pie de la madre, que además de influir en el peso al destete como se explicó previamente, condiciona la edad a la 
pubertad de las hembras a través de la importancia de la nutrición en el establecimiento de un aumento temprano y transitorio de la LH.

En cuanto a la selección por biotipo depende de los objetivos de cada establecimiento en particular. Cabe desatacar que al realizar una reposición con las hembras producidas en el propio establecimiento, la presión de selección que se pueda realizar sobre las mismas depende en gran medida del porcentaje de parición y del número de terneras nacidas en cabeza, de modo que se conecta con los objetivos generales del sistema de cría, más terneros y más pesados.

\subsubsection{Selección en el preservicio.}

En esta segunda intervención de selección en el rodeo de vaquillonas se realiza una selección de las mismas a través de su peso corporal, biotipo, grado de desarrollo reproductivo y área pélvica (Casaro y Mihura, 1999). La influencia del peso corporal en la pubertad y en la productividad de una vaquillona ha sido discutida previamente en este trabajo. Cabe agregar que la evaluación del peso corporal debería realizarse periódicamente durante la recría de modo de poder realizar ajustes de ser necesario para garantizar que al momento del servicio las vaquillonas hayan alcanzado al menos el 66\% del peso adulto (Carrillo, 1997). En cuanto al biotipo nuevamente depende de los objetivos de selección del propio establecimiento. La evaluación del grado de desarrollo reproductivo (GDR) en las vaquillonas previo al servicio, consiste en asignar un puntaje a las vaquillonas en función del nivel de desarrollo del útero y los ovarios a través de palpación rectal (Casaro y Mihura, 1999) (Tabla 1.1). Esta es la primera evaluación en la vida del 
animal que permite hacer una selección entre hembras púberes y prepúberes, reteniendo para reproducción a aquellas que han alcanzado la pubertad. Al hacerlo sistemáticamente en todas las hembras para reposición estaremos renovando el rodeo con hembras precoces, más aún si esta maniobra fuera hecha unos 45 días previos al servicio estaríamos maximizando las probabilidades de obtener un alto número de preñeces en cabeza en los rodeos de vaquillonas, utilizando una herramienta que no solo permite realizar una mejora genética, sino también una mejora de la preñez inmediata.

Tabla 1.1. Escala de grado de desarrollo reproductivo (GDR). Adaptado de Casaro y Mihura (1999)

\begin{tabular}{ccc}
\hline GDR & Cuernos Uterinos & Ovarios \\
\hline 1 & Inmaduro. $<5 \mathrm{~mm}$ de diámetro. & $<10 \mathrm{~mm}$ de largo y ancho. Liso \\
2 & $\begin{array}{c}5-10 \mathrm{~mm} \text { de diámetro. Tono } \\
\text { moderado. }\end{array}$ & $15 \mathrm{~mm}$ de largo y $10 \mathrm{~mm}$ de ancho. Liso \\
3 & $10-15 \mathrm{~mm}$ de diámetro. Tono & $15 \mathrm{~mm}$ de largo y $15 \mathrm{~mm}$ de ancho. Presencia \\
firme & de folículos preovulatorios \\
4 & firme. & $>20 \mathrm{~mm}$ de largo. Cuerpo lúteo presente. \\
\hline
\end{tabular}

Hembras con un grado de desarrollo reproductivo de 3 y 4 logran un mayor número de preñeces totales al final del servicio, y una mayor proporción de las crías en cabeza de parición (Casaro y Mihura, 1999)

En cuanto a la selección por área pélvica es una herramienta muy útil para disminuir el número de distocias, pero debe ser utilizada juntamente con el frame score, ya que seleccionando únicamente a través del área pélvica se corre el riesgo de aumentar el tamaño corporal de las hembras, y no solucionar el problema de las 
distocias, e incluso incrementarlo. Otra herramienta útil y disponible en el mercado es evaluar a los toros que van a ser utilizados para el servicio de vaquillonas a través de su valor de cría para facilidad de parto o bien peso al nacimiento.

\subsubsection{Selección por características correlacionadas}

Además del GDR, otras formas que permiten realizar una mejora genética en la precocidad sexual de las hembras es la selección de machos de alta circunferencia escrotal (CE), ha sido calculada una correlación genética negativa entre la $\mathrm{CE}$ de los machos y la edad a la pubertad de las hembras (Martinez-Velazquez y col., 2003). El uso de la CE permite ejercer una mayor presión de selección, ya que el efecto de los machos en el rodeo es mucho más marcado. Un macho en servicio natural puede lograr hasta 60 hijos en una parición, diseminando la genética mucho más rápidamente que las hembras. Existen reportes que relacionan la edad a la pubertad con la capacidad de deposición grasa, el frame score y el tamaño adulto. Muchas de estas características están incluidas en las evaluaciones genéticas, por lo que están disponibles a la hora de adquirir reproductores. Además, algunas pruebas de progenie en el mundo incluyen DEPs (Desvío esperado de progenie o Expected Progeny Differences), o EBVs (Expected Breeding Value) de características relacionadas directamente con la precocidad sexual, tal es el caso de la edad al primer parto o probabilidad de parto precoz. Sin embargo, aún no están disponibles en las pruebas nacionales. 


\subsubsection{Selección a través de información de marcadores genéticos.}

Actualmente, existen varios trabajos de asociación de la edad al primer parto con diferentes polimorfismos de nucleótido simple (SNP, por su sigla en inglés), que permiten detectar loci de caracteres cuantitativos (quantitative trait loci, QTLs por su sigla en inglés), y estos podrían ser utilizados en programas de mejora (Habier y col., 2009; Knol y col., 2016). La principal desventaja de esta tecnología es la naturaleza poligénica de las características reproductivas, de manera que identificando pocos genes se consigue solo explicar una pequeña proporción de la varianza genética. Estos análisis tienen por objetivo determinar el efecto de sustitución alélica en una característica cuantitativa, para posteriormente utilizarlos como candidatos un programa de selección asistida por marcadores.

Por otra parte, los estudios asociación genómica (Genome Wide Association Study, GWAS por su acrónimo en inglés) a través del estudio de un gran número de SNPs distribuidos a lo largo del genoma permiten evaluar simultáneamente la asociación con muchos marcadores en un mismo análisis. De esta manera, se logra identificar el peso relativo de cada SNP con la variable y facilita el diseño de paneles personalizados para la característica.

\subsubsection{Selección a través de evaluaciones genéticas.}

El BLUP es una metodología estadística que permite predecir los valores de cría, desde su desarrollo por Henderson (1984) ha sido el verdadero motor del mejoramiento genético. Actualmente, el desarrollo de la genómica y los paneles de alta densidad ha posibilitado nuevas formas de análisis, y abren nuevas puertas para 
su utilización en el mejoramiento genético, tal son los casos del RRBLUP(Meuwissen y col., 2001), el GBLUP (Van Raden, 2008), el SSGBLUP (Legarra y col., 2014) y la regresión ancestral (Cantet y col., 2017).

Sea cual sea el modelo de análisis el objetivo de cualquier evaluación genética es obtener una predicción con la mayor exactitud posible del valor de cría de un reproductor, es decir de su verdadero mérito genético. Estos resultados son aplicados en los programas de mejora diseñados para los establecimientos de modo de definir los apareamientos en función del mérito genético de los machos y de las hembras según los objetivos de selección. En este sentido el diseño, ejecución y seguimiento de un programa de mejora es fundamental para los establecimientos dedicados al mejoramiento y venta de reproductores, ya que permite tomar decisiones sobre elementos claros, definidos y planificados, con la consiguiente disminución del azar en los resultados.

En Argentina, actualmente ninguna evaluación genética cuenta con una evaluación de la precocidad sexual de manera directa en las pruebas de progenie, si bien la selección por características correlacionadas, en conjunto con una adecuada recría y mediciones en el preservicio suelen ser suficientes para garantizar un adecuado desempeño de las vaquillonas la precisión de la mejora es menor. En el mundo existen algunas evaluaciones genéticas que incorporan características de precocidad sexual, por ejemplo, preñez de las vaquillonas (heifer pregnancy, HP) en la evaluación de la Asociación de Angus Americano (American Angus Association), días al parto (days to calving) en la evaluación de Breedplan Australian Angus (https://www.angusaustralia.com.au/breedplan/), y algunos otros ejemplos en otras pruebas y en otras razas como la probabilidad de parto precoz 
(3P) o edad al primer parto (IPP) en la prueba de Nelore de ANCP (http://www.ancp.org.br/).

\section{OBJETIVO GENERAL}

El presente trabajo de Tesis Doctoral tiene como objetivo general describir la variación genética y ambiental en el arribo a la pubertad en vaquillonas Angus producidas en sistemas pastoriles, determinar la asociación entre una menor edad a la pubertad y marcadores genéticos, como así también su relación con la precocidad sexual en machos.

\section{OBJETIVOS PARTICULARES}

Estudiar el impacto de recrías pastoriles en la precocidad sexual.

Cuantificar el riesgo asociado a la presencia de polimorfismos en los SNPs IGF-SnaBI y GNRHR-SNP6.

Estimar los componentes de varianza de la edad al primer parto (como indicador indirecto de la precocidad sexual) y la circunferencia escrotal de los machos relacionados a diferentes edades de medición.

\section{HIPOTESIS}

Existe variabilidad fenotípica para la precocidad sexual en las hembras Angus.

Algunos genes con efecto mayor explican parte de esta variabilidad fenotípica de la edad de arribo a la pubertad.

Existe una relación entre la precocidad sexual de las hembras medida a través de la edad al primer parto con la circunferencia escrotal de los machos. 


\section{CAPITULO II}

\section{ANÁLISIS LONGITUDINAL DE LAS DIFERENCIAS EN CURVAS DE CRECIMIENTO PRESERVICIO EN VAQUILLONAS ANGUS PARA ENTORE A 15 MESES BAJO DOS TRATAMIENTOS NUTRICIONALES BASADOS EN PASTOREO.}

\subsection{INTRODUCCIÓN}

El entore a 15 meses se propone como una forma de aumentar la eficiencia productiva de la hembra, obteniendo un ternero más en su vida, mejora la productividad del sistema disminuyendo la proporción de animales improductivos en el rodeo (Carrillo, 1997; Albuquerque y Baldi, 2008) y posibilita reducir el intervalo generacional (Pereira Gomes de Freitas, 2005). Los beneficios de esta práctica pueden maximizarse si la hembra se preña al inicio de la estación reproductiva, ya que destetará un ternero más pesado debido a su mayor edad. Además, si esta condición se cumple, la vaca de primer parto tendrá un mayor tiempo para recuperarse hasta su próximo servicio (Patterson y col., 1992), por lo que la probabilidad de una segunda preñez temprana será mayor, y este ciclo tenderá a perpetuarse durante sus próximos partos. Es en este sentido que la edad al primer parto de la hembra representa el "cuello de botella" en la eficiencia productiva de la misma (Day y Nogueira, 2013), y la pubertad es un factor limitante para lograr una concepción temprana en su primer servicio.

Para lograr un servicio exitoso, todas las hembras deben haber alcanzado la pubertad antes del entore. Este desarrollo reproductivo es influenciado por el sistema productivo, por la fisiología de la hembra y por la genética (Short y 
Bellows, 1971; Martin y col., 1992; Patterson y col., 1992), es necesario tener en cuenta que la tasa de concepción aumenta a medida que los ciclos estrales se suceden, siendo el tercer ciclo estral un 20\% más fértil que el primero (Byerley y col., 1987; Holm y col., 2015). En las vaquillonas el primer ciclo estral define la pubertad (Atkins y col., 2013) y por lo tanto la capacidad reproductiva siendo el último escalón de una serie de procesos del desarrollo de cualquier mamífero (Ramaley, 1979; Patterson y col., 1992).

La edad a la pubertad es influenciada por el peso adulto de los animales, la raza, la genética individual y el ambiente, donde la nutrición juega un papel central. (Buttram y Willham, 1989; Gasser y col., 2006; Lamb, 2013). Se ha propuesto que la pubertad debe alcanzarse unos 45 días antes de la estación de servicios (Hall, 2013), porque una pubertad temprana viene acompañada de concepciones anticipadas en la temporada de servicios, mayor productividad de la vacas, mayor permanencia en el rodeo y una diferencia en la renta obtenida al final del cuarto año de entorada la vaquillona (Patterson y col., 1992; Day y Nogueira, 2013; Hall, 2013).

En los países donde el recurso más barato disponible es el pasto, como en el caso de Argentina, Brasil, Uruguay, Nueva Zelanda, Australia, Canadá y los Estados Unidos, los rodeos de carne son manejados sobre sistemas pastoriles, donde la calidad del forraje varia tanto en su composición como en su digestibilidad a lo largo del año de acuerdo a las condiciones ambientales (Buxton y col., 1995). Además de ello, existe una fuente adicional de variabilidad relacionada con el comportamiento individual en pastoreo (Decruyenaere y col., 2009), ambos factores afectan el aumento diario de peso (ADP). 
La recría sobre pasturas permite alimentar los animales con un recurso voluminoso a un bajo costo, pero la ingesta de energía podría estar limitada dependiendo de la calidad de la pastura.

Algunos autores sugieren que un crecimiento adecuado se logra con un ADP de $0,68 \mathrm{~kg} / \mathrm{d}$ durante toda la recría (Hughes, 2013). En el caso de las vaquillonas de reposición es necesario alcanzar también un adecuado grado de desarrollo reproductivo, de manera de lograr un buen porcentaje de preñez y pariciones en cabeza de parición para definir una recría exitosa (Albuquerque y Baldi, 2010; Perry y Cushman, 2013; Vraspir y col., 2014).

Sin embargo, el ADP promedio no informa acerca de variaciones en el crecimiento en periodos cortos de tiempo y esto podría impactar en el desarrollo. Los análisis longitudinales proveen estimadores más eficientes para testear diferencias en las curvas de crecimiento respecto a los análisis transversales utilizando el mismo número de observaciones. Estos análisis logran explotar toda la información contenida en las observaciones repetidas de cada individuo, excluyendo variación entre animales del término del error (Hedeker y Gibbons, 2006). Este tipo de análisis han sido utilizados en vacas para detectar diferencias en el crecimiento diario entre grupos de genotipos diferentes para establecer periodos donde esas diferencias eran significativas (Rogberg-Muñoz y col., 2013).

Para testear estadísticamente estos cambios, en este estudio se utilizó un modelo de regresión de efectos mixtos para datos longitudinales adaptando el análisis aplicado por Rogberg-Muñoz y col. (2013). Específicamente, se evaluaron dos condiciones de recría: i) pastoreo ad-libitum (AD), donde el límite para la ingesta energética fue impuesto por el volumen ruminal y la calidad de la pastura, 
$\mathrm{y}$ ii) pastoreo controlado (PC), donde la oferta forrajera era reasignada cada 2 semanas, buscando un crecimiento objetivo de $0.5 \mathrm{~kg} / \mathrm{d}$.

El objetivo de este estudio fue evaluar si un sistema de pastoreo con una ganancia diaria de peso objetivo de $0,5 \mathrm{~kg} / \mathrm{d}$, restringe el arribo a la pubertad durante la recría. Complementariamente se buscó evaluar si los modelos de análisis longitudinal de datos son capaces de detectar diferencias en el crecimiento en periodos cortos de tiempo que pueden afectar la pubertad al inicio de la temporada de servicio en vaquillonas Angus en recría pastoriles para entore a 15 meses.

\subsection{MATERIALES Y MÉTODOS}

\subsubsection{Animales, condiciones alimenticias y datos fenotípicos.}

El estudio incluyó 468 medidas repetidas obtenidas de 36 vaquillonas Angus nacidas en el año 2012 en el campo experimental “El Amanecer” perteneciente a la Universidad Nacional de La Plata (Magdalena, Buenos Aires, Argentina 351' $\mathrm{S}-$ $57^{\circ} 37^{\prime}$ O). El rodeo se caracteriza por una selección funcional con biotipo de tamaño adulto moderado, los vientres adultos tienen un peso promedio al destete de $430 \mathrm{~kg}$.

Si bien las vaquillonas eran hijas de 7 padres diferentes, con el uso de los registros de pedigrí del establecimiento, pueden rastrearse los antecesores de cada animal por al menos 3 generaciones, de manera que las relaciones entre las vaquillonas pueden ser evaluadas de manera concreta.

Todos los procedimientos realizados sobre los animales fueron revisados y aprobados por el Comité Institucional para el Cuidado y Uso de Animales de 
Laboratorio (CICUAL), de la Facultad de Ciencias Veterinarias de la Universidad Nacional de La Plata (Res n 74-4-18T).

Las vaquillonas nacieron entre el 27 de julio y el 29 de septiembre del 2012, y fueron destetadas el primero de marzo de 2013. Al inicio del ensayo las vaquillonas tenían una edad de $248 \pm 17$ días, y un peso de $167 \pm 21 \mathrm{~kg}$, las mismas fueron asignadas aleatoriamente a dos tratamientos de recría, pastoreo ad-libitum (AD) y pastoreo controlado (PC), por 182 días desde el 4 de abril hasta el 10 de octubre de 2013. Ambos tratamientos consistían en pastoreo de promociones de especies invernales, realizadas a través de la modificación de un pastizal natural mediante la aplicación de herbicidas para promocionar la germinación y el establecimiento principalmente de Lolium multiflorum, Bromus catharticus y Gaudinia fragilis.

La disponibilidad de forraje en ambos tratamientos fue monitoreada cada 14 \pm 1 días. Se determinó la oferta forrajera en $\mathrm{kg} / \mathrm{ms}$ por hectárea con el método descripto por Haydock and Shaw (1975). Se seleccionaron aleatoriamente cuatro áreas de 0,5 m de lado, todo el forraje contenido en esa área fue cortado y pesado. Una submuestra fue secada a $60{ }^{\circ} \mathrm{C}$ hasta peso constante para determinar el porcentaje de materia seca.

El tratamiento $\mathrm{AD}$ se diseñó de forma tal que las vaquillonas no experimenten restricciones al consumo originadas por la disponibilidad de forraje. El área de pastoreo para el tratamiento PC fue asignada cada $14 \pm 1$ días, a través de la determinación de la cantidad de materia seca ofrecida, considerando una eficiencia de cosecha del 50\%, y los requerimientos de las vaquillonas en función 
del peso y un ADP esperado de $0,5 \mathrm{~kg} / \mathrm{d}$, estableciendo un consumo de alrededor del 3\% del peso vivo de MS de forraje por día.

Durante la recría se registró el peso utilizando una balanza digital VESTA 3513 (Rosario, Santa Fe, Argentina), la actividad ovárica de las vaquillonas y el engrasamiento en la cadera en la intersección de los músculos glúteo medio y bíceps femoral, mediante un transductor lineal de 7,5 MHz conectado a un ecógrafo modo B (Aquila vet, Esaote SpA, Genova, Italia) cada $14 \pm 1$ días, registrando 13 medidas de cada animal. Se consideró que la hembra había alcanzado la pubertad cuando se identificó por primera vez un cuerpo lúteo (Honaramooz y col., 2004; Johnston y col., 2009).

La asignación aleatoria de los tratamientos fue chequeada mediante un análisis de varianza, para determinar que no existieran diferencias en el peso y/o la edad al destete y al inicio del tratamiento de recría (Tabla 2.1).

\subsubsection{Estimación del balance energético durante el estudio.}

Al finalizar el ensayo, se calculó el balance energético (BE) de cada animal en megacalorías de energía metabolizable (Mcal EM) para el periodo entre mediciones (14 \pm 1 días), estimado como la diferencia entre la energía ofrecida y los requerimientos calculados para los animales en función de su peso y el ADP logrado en el periodo $(\mathrm{BE}=$ energía ofrecida - energía requerida $)$.

La energía ofrecida fue calculada a partir de datos de composición energética del forraje (Guaita y Fernández, 2011) y la cantidad de materia seca disponible para pastoreo al día de la medición. 
Los requerimientos energéticos (Req) fueron estimados ajustando una regresión múltiple considerando el efecto lineal del peso y el efecto lineal y cuadrático del ADP, según los requerimientos expresados en las Tablas de Requerimientos Nutricionales del Ganado Bovino de Carne del NRC (National Research Council, 2000, Anexo 1) de manera de obtener una ecuación predictiva de los requerimientos de una vaquillona dependiendo de su peso y su ADP. El modelo fue ajustado mediante el procedimiento REC de $\mathrm{SAS}^{\circledR} 9.4$ (2012). Se evaluaron cuatro diferentes modelos para estimar los requerimientos de vaquillonas con peso vivo entre 200 y $400 \mathrm{~kg}$ y ADP entre 0 y $1 \mathrm{~kg} / \mathrm{d}$. Finalmente se utilizó el modelo más parsimonioso (el de mayor $\mathrm{r}^{2}$ ) siendo:

$$
R e q=-2,532+0,043 * P+12,786 * A D P-3,953 * A D P^{2}
$$

donde Req son los requerimientos energéticos estimados de un animal, $\beta_{0}$ es la ordenada al origen de la función, $\beta_{1}, \beta_{2}$ y $\beta_{3}$ son las pendientes para el efecto lineal del peso, y lineal y cuadrático del ADP respectivamente. El valor de $r^{2}$ de esta ecuación resulto mayor a 0,95 .

\subsubsection{Análisis estadístico}

En ambos grupos, se ajustó un ANOVA utilizando el procedimiento GLM de $\operatorname{SAS}^{\circledR} 9.4$ para chequear la asignación aleatoria de las vaquillonas a cada tratamiento de los animales, de acuerdo con la edad y peso inicial y para analizar si existían diferencias en la edad y peso a la pubertad y en la edad al final del ensayo. 
Las diferencias entre grupos fueron testeadas utilizando la corrección de Bonferroni.

El análisis longitudinal del peso (234 registros de peso para cada tratamiento) fue realizado a través de un modelo de regresión de efectos mixtos (Hedeker y Gibbons, 2006), que permite usar toda la información incluida en registros correlacionados y corregir el efecto de animales relacionados genéticamente. Utilizando el siguiente modelo:

$$
y_{i j k t}=\mathrm{g}(t)_{\mathrm{j}}+\mathrm{r}(\delta, t)+e_{i j k t}
$$

donde $y_{i j k t}$ representa el $k_{e s i m o}$ peso del individuo $i$ en el tratamiento $j$ a la edad $t, g(t)_{j}$ considera el efecto de la trayectoria del peso promedio para todos los animales en el $j$-ésimo tratamiento, definido por el siguiente polinomio,

$$
g(t)_{j}=\alpha_{0 j}+t \alpha_{1 j}+t^{2} \alpha_{2 j}
$$

y $r(\delta, t)_{i}$ es el efecto cuadrático aleatorio asociado al $i$-ésimo animal, definido como

$$
r(\delta, t)_{i}=t \delta_{1 \mathrm{i}}+\mathrm{t}^{2} \delta_{2 \mathrm{i}}
$$

donde, $\delta_{1 i}$ y $\delta_{2 i}$ son los coeficientes aleatorios lineal y cuadrático para el animal $i$ a la edad $t$. Esta función modela las desviaciones individuales alrededor de la trayectoria fenotípica media. Se asumió la siguiente estructura de covarianza para las funciones de regresión,

$$
\left[\operatorname{Var}\left(\delta_{1 \mathrm{i}}\right) \operatorname{Cov}\left(\delta_{1 \mathrm{i}}, \delta_{2 \mathrm{i}}\right) \operatorname{Cov}\left(\delta_{2 \mathrm{i}}, \delta_{1 \mathrm{i}}\right) \operatorname{Var}\left(\delta_{2 \mathrm{i}}\right)\right] \otimes \mathrm{A}
$$

donde $\mathbf{A}$ es la matriz de relaciones aditivas $\mathrm{y}$ ' $\otimes$, es el operador de Kronecker. Por último, $e_{i j k t}$ es el error normal e independientemente distribuido.

Se realizo un segundo análisis para testear las diferencias entre las curvas de peso de animales púberes y no púberes al finalizar el ensayo utilizando un modelo similar: 


$$
Y_{i j k t}=x_{i} \beta+g(t)_{\mathrm{j}}+r(\delta, t)_{i}+e_{i j k . t}
$$

donde $y_{i j k t}$ representa el $k$-ésimo peso del individuo $i$ en el $j$ nivel de clasificación de estado puberal (púber o no púber) a la edad $t$, fue incluido un efecto fijo tiempo independiente para considerar el efecto de tratamiento, entonces $\beta$ es el vector de parámetros de efectos fijos de tratamiento (2 niveles), y $\boldsymbol{x}_{i}$ es el vector de incidencia para el $i$-ésimo individuo. La función $g(t)_{j}$ es una función cuadrática polinómica, en este caso modelando la curva de peso fenotípico promedio para los animales púberes y no púberes. Finalmente, $r(\delta, t)_{i}$ es la función de regresión cuadrática aleatoria asociada al $i$-ésimo animal, definido igual que en el caso anterior, y $e_{i j k t} \mathrm{el}$ error del modelo normal e independientemente distribuido.

Los mismos modelos fueron ajustados para la estudiar la posible deposición diferencial de grasa en la cadera entre tratamiento y entre vaquillonas púberes y no púberes al momento del servicio.

En todos los casos el modelo fue ajustado con $\mathrm{SAS}^{\circledR}$ 9.4, se utilizó el procedimiento INBREED para generar la Matriz A, y las ecuaciones de Máxima Verisimilitud Restricta (REML), implementadas en el procedimiento MIXED, para estimar los componentes de covarianza. Las diferencias entre los pesos a través de la edad para los tratamientos de pastoreo, como para los estados de pubertad fueron estimados utilizando contrastes lineales, como así también para el aumento diario de peso derivado (APd), estimado como la primera derivada de la ecuación anterior.

\subsection{RESULTADOS}

Los valores de edad y peso iniciales, así como los resultados obtenidos al finalizar el ensayo para ambos tratamientos de recría se presentan en la tabla 2.1. 
El período comprendido entre el destete y el inicio del tratamiento de recría no afectó diferencialmente a ninguno de los grupos (Tabla 2,1; Tabla 2,2).

El ANOVA para peso y edad final no mostró diferencias significativas entre los animales en los diferentes tratamientos de recría. El número de vaquillonas púberes fue diferente $(\mathrm{P}<0,05)$ al final de la recría entre tratamientos, $17(94,4 \%)$ en el tratamiento AD y $12(66,7 \%)$ en el tratamiento PC. Teniendo en cuenta solo los animales púberes (29 de los 36 evaluados) la edad promedio a la pubertad fue de $391 \pm 30$ días con un peso de $256 \pm 23,8 \mathrm{~kg}$ (Tabla 2.1). En el último muestreo, correspondiente a la revisación pre-servicio, las vaquillonas que habían alcanzado la pubertad eran $22 \mathrm{~kg}$ más pesadas y 5 días más jóvenes comparados con las no púberes (Tabla 2.2).

El BE en el tratamiento AD muestra una constante reducción durante el ensayo, determinado principalmente por una declinación en oferta de materia seca, debido al aumento del consumo de los animales, sobrepasando la tasa de crecimiento del forraje en el área de superficie fija de pastoreo. Sin embargo, la oferta forrajera en el tratamiento $\mathrm{AD}$, reflejada en el $\mathrm{BE}$, fue superior que en el tratamiento PC durante todo el estudio. En el grupo PC la oferta forrajera fue reajustada cada 2 semanas de acuerdo con el peso de los animales, por lo que se mantuvo relativamente estable durante todo el estudio (Figura 2.1).

Durante toda la recría, las vaquillonas del tratamiento AD tuvieron mayor energía disponible que los requerimientos necesarios para mantenimiento y crecimiento logrados de manera que la limitante del consumo energético fue la interacción entre la capacidad de ruminal y la calidad del forraje, mientras que la oferta forrajera del tratamiento PC fue asignada para un crecimiento animal a una 
tasa de $0,5 \mathrm{~kg} / \mathrm{d}$, lo que implica una fuente más de limitación en la oferta energética (figura 2.1).

Durante un periodo corto de tiempo, entre los 350 y 370 días de edad promedio, el $\mathrm{BE}$ de las vaquillonas en el tratamiento $\mathrm{PC}$ resultó negativo, en coincidencia con el momento donde las primeras vaquillonas de ambos tratamientos alcanzan la pubertad. Inmediatamente después, el balance energético del tratamiento PC se vuelve positivo y si bien la mayoría de las vaquillonas de ambos tratamientos alcanzan la pubertad no se alcanza a compensar la diferencia generada durante ese período (figura 2.1).

Figura 2.1. Balance Energético (BE), aumento de peso derivado (APd) y fracción de pubertad acumulada (FPA) para cada tratamiento durante el ensayo.

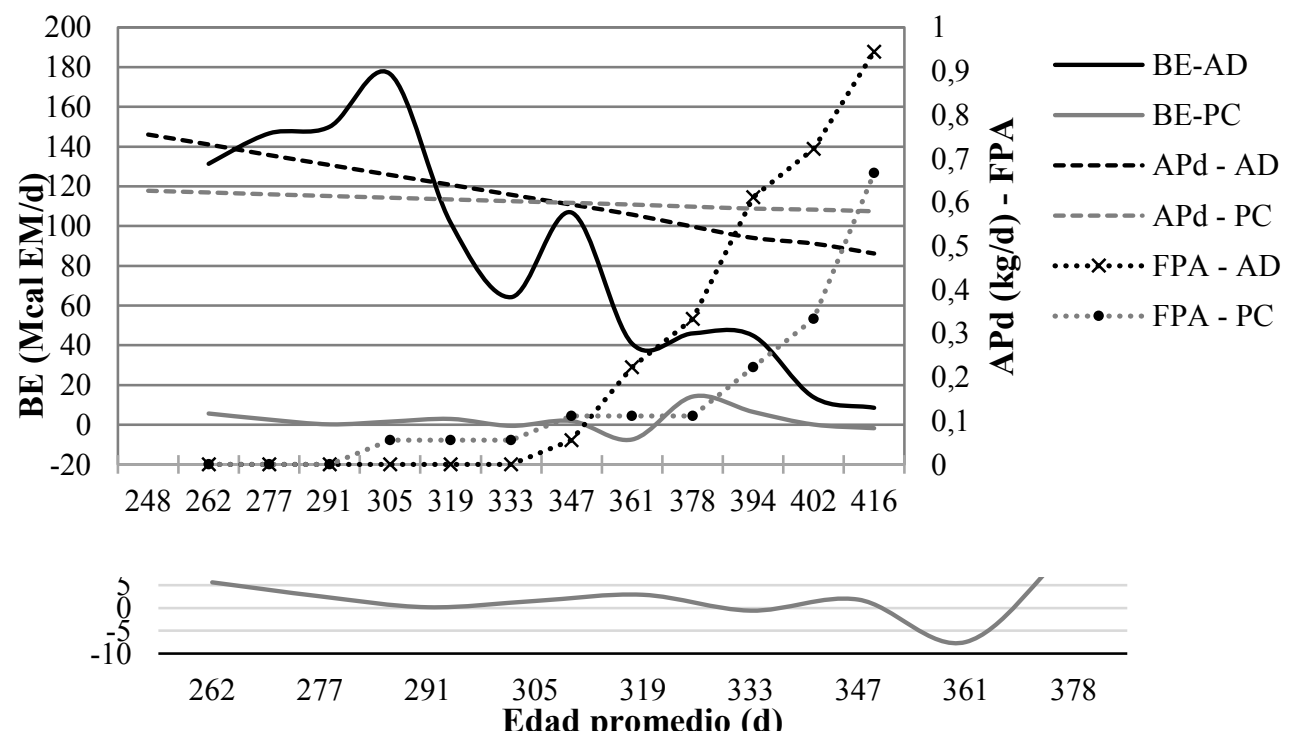

Nota: El panel inferior, aumenta la para el BE-PC entre los 262 y 378 días de edad. El BE fue determinado en fechas específicas, la edad es considerada como el promedio de edad de las vaquillonas en esa fecha.

El APd fue calculado como la primera derivada de la curva de peso.

Referencias: $\mathrm{BE}$ en tratamiento de pastoreo ad-libitum (BE-AD); $\mathrm{BE}$ en tratamiento de pastoreo controlado (BE-PC); APd en tratamiento de pastoreo ad-libitum (APd-AD); APd en tratamiento de pastoreo controlado (APd-PC); FPA en tratamiento de pastoreo ad libitum (FPA-AD); FPA en tratamiento de pastoreo controlado (FPA-PC). 
Tabla 2.1. Peso, edad y aumento diario de peso de vaquillonas bajo pastoreo ad libitum (AD) y pastoreo controlado (PC).

\begin{tabular}{|c|c|c|c|c|c|c|c|c|c|}
\hline Tratamiento & $\mathbf{N}$ & $\begin{array}{c}\text { Edad } \\
\text { destete } \\
\text { (d) }\end{array}$ & $\begin{array}{l}\text { Peso destete } \\
\text { (kg) }\end{array}$ & $\begin{array}{l}\text { Edad inicio } \\
\text { (d) } * *\end{array}$ & $\begin{array}{l}\text { Peso inicio } \\
\text { (kg) })^{* *}\end{array}$ & $\begin{array}{c}\text { Edad a la } \\
\text { pubertad (d)* }\end{array}$ & $\begin{array}{c}\text { Peso a la } \\
\text { pubertad (kg)* }\end{array}$ & $\begin{array}{l}\text { Peso final } \\
(\mathbf{k g})^{* *}\end{array}$ & $\operatorname{ADP}(\mathrm{kg} / \mathrm{d})$ \\
\hline $\mathrm{AD}$ & 18 & $192 \pm 15$ & $167 \pm 23.7$ & $247 \pm 9$ & $169 \pm 21,6$ & $388 \pm 24$ & $255 \pm 21,8$ & $268 \pm 25,9$ & $0,589 \pm 0,116$ \\
\hline $\mathrm{PC}$ & 18 & $194 \pm 19$ & $162 \pm 25.2$ & $249 \pm 12$ & $165 \pm 20,1$ & $395 \pm 40$ & $258 \pm 29,4$ & $264 \pm 16,5$ & $0,588 \pm 0,089$ \\
\hline Total & 36 & $193 \pm 17$ & $164 \pm 24.2$ & $248 \pm 17$ & $167 \pm 20,7$ & $391 \pm 30$ & $256 \pm 23,8$ & $266 \pm 23,7$ & $0,589 \pm 0,102$ \\
\hline
\end{tabular}

Nota: Datos expresados como medias \pm DS. Los valores de peso y edad al inicio se utilizaron para chequear la correcta asignación de tratamientos *Valores obtenidos solo de los animales púberes: $\mathrm{N}(\mathrm{AD})=17, \mathrm{~N}(\mathrm{CG})=12$.

**Valores obtenidos al inicio y final del tratamiento nutricional.

Tabla 2.2. Peso, edad y aumento diario de peso de vaquillonas púberes $(\mathrm{P})$ y no púberes $(\mathrm{NP})$ bajo pastoreo ad libitum (AD) y pastoreo controlado (PC).

\begin{tabular}{|c|c|c|c|c|c|c|c|}
\hline Tratamiento & $\begin{array}{c}\text { Estado } \\
\text { puberal }\end{array}$ & $\mathbf{N}$ & Edad final (d)* & Peso final (kg)* & $\begin{array}{c}\text { ADP pre destete } \\
(\mathrm{kg} / \mathrm{d})\end{array}$ & $\begin{array}{c}\text { ADP destete-recria } \\
(\mathrm{kg} / \mathrm{d})\end{array}$ & ADP recria $(\mathrm{kg} / \mathrm{d})$ \\
\hline \multirow{2}{*}{$\mathrm{AD}$} & $\mathrm{P}$ & 17 & $414 \pm 15$ & $268 \pm 21,0$ & $0,725 \pm 0,090$ & $-0,035 \pm 0,327$ & $0,598 \pm 0,113$ \\
\hline & NP & 1 & $427 \pm 0$ & $259 \pm 0,0$ & $0,714 \pm 0,000$ & $0,054 \pm 0,000$ & $0,440 \pm 0,000$ \\
\hline \multirow{2}{*}{$\mathrm{PC}$} & $\mathrm{P}$ & 12 & $416 \pm 20$ & $272 \pm 23,9$ & $0,736 \pm 0,111$ & $-0,030 \pm 0,311$ & $0,623 \pm 0,073 \mathrm{~A}$ \\
\hline & NP & 6 & $419 \pm 21$ & $247 \pm 26,3$ & $0,620 \pm 0,117$ & $0,149 \pm 0,263$ & $0,520 \pm 0,083 \mathrm{~B}$ \\
\hline \multirow{2}{*}{ TOTAL } & $\mathrm{P}$ & 29 & $415 \pm 17$ & $270 \pm 21,9 a$ & $0,725 \pm 0,102 \mathrm{a}$ & $-0,014 \pm 0,344$ & $0,608 \pm 0,097 \mathrm{~A}$ \\
\hline & NP & 7 & $420 \pm 20$ & $248 \pm 24,5 b$ & $0,635 \pm 0,114 b$ & $0,136 \pm 0,243$ & $0,509 \pm 0,081 \mathrm{~B}$ \\
\hline
\end{tabular}

Datos presentados como media \pm DS. * Datos al final del ensayo (inicio del servicio)

Nota: Letras diferentes indican diferencias significativas (dentro de tratamiento). Letras mayúsculas, $\mathrm{P}<0,01$; Letras minúsculas, $\mathrm{P}<0,05$. 
El análisis longitudinal del peso mostró diferencias significativas $(\mathrm{p}<0,05)$ en los parámetros $\left(\alpha_{i}\right)$ de las curvas de crecimiento entre los tratamientos (Tabla 2.3, Figuras $2.2 ; 2.3)$. El APd, calculado como la primera derivada de la curva de crecimiento, mostró diferencias significativas $(\mathrm{p}<0,05)$ hasta los 289 días (Figura 2.2), siendo mayor para los animales en el tratamiento AD al inicio de la recría. Sin embargo, los contrastes lineales de pesos promedio estimados a cada edad no mostraron diferencias significativas entre tratamientos.

Tabla 2.3. Estimación de los parámetros de las curvas de crecimiento entre tratamientos y entre estados puberales.

\begin{tabular}{cccccc}
\hline \multirow{2}{*}{ Efecto } & \multicolumn{2}{c}{ Tratamiento } & & \multicolumn{2}{c}{ Estado Puberal } \\
& AD & PC & & P & NP \\
\hline \multirow{2}{*}{$\alpha_{0}$} & $-74,68^{\mathrm{a}}$ & $-3,56^{\mathrm{b}}$ & AG & $-40,41$ & $-4,98$ \\
& & & CG & $-42,66$ & $-7,24$ \\
\hline$\alpha_{1}$ & $1,155^{\mathrm{A}}$ & $0,696^{\mathrm{B}}$ & & $0,946^{\mathrm{A}}$ & $0,711^{\mathrm{B}}$ \\
\hline$\alpha_{2}$ & $-0,00081^{\mathrm{A}}$ & $-0,00014^{\mathrm{B}}$ & & $-0,00048^{\mathrm{a}}$ & $-0,00025^{\mathrm{b}}$ \\
\hline
\end{tabular}

Nota: Letras diferentes indican diferencias significativas (dentro de análisis y efecto).

Letras mayúsculas, $\mathrm{P}<0,01$; Letras minúsculas, $\mathrm{P}<0,05$.

Cuando se analizan las curvas de peso de los animales púberes y no púberes al final del tratamiento de recría se observan diferencias significativas en los parámetros lineales y cuadráticos $(\mathrm{p}<0,05)$ (Tabla 2.3, figura 2.3). El APd fue también significativamente diferente $(\mathrm{p}<0,05)$ desde los 257 días de edad, siendo mayor en las vaquillonas que alcanzaron la pubertad en ambos tratamientos durante el periodo de estudio (figura 2.3). 
Figura 2.2: Fracción acumulada de vaquillonas púberes (FPA), peso estimado (PE) por el modelo y aumento de peso derivado (APd) para cada tratamiento durante el ensayo.

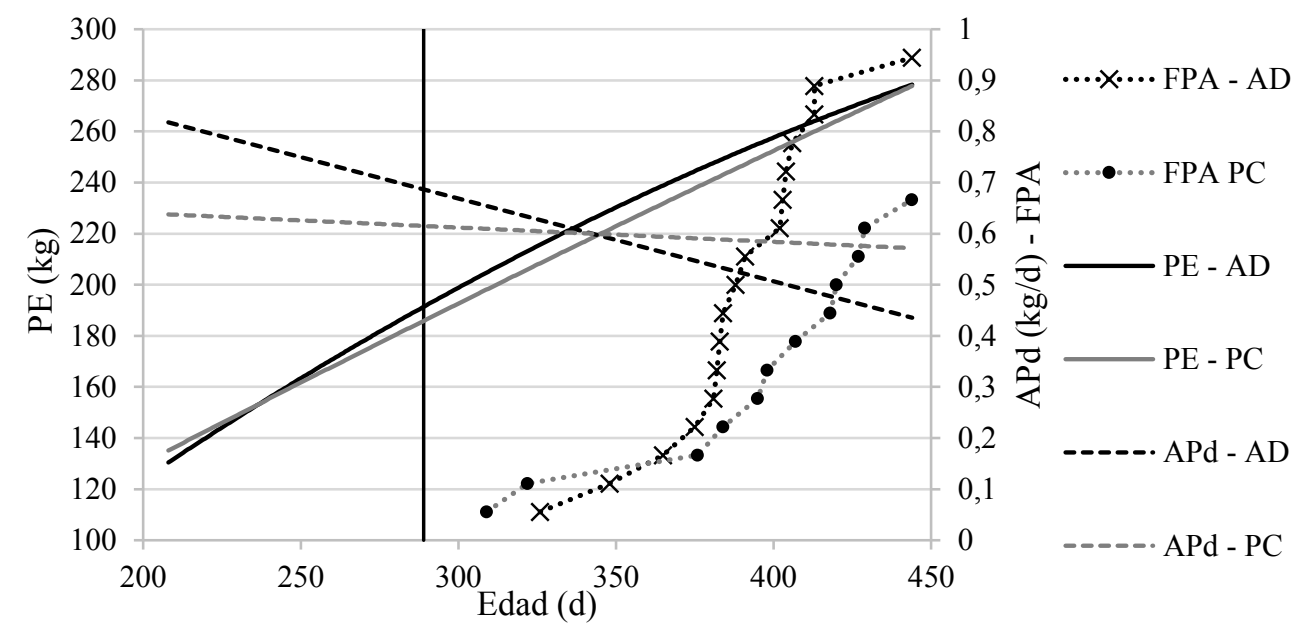

Nota: El APd fue calculado como la primera derivada de la curva de peso.

Referencias: FPA en tratamiento de pastoreo ad-libitum (FPA-AD); FPA en tratamiento de pastoreo controlado (FPA-PC); PE en tratamiento de pastoreo ad libitum (PE-AD); PE tratamiento de pastoreo controlado (EW-PC); APd en tratamiento de pastoreo ad libitum (APd-AD); APd en tratamiento de pastoreo controlado (APd-PC). La línea vertical a los 289 días representa el limite hasta donde se observaron diferencias en el APd promedio.

Figura 2.3: Peso medio estimado por el modelo (PE) y aumento de peso derivado (APd) en vaquillonas púberes $(\mathrm{P})$ y no púberes $(\mathrm{NP})$.

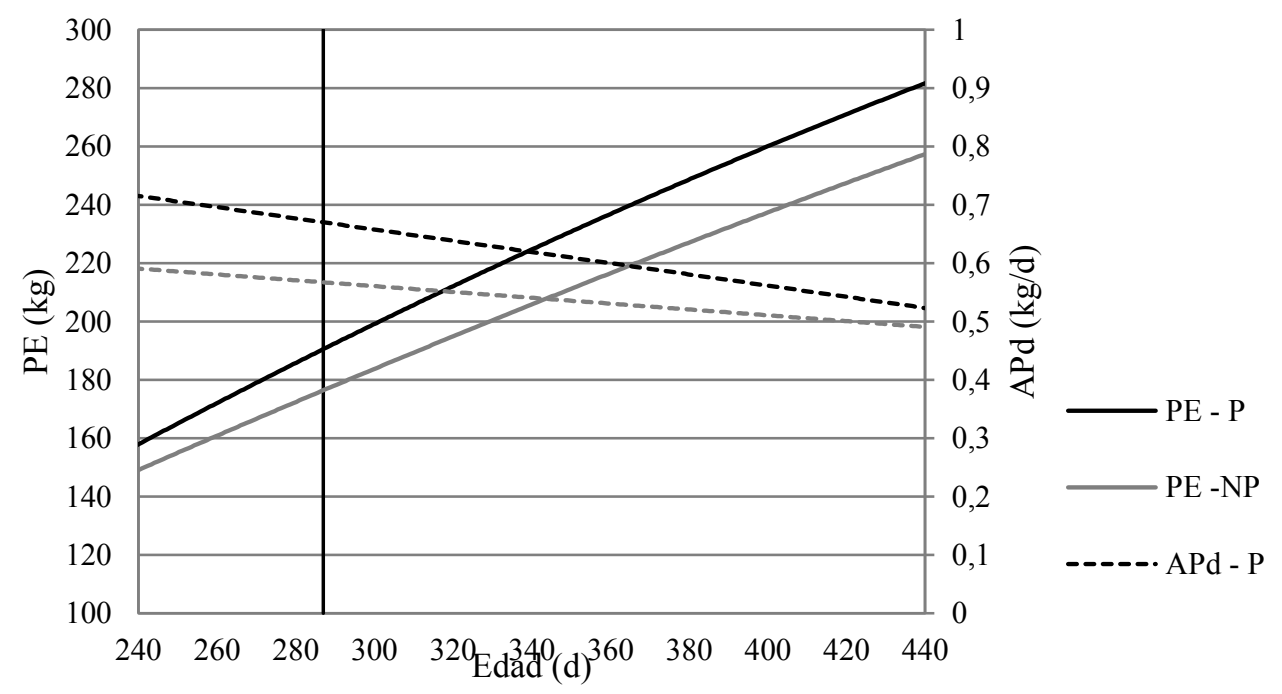

Nota: El APd fue calculado como la primera derivada de la curva de peso

Referencias: $\mathrm{PE}$ en vaquillonas púberes (PE -P); PE en vaquillonas no púberes (PE - NP); APd vaquillonas no púberes (APd - NP); APd en vaquillonas no púberes (APd - NP). La línea solida vertical a los 287 días representa el limite hasta donde se observaron diferencias en el APd. 
Además, el ADP desde el nacimiento al destete y durante la recría en los animales que alcanzaron la pubertad fue mayor independientemente del tratamiento (Tabla 2.2). El ADP pre y postdestete se muestran la figura 2.4, allí se observa que todos los animales tienen un ADP mayor a $0,4 \mathrm{~kg} / \mathrm{d}$ durante todo el periodo desde el nacimiento hasta el servicio. En ambos tratamientos, los animales que tuvieron un ADP predestete superior a $0,75 \mathrm{~kg} / \mathrm{d}$ o superior a $0,65 \mathrm{~kg} / \mathrm{d}$ durante la recría, alcanzaron la pubertad antes del servicio.

Figura 2.4. Aumento diario de peso (ADP) predestete y durante la recría en vaquillonas púberes $(\mathrm{P})$ y no púberes $(\mathrm{NP})$ para cada tratamiento.

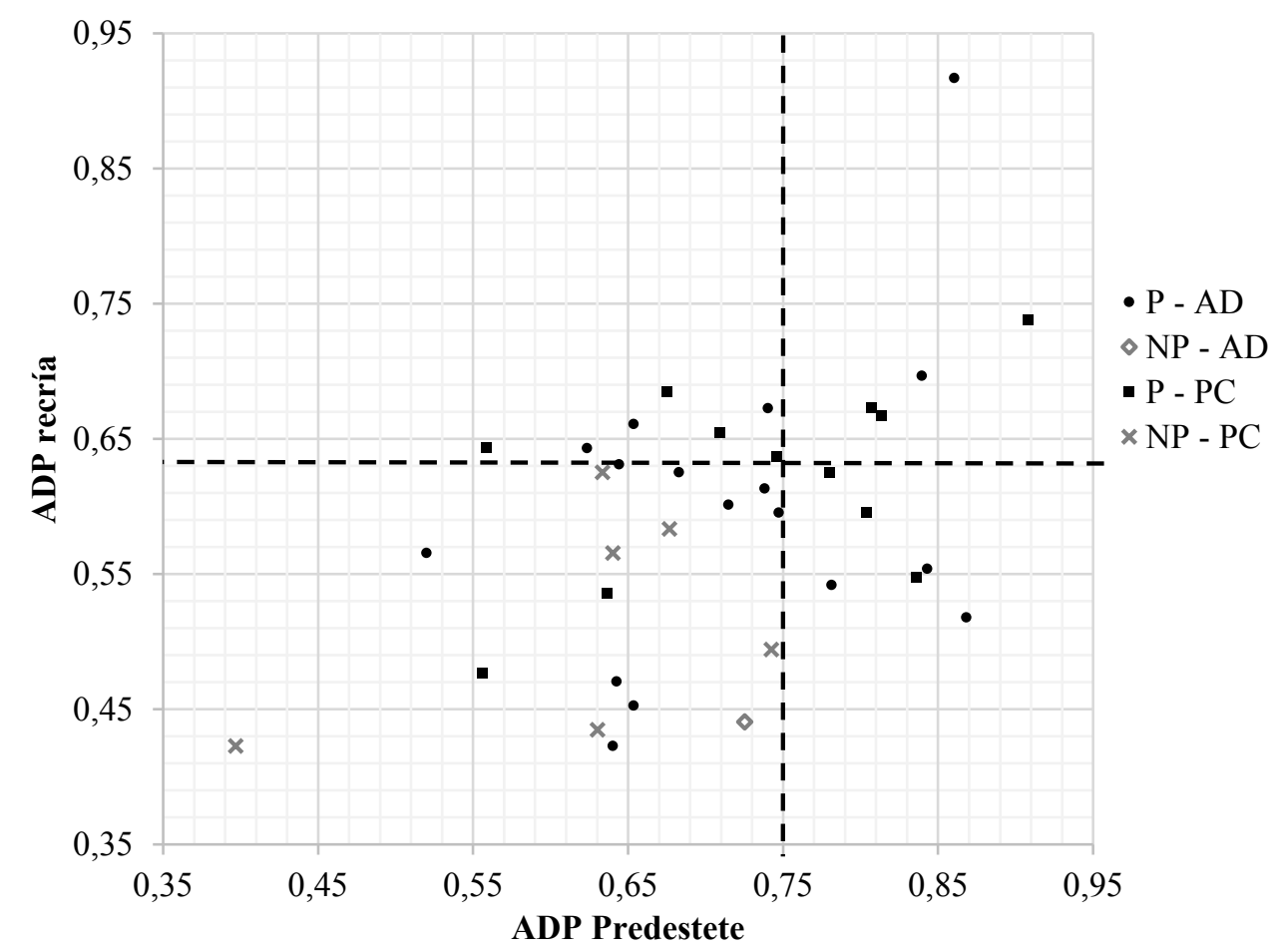

Referencias: Vaquillonas púberes en tratamiento de pastoreo ad libitum (P-AD); Vaquillonas no púberes em tratamiento de pastoreo ad libitum (NP-AD); Vaquillonas púberes en tratamiento de pastoreo controlad (P-PC); Vaquillonas no púberes en tratamiento de pastoreo controlado (NP -PC). 
Las mediciones de engrasamiento en la cadera no mostraron diferencias entre los tratamientos, de la misma manera tampoco se encontraron diferencias entre la curva de engrasamiento de vaquillonas púberes y no púberes.

\subsection{DISCUSIÓN}

Los resultados demostraron diferencias en los parámetros las curvas de crecimiento entre los tratamientos y en el APd hasta los 289 días de edad. Aunque los ADPs evaluado desde el inicio al final de la recría fueron similares para ambos tratamientos y el peso promedio estimado no mostró diferencias a ninguna edad, la forma de la curva fue diferente. Estas diferencias no pudieron ser demostradas por estudios transversales, evidenciando las ventajas de los análisis longitudinales, que al utilizar toda la información disponible, permiten excluir variación entre los individuos del término del error, aumentando así los grados de libertad de los test de hipótesis (Hedeker y Gibbons, 2006; Rogberg-Muñoz y col., 2013), y como consecuencia aumenta la potencia del análisis.

Las diferencias en la curva de peso entre los tratamientos AD y PC podrían ser la consecuencia de las diferencias observadas en el BE entre tratamientos (figura 2.1), particularmente al BE negativo o neutral en los animales del tratamiento PC. Esto podría estar relacionado con las diferencias en la curva de pubertad acumulada. Además, analizando conjuntamente APd, BE y FPA (figura 2.1), existió un BE negativo en el tratamiento PC en simultáneo con el arribo a la pubertad de las primeras vaquillonas, y esto podría haber sido una causa del retraso en la ciclicidad de este grupo. 
Existen evidencias que sugieren una interacción entre las reservas energéticas y el arribo a la pubertad (Day y Anderson, 1998; Chelikani y col., 2003; Ojeda y col., 2006; Lomniczi y col., 2013b); incluso la base fisiológica de este proceso ha sido estudiada en bovinos (Johnston y col., 2009; Atkins y col., 2013; Amstalden y col., 2014; Estill, 2014) y algunos autores proponen un peso umbral para alcanzar el estado metabólico puberal (Short y Bellows, 1971; Patterson y col., 1992; Gasser y col., 2006a; Gasser y col., 2006d; Hall, 2013), los resultados del presente trabajo sugieren que no solo el peso final, sino también el patrón de crecimiento puede influenciar el arribo a la pubertad.

Los estudios animales en pastoreo tienen la dificultad adicional de la variabilidad en la calidad del forraje y el comportamiento ingestivo de los animales, las diferencias observadas entre tratamientos en este trabajo pueden ser atribuidas al consumo de forraje, asumiendo la homogeneidad entre las parcelas. En el caso del tratamiento $\mathrm{AD}$, donde la oferta de forraje excedió los requerimientos de los animales, la energía consumida por los mismos fue determinada por el recurso (volumen de forraje, calidad y distribución espacial) y las características de los animales (selección y comportamiento ingestivo), tal como fue reportado por Chilibroste (1998) y Decruyenaere y col. (2009). Para el caso del tratamiento PC, el tamaño del área bajo pastoreo adiciona otra fuente de restricción, y probablemente sea esta la mayor limitación al consumo de energía. A pesar de esto, todos los animales tuvieron ADPs por encima de los $0,4 \mathrm{~kg} / \mathrm{d}$ durante los periodos predestete y de ensayo, lo que a priori podría considerarse una performance adecuada. 
El crecimiento durante el período comprendido entre el destete y el inicio del período de recría fue menor, esta situación es típica en los campos de cría de la región debida al efecto del destete y a la pérdida de calidad de los pastos en la transición a los recursos de invierno. De todas maneras, un ADP mayor a $0,4 \mathrm{~kg} / \mathrm{d}$ desde el nacimiento al primer servicio (a los 15 meses), ya sea con un ADP predestete mayor a $0,75 \mathrm{~kg} / \mathrm{d}$ o un ADP postdesetete mayor a $0,63 \mathrm{~kg} / \mathrm{d}$ resultó suficiente para alcanzar la pubertad antes del primer servicio.

Los resultados muestran diferencias significativas en el ADP entre las vaquillonas púberes y no púberes al momento del servicio, lo que ya ha sido reportado (Arije y Wiltbank, 1971; Gasser y col., 2006a). Roberts y col. (2009) determinaron que el ADP durante los primeros 8 meses de vida tiene mayor influencia en el arribo a la pubertad, y sugirieron que una reducción en el postdestete inmediato (durante un periodo de 60 días), podría resultar en al menos un $40 \%$ de reducción en el número de vaquillonas púberes al inicio del servicio.

Ha sido propuesto que el efecto del ADP sobre la pubertad podría estar relacionado con una secreción temprana de gonadotrofinas, que determinaría el momento de la pubertad (Schams y col., 1981; Adams y col., 1994; Evans y col., 1994b). Por otro lado, un mayor ADP post destete, puede reducir el efecto condicionante negativo en la edad a la pubertad de un bajo ADP predestete (Hall y col., 1993; Gasser y col., 2006a; Roberts y col., 2009).

En los sistemas ganaderos, la energía requerida para tener la mayor cantidad de vaquillonas ciclando al servicio podría ser obtenida asignando una adecuada superficie de pastoreo, o bien con suplementación estratégica (Caton and Dhuyvetter, 1997). Por otro lado, alcanzar el momento del servicio con todas las 
vaquillonas ciclando podría acortar a unos 60 días la estación de monta, lo que permitiría ajustar mejor los requerimientos del binomio vaca ternero a la producción de forrajes.

Las vaquillonas evaluadas alcanzaron la pubertad a los 391 días y a un peso promedio de $256 \mathrm{~kg}$, lo que representa un $59,53 \%$ del peso de los vientres adultos para este rodeo (430 kg). Morris y col., (2000) y Morris y Wilson (1997) reportan resultados similares en un programa de selección por pubertad y características relacionadas en sistemas pastoriles en un rodeo Angus.

En vaquillonas de una raza compuesta ( $1 \frac{2}{2}$ Angus, 1/4 Charolais, $1 / 4$ Tarentaise), $60 \%$ del peso adulto debe ser superado para alcanzar la pubertad, a pesar de que el peso y la edad a la pubertad eran diferentes a las reportadas por este trabajo (Roberts y col., 2009). Ha sido propuesto que el peso objetivo para alcanzar la pubertad es del $55-65 \%$ del peso adulto (Patterson y col., 1992), mientras que las diferencias observadas en la edad y peso a la pubertad podrían ser consecuencias de la variabilidad existente entre los rodeos. En este sentido, diversos resultados han sido reportados en la bibliografía que podrían ser explicados por diferencias en la raza o el biotipo utilizados en el experimento (Short y Bellows, 1971; Ferrell, 1982; Patterson y col., 1992; Honaramooz y col., 2004; Gasser y col., 2006a; Roberts y col., 2009).

Funston y Deutscher (2004) sugieren que solo hay que alcanzar el $50 \%$ del peso adulto al inicio de la temporada de servicios en recrías en sistemas de feed-lot para que la operación se justifique económicamente. Solo una vaquillona estaba ciclando a esa proporción del peso adulto $(215 \mathrm{~kg})$, representando el $6 \%$ del total, en las condiciones del presente trabajo. Consecuentemente, esta fracción de peso 
objetivo podría no ser adecuada en sistemas pastoriles, donde el recurso alimenticio es más barato y podría traer aparejado el riesgo de reducir la cantidad de vaquillonas disponibles para entorar, o bien aumentar los partos de vaquillonas en cola de parición, disminuyendo los pesos al destete y acortando el intervalo parto inicio de servicio en los vientres de primer parto (Byerley y col., 1987; Perry y col., 1991). Considerando lo anterior, los resultados de este trabajo sugieren que en un sistema de recrías para servicio a 15 meses en pastoreo debe garantizarse una ganancia mínima de $0,4 \mathrm{~kg} / \mathrm{d}$, y los pesos umbrales para lograr el 50\% y $90 \%$ de las vaquillonas ciclando es del 60\% (260 kg) y 64\% (275 kg) del peso adulto antes del servicio, respectivamente.

No se encontraron en este trabajo engrasamientos diferenciales entre tratamientos, ni tampoco entre animales púberes y no púberes. Es probable que la poca diferencia observada en las tasas de crecimiento explique esa situación, donde otros autores reportan que las diferencias en el crecimiento generan una diferencia en el engrasamiento (Hopper y col., 1993; Johnston y col., 2009).

Finalmente, en los últimos años la pubertad temprana ha sido involuntariamente seleccionada en sistemas con entore a 15 meses (Funston y col., 2012a; Funston y col., 2012b). En estos sistemas, las vaquillonas que no conciben al primer servicio son engordadas o vendidas preñadas pasado el próximo servicio, consecuentemente, esos animales menos precoces son retenidos en rodeos comerciales menos intensivos. Gregory y col., (1979) y Roberts y col., (2009) observaron que alrededor del 35\% de las vaquillonas no logran alcanzar la pubertad al momento del servicio. En este trabajo el porcentaje total fue de $20 \%$ (6\% y 33\% 
para AD y PC, respectivamente), sugiriendo que la edad a la pubertad puede ser reducida mejorando las recrías y/o seleccionando animales más precoces.

\subsection{CONCLUSIONES}

Este trabajo demuestra la robustez de los modelos longitudinales de análisis de datos, para aprovechar toda la información contenida en los registros, mostrando diferencias cuando los análisis transversales se ven limitados por un bajo número de muestras. Además, ADP durante la recría de $0,5 \mathrm{~kg} / \mathrm{d}$ pueden impactar en el crecimiento y desarrollo de las vaquillonas reduciendo el número de vaquillonas púberes al inicio del servicio a los 15 meses. Bajo condiciones pastoriles, un 60 a $65 \%$ del peso adulto debe ser alcanzado para lograr un 50 a $90 \%$ de vaquillonas ciclando al momento del servicio. Por último, es necesario controlar la ganancia de peso durante toda la vida de la vaquillona, asegurando ganancias de peso adecuadas durante todo el proceso de cría al pie de la madre y recría. 


\section{CAPITULO III}

\section{RIESGO DE PUBERTAD ASOCIADO A LA PRESENCIA DE POLIMORFISMOS EN GENES CANDIDATOS. UN ENFOQUE UTILIZANDO MODELOS DE SUPERVIVENCIA.}

\subsection{INTRODUCCIÓN}

El arribo a la pubertad es un fenómeno de suma importancia en la vida de una vaquillona en términos de productividad (Arije y Wiltbank, 1971), ya que la pubertad a edades tempranas permitirá adelantar el inicio de esa futura vaca en la actividad productiva, logrando así un primer parto a los dos años de edad y en el inicio de la estación de parición. De esta manera se aumenta el intervalo parto servicio de las vacas de primer parto y se reducen las categorías improductivas dentro del rodeo (Lesmeister y col., 1973; Carillo, 1994).

La pubertad es la culminación de una serie de eventos fisiológicos altamente coordinados que va sufriendo una hembra hasta alcanzar su primera ovulación, seguida de una función lútea de duración normal (Moran y col., 1989), para luego comenzar a ciclar regularmente. Este proceso se inicia en la vida uterina, pero uno de los eventos determinantes en el inicio de la pubertad es el pico de LH que se da alrededor de los 3 meses de edad, se asocia con un desarrollo folicular temprano y podría regular el momento de la pubertad (Schams y col., 1981; Estill, 2014). El segundo evento endocrino que determina la pubertad es una desrepresión central del feedback negativo ejercido por el 17- $\beta$-estradiol producido por los folículos sobre la GnRH, cuando esto ocurre la vaquillona comienza a ciclar normalmente en unas pocas semanas (Day y Anderson, 1998). 
La hormona GnRH y su receptor (GnRHR) juegan un rol fundamental al momento de la pubertad. Esta hormona induce la liberación de FSH y LH, que ejercen un papel principal en el desarrollo maduración y ovulación de los folículos. Han sido reportados polimorfismos en el receptor de GnRH asociados a la edad a la pubertad en humanos y ratones, como también la presencia de estos polimorfismos en poblaciones bovinas (Lirón y col., 2011; Lirón y col., 2012).

El factor de crecimiento similar a insulina tipo 1 (IGF-1) es secretado por la mayoría de los tejidos, pero principalmente por el hígado en respuesta a la secreción de la hormona de crecimiento $(\mathrm{GH})$, y es uno de los principales efectores de la misma, siendo su concentración plasmática más estable en el tiempo que la GH. Su actividad principal es estimular la proliferación celular y el crecimiento. Está comprobado el efecto de IGF-1 en el crecimiento y la reproducción (Daftary y Gore, 2005), a través de su efecto en el ovario, actuando tanto de manera endocrina, como así también paracrina y autocrina (Schams y col., 1981). Además, participa en la remodelación de las células de la neuroglia inducida por el estradiol en el periodo prepuberal (Ojeda y col., 2006). Por otro lado, IGF-1 es una importante aferencia reguladora de la secreción de GnRH en el hipotálamo, siendo propuesta como uno de los nexos entre la nutrición y la actividad reproductiva (Zulu y col., 2002).

El efecto de IGF1 sobre el crecimiento es controversial. Existen reportes de correlaciones positivas entre el crecimiento y los niveles plasmáticos de la hormona (Bishop, 1990; Yelich y col., 1996), y algunos reportes de correlaciones negativas, tal es el caso de Yilmaz (2003) en un rodeo seleccionado de manera divergente por niveles plasmáticos de IGF1. Existen reportes de la asociación de un SNP, situado en la región promotora del gen de IGF1, IGF1-SnaBI, en poblaciones Angus con el 
crecimiento y la precocidad sexual en machos (Lirón y col., 2012; Rogberg-Muñoz y col., 2013). Además, se ha asociado este SNP con la expresión diferencial del gen IGF1, como así también, con los niveles de hormona circulante (Maj y col., 2008).

La mayoría de los caracteres productivos tienen una herencia cuantitativa y poligénica, si bien se supone la existencia de genes con efectos importantes en la variabilidad de la característica. Al identificar estos y su asociación con determinado fenotipo se obtiene un QTL. La utilización de polimorfismos en QTLs en sistemas comerciales puede basarse en: el uso de loci que codifican para una mutación funcional, el uso del desequilibrio de ligamiento (linkage desequilibrium, LD) con una mutación funcional y el uso de marcadores ligados a una mutación funcional (linkage equilibrium, LE) (Dekkers, 2004). El LD ha sido la estrategia más utilizada para la identificación de genes candidatos (Rothschild and Soller, 1997). En caracteres cuantitativos, el uso de los marcadores moleculares en estos sistemas tiene mayor aplicación en caracteres difíciles de medir, o en aquellos que son muy onerosos o solo pueden medirse tardíamente en la vida del animal.

La selección asistida por marcadores (SAM o MAS por su sigla en inglés) puede lograr progresos genéticos de hasta un 15 al 30\% (Kashi y col., 1990). Sin embargo, en caracteres productivos y reproductivos esta técnica no logró extenderse, principalmente debido a que hay miles de genes implicados en estas variables y generalmente el efecto de genes aislados suele ser demasiado pequeño. Además, han sido reportados problemas de perdida de $\mathrm{h}^{2}$ por el aumento de los alelos favorables en la población por efecto de la selección, pudiendo afectar su incorporación en los programas de selección (Meuwissen y col., 2016). Esto sumado a las nuevas técnicas de incorporación de datos genómicos en los 
programas de mejoramiento genético, han ido dejando a la MAS en un segundo plano, si bien los costos de genotipificación son altos para los paneles de alta o mediana densidad propuestos para la selección genómica, y los paneles de baja densidad aun presentan algunos problemas para su imputación (Dassonneville y col., 2011). En este sentido la identificación de los genes implicados en características de interés productivo permite el diseño de paneles de baja densidad, con un costo considerablemente inferior (Habier y col., 2009), permitiendo, además en caso de utilizar SNPs incluidos en los paneles de alta densidad, combinar la información de ambos métodos de genotipificación, permitiendo una masificación del acceso en su uso en programas de mejora.

La variable precocidad sexual ha sido evaluada de distintas maneras según los autores. En líneas generales la forma más común de medirla en las hembras en condiciones experimentales es la edad al primer CL o bien la superación de umbral de 1 ng/ml de P4 sérica (Wehrman y col., 1996; Honaramooz y col., 2004). El problema de la evaluación de la precocidad sexual a través de la edad a la pubertad reside en que la pubertad es una variable dicotómica y que su determinación generalmente se hace en mediciones separadas por intervalos de tiempo. Por otra parte, en condiciones productivas los muestreos suelen tener una fecha de inicio y una de finalización, por lo que se originan dos tipos de censuras de información, tanto dentro del intervalo medido por un lado, como también en alguna o ambas colas por otro. De modo que las aproximaciones por modelos longitudinales presentan algunos problemas para trabajar este tipo de variables.

Una de las formas para manejar estos problemas es el trabajar con regresiones logísticas con variables dependientes dicotómicas, pero el efecto del tiempo no 
estaría siendo considerado y modelando el tiempo hasta el evento (con un modelo lineal) se perdería la información contenida en los registros de los animales que no sufren el evento y si descartamos estos animales corremos el riesgo de subestimar o sobreestimar algunos efectos. Los modelos de supervivencia en cambio permiten modelar variables en el tiempo. Además de la incorporación de covariables tiempo dependientes y trabajar con todos los datos, incluyendo aquellos que tienen observaciones censuradas, y permitiendo explorar la información que se pierde en la censura de los individuos que no sufren el evento (Allison, 2010).

El objetivo del presente trabajo fue evaluar la presencia de polimorfismos de los SNPs IGF1-SnaBI del gen IGF1 y SNP6 del gen GnRHR, y su efecto en el riesgo de pubertad y en el crecimiento en vaquillonas Angus manejadas en sistemas pastoriles de la provincia de Buenos Aires. Evaluando además el uso modelos de supervivencia en la asociación de variables productivas con genes candidatos.

\subsection{MATERIALES Y MÉTODOS}

\subsubsection{Material animal.}

Para la realización del presente trabajo se utilizaron 226 hembras Angus nacidas entre junio y octubre del año 2012, pertenecientes a dos rodeos: 1. El Campo Experimental "El Amanecer" perteneciente a la Universidad Nacional de La Plata (R1), ubicado en el partido de Magdalena, Buenos Aires, Argentina (35 $\left.15^{\prime} \mathrm{S}-57^{\circ} 38^{\prime} \mathrm{O}\right)$, y 2 . El establecimiento “Don Alejandro" perteneciente a la firma TAESA (R2), ubicado en el partido de Junín, Buenos Aires, Argentina (34 31' S $\left.-61^{\circ} 14^{\prime} \mathrm{O}\right)$ 
En el R1, los animales se destetaron en marzo de 2013, y se realizó la recría sobre promoción de especies invernales desde abril de 2013, hasta octubre del mismo año, momento en que se inició el servicio. Hasta el momento de ingreso a la promoción los animales pastorearon pasturas base festuca y agropiro.

En el R2, los animales se destetaron en el mes de abril para ingresar a potreros de pasturas perennes base gramínea alternando con verdeos de invierno (principalmente Avena sativa) con suplementación con grano de maíz al $0.5-1 \%$ del pv. desde el mes de julio hasta mediados de septiembre. En ambos rodeos luego del último muestro las vaquillonas fueron incorporadas a un programa de sincronización de celos para IATF.

Al inicio del estudio, las vaquillonas tenían un promedio de $254 \pm 37$ días de edad $(248 \pm 17$ en $\mathrm{R} 1$ y $267 \pm 25$ en $\mathrm{R} 2)$ y $187 \pm 28 \mathrm{~kg}$ de peso $(167 \pm 21$ en $\mathrm{R} 1 \mathrm{y}$ $192 \pm 27$ en R2). De cada individuo se registró la fecha y el peso al nacimiento, y sus padres.

Todos los procedimientos realizados sobre los animales fueron revisados y aprobados por el Comité Institucional para el Cuidado y Uso de Animales de Laboratorio (CICUAL), de la Facultad de Ciencias Veterinarias de la Universidad Nacional de La Plata (Res n $74-4-18 T)$.

\subsubsection{Datos fenotípicos sobre los animales.}

Las mediciones sobre los animales fueron realizadas en R1 desde el 25 de abril al 10 de octubre de 2013 cada $14 \pm 1$ días, mientras que en $\mathrm{R} 2$ se midieron las hembras cada $28 \pm 3$ días desde el 7 de mayo hasta el 12 de septiembre del 2013. 
En cada medición se registró el peso de las hembras con 12 hs de desbaste, mediante el uso de balanza electrónica en R1 (Vesta 3513, Rosario, Santa Fe, Argentina) y balanza mecánica tipo báscula en R2. Además, se determinó la actividad ovárica mediante ecografía con un transductor lineal de $7.5 \mathrm{MHz}$ conectado a un ecógrafo modo B (Aquila vet., Esaote SpA, Génova, Italia). Se consideró que la vaquillona había alcanzado la pubertad al momento de identificar un cuerpo lúteo por primera vez (Honaramooz y col., 2004; Johnston y col., 2009). Se totalizaron un total de 13 mediciones en R1 y 5 mediciones en R2.

\subsubsection{Obtención, procesamiento de muestras, determinación de genotipos.}

De cada animal se obtuvo una muestra de $5 \mathrm{ml}$ de sangre periférica por punción de los vasos coccígeos. Las muestras fueron almacenadas en tubos con EDTA al $0,5 \%$ y conservadas a $-20^{\circ} \mathrm{C}$ hasta el momento de su procesamiento. De cada muestra de sangre se extrajo una alícuota para obtención de ADN total de la serie blanca mediante la técnica de extracción orgánica con cloroformo (Anexo 2). El ADN se resuspendió en EPES y almacenó a $-20^{\circ} \mathrm{C}$ hasta el momento de su utilización. La cuantificación del ADN obtenido se realizó mediante un espectrofotómetro NanoVue ${ }^{\circledR}$ Plus (GE Healthcare, USA).

Se seleccionaron dos SNPs para su genotipificación: el IGF1-SnaBI (rs13452733) localizado en la región promotora del gen IGF1 en el sitio de unión del factor de transcripción NF1, y GnRHR-SNP6 (rs110651901) localizado en el exón 2 del gen del receptor de la hormona GnRH (Liron y col., 2010). 
Los segmentos se amplificaron por la técnica de PCR (Anexo 3), utilizando los primers reportados por Liron y col. (2012) (Tabla 3.1; Anexo 4). Los primers forward presentaban una molécula de biotina en su extremo 5'. Los productos de amplificación se verificaron en geles de poliacrilamida al 6\% en solución buffer $1 \mathrm{X}$ TBE (0,089 M Tris; 0,089 M Ácido Bórico; 0,002 M EDTA). En cada pocillo se sembró $2 \mu 1$ de amplificado y $1 \mu 1$ de colorante ( $4 \mathrm{~g} \%$ de sacarosa, $0,025 \mathrm{~g} \%$ de azul de bromofenol) y se corrieron a $170 \mathrm{v}$. durante 30 minutos. El ADN en los geles se tiñó con bromuro de etidio $1 \mu \mathrm{g} / \mathrm{ml}$ durante 15 minutos, y las bandas de ADN se visualizaron en un transiluminador con luz UV a $310 \mathrm{~nm}$ para corroborar la presencia de los productos de amplificación.

Tabla 3.1 Listado de los polimorfismos evaluados y su ubicación en el genoma bovino

\begin{tabular}{|c|c|c|c|c|c|}
\hline SNP & Gen & Cromosoma & $\begin{array}{c}\text { Posición } \\
\text { nucleotídica - } \\
\text { Polimorfismo - } \\
\text { Sitio amino } \\
\text { acídico }\end{array}$ & $\begin{array}{l}\text { Región } \\
\text { Génica }\end{array}$ & $\begin{array}{c}\text { Tipo de } \\
\text { mutación }\end{array}$ \\
\hline $\begin{array}{l}\text { GnRHR- } \\
\text { SNP6 }\end{array}$ & GnRHR & BTA 6 & $\begin{array}{c}\text { NW_001495209,1: } \\
\text { g.884033-T>C - } \\
\text { aa137 }\end{array}$ & Exon 2 & Silente \\
\hline $\begin{array}{l}\text { IGF1- } \\
\text { SnaBI }\end{array}$ & IGF1 & BTA 5 & $\begin{array}{c}\mathrm{AF} 017143,1: \mathrm{g} 512- \\
\mathrm{T}>\mathrm{C}\end{array}$ & Promotor & -- \\
\hline
\end{tabular}

Los productos de amplificación se tipificaron mediante la técnica de pirosecuenciación (Anexo 5). Para ello la cadena biotinilada se purificó mediante el uso de perlas de sefarosa unidas a estreptavidina en una estación de lavado (Workstation, Biotage, AB, Uppsala, Suecia). Las cadenas fueron amplificadas 
usando cebadores internos, próximos al SNP en un pirosecuenciador PCQ96MA (Biotage, USA). Los resultados se analizaron utilizando el software Pyrosequencing (Biotage, USA) (Anexo 4).

\subsubsection{Análisis estadísticos.}

Se analizaron las frecuencias alélicas y genotípicas de los dos SNPs y se determinó si los polimorfismos se encontraban en equilibrio de Hardy-Weinberg, para ello se utilizó el paquete HardyWeinberg de R (R core team, 2008).

Para el análisis de asociación entre el riesgo de pubertad y el genotipo para IGF1-SnaBI se ajustó en primer lugar un análisis de Kaplan-Meier, estimando una función de supervivencia $\hat{S}(t)$ de la función real de supervivencia $S(t)$. Esta última es la probabilidad de que una vaquillona alcance la pubertad después de un tiempo $t$. Para estimar esta función se ajustó el siguiente modelo:

$$
\hat{S}(t)=\prod_{J: t_{j} \leq t}\left(1-\frac{d_{j}}{n_{j}}\right) \quad \text { para } t_{1} \leq t \leq t_{k}
$$

mediante el procedimiento LIFETEST de SAS 9.4, donde a cada tiempo $t_{j}$ hay $n_{j}$ vaquillonas no púberes (en riesgo de alcanzar la pubertad) y $d_{j}$ alcanzan la pubertad en ese momento.

La comparación entre las funciones de supervivencia de los distintos genotipos se realizó mediante un análisis de chi cuadrado de los estadísticos logrank y wilcoxon.

El estadístico log-rank para el i-ésimo grupo puede escribirse como: 


$$
\log -\operatorname{rank}=\sum_{j=1}^{r}\left(d_{i j}-e_{i j}\right)
$$

Donde $d_{i j}$ son el número de eventos en el i-ésimo grupo al tiempo $j$ y $e_{i j}$ es el número esperado de eventos en el $i$-ésimo grupo al tiempo $j$, definido como:

$$
e_{i j}=\frac{n_{i j} d_{j}}{n_{j}}
$$

donde $n_{j}$ es el total de casos en riesgo justo antes del tiempo $j, n_{i j}$ es el numero de individuos en riesgo para el $i$-ésimo grupo antes del tiempo $j$ y $d_{j}$ es el número de eventos al tiempo $j$.

Por su parte el estadístico de wilcoxon se calcula como:

$$
\text { wilcoxon }=\sum_{j=1}^{r} n_{j}\left(d_{i j}-e_{i j}\right)
$$

Posteriormente, se ajustó un modelo de riesgos proporcionales de COX con el procedimiento PHREG en SAS 9.4 agregando el peso como variable explicatoria tiempo dependiente, evaluando además la estratificación por rodeos, bajo el siguiente modelo:

$$
h_{i j}(t)=h_{i 0}(t) e^{\beta_{1} X_{i j}+\beta_{2} X_{i j}(t)}
$$

Donde $h_{i j}(t)$ es la función de riesgo del j-ésimo individuo en el i-ésimo rodeo al tiempo t; $h_{i 0}(t)$ es la función de riesgo basal para el i-ésimo rodeo al tiempo t; $\beta_{1}$ es el vector de parámetros regresores correspondientes al genotipo; $\boldsymbol{X}_{i j}$ es el vector de genotipos para el j-ésimo individuo en el i-ésimo rodeo y el segundo término del exponente corresponde al efecto del peso en el tiempo t. 
Conjuntamente se realizó un análisis de sensibilidad de modo de evaluar si la censura producida a la derecha era informativa a la variable, para esto se realizaron dos análisis ajustando el mismo modelo de riesgos proporcionales de COX, en el primero (SA1) de estos se computó la edad a la pubertad para las vaquillonas que no habían alcanzado la pubertad durante los sucesivos muestreos, como la edad al momento de la última medición sobre la vaquillona, en el segundo análisis (SA2) se asumió que estos mismos animales habían alcanzado la pubertad un día más tarde que la vaquillona más tardía diagnosticada como púber.

Se evaluó para todos los modelos ajustados la correlación entre los residuos de Schoenfeld y el tiempo, para chequear la proporcionalidad del riesgo entre los genotipos a lo largo del tiempo, como supuesto del modelo de análisis.

Se evaluaron además las curvas de crecimiento para los distintos genotipos en ambos establecimientos, bajo el mismo modelo de análisis utilizado en el capítulo 2 de este trabajo, con el procedimiento MIXED en SAS 9.4.

\subsection{RESULTADOS}

Las frecuencias genotípicas se encontraban en equilibrio de Hardy Weinberg, pero se observó para el genotipo CC del marcador GnRHR-SNP6 una frecuencia demasiado baja (Tabla 3.2), que fue más marcado en R2, establecimiento que aportó el mayor número de vaquillonas a los análisis. Debido a esto el genotipo CC del marcador GnRHR-SNP6 fue excluido de los análisis siguientes, conservando solo el genotipo CT y TT. 
Tabla 3.2. Frecuencias genotípicas para los SNPs IGF1-SnaBI y GnRHR- SNP6. Datos por establecimiento y totales.

\begin{tabular}{cccccccc}
\hline \multirow{2}{*}{ Genotipo } & \multicolumn{3}{c}{ IGF1-SnaBI } & & \multicolumn{3}{c}{ GnRHR-SNP6 } \\
\cline { 2 - 4 } \cline { 6 - 8 } & $\mathbf{R 1}$ & $\mathbf{R 2}$ & Total & & R1 & R2 & Total \\
\hline CC & 0,353 & 0,178 & 0,205 & & 0,114 & 0,033 & 0,046 \\
CT & 0,412 & 0,459 & 0,452 & & 0,200 & 0,298 & 0,283 \\
TT & 0,235 & 0,362 & 0,342 & & 0,686 & 0,663 & 0,671 \\
\hline
\end{tabular}

Nota: observar la baja frecuencia para el genotipo CC del marcador SNP6-GnRHR. Debido a esto no fue tenido en cuenta en los análisis siguientes

La censura observada para el genotipo CC del marcador IGF-SnaBI fue mayor que para los demás genotipos. Lo mismo ocurre para el genotipo TT del marcador GnRHR-SNP6 esto demuestra la proporción de animales que no alcanzaron la pubertad durante el tiempo de muestro (Tabla 3.3).

Tabla 3.3. Distribución de los animales entre los genotipos, animales púberes y censurados (cens.) utilizados para el análisis de supervivencia.

\begin{tabular}{|c|c|c|c|c|c|c|c|}
\hline \multirow[t]{2}{*}{ Genotipo } & \multicolumn{2}{|c|}{$\mathbf{R} 1$} & \multicolumn{2}{|c|}{$\mathbf{R 2}$} & \multicolumn{3}{|c|}{ Total } \\
\hline & Púber & Cens. & Púber & Cens. & Púber & Cens & $\%$ cens \\
\hline \multicolumn{8}{|c|}{ IGF1 -SnaBI } \\
\hline $\mathrm{CC}$ & 10 & 2 & 12 & 20 & 22 & 22 & 50,00 \\
\hline CT & 10 & 4 & 51 & 29 & 61 & 33 & 35,11 \\
\hline TT & 7 & 1 & 39 & 23 & 46 & 24 & 34,29 \\
\hline Total & 27 & 7 & 102 & 72 & 129 & 79 & 37,98 \\
\hline \multicolumn{8}{|c|}{ GnRHR - SNP6 } \\
\hline CT & 6 & 1 & 39 & 14 & 45 & 15 & 25,00 \\
\hline TT & 19 & 5 & 55 & 56 & 74 & 61 & 45,19 \\
\hline Total & 25 & 6 & 94 & 70 & 119 & 76 & 38,97 \\
\hline
\end{tabular}

El análisis de Kaplan-Meier para el marcador IGF-SnaBI mostró diferencias significativas mediante el test de wilcoxon $(p<0,05)$, pero no para el test de log- 
rank $(p=0,08)$. Demostrando un mayor riesgo de pubertad asociado al genotipo TT, el mismo que además posee menos censura (Tabla 3.3), se observa que la mediana de la probabilidad de supervivencia al evento pubertad, o la probabilidad de pubertad (su complemento) se encuentra a los 388 días para el genotipo TT, cuando en el genotipo CT y CC se sitúa a los 408 y 445 días respectivamente (Figura 3.1.A).

Figura 3.1.A. Curvas de supervivencia de Kaplan - Meier para los distintos genotipos del SNP IGF1-SnaBI, para toda la población evaluada.

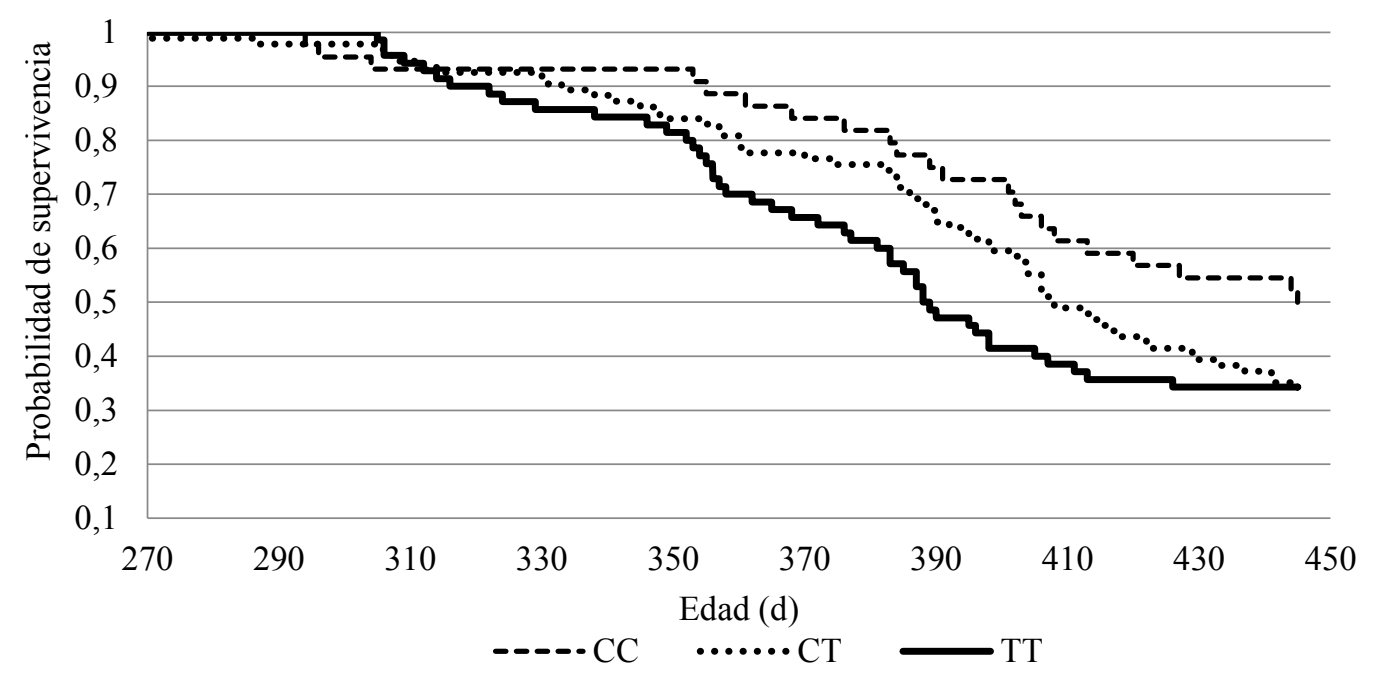

El análisis por rodeo no mostró diferencias estadísticamente significativas en la probabilidad de supervivencia para los distintos genotipos de IGF1-SnaBI para R1 (Log-Rank: $p=0,26$ y Wilcoxon: $p=0,12$ ). En el caso de R2 los resultados tampoco mostraron diferencias, si bien muestran una tendencia $(\log -$ Rank: $p=$ 0,054 y Wilcoxon: $\mathrm{p}=0,079)$. La mediana de ocurrencia de pubertad para los tres genotipos en R1 se da a una edad más temprana que en R2. (Figura 3.1.B; Figura 3.1.C). 
Figura 3.1.B. Curvas de supervivencia de Kaplan - Meier para los distintos genotipos del SNP IGF1-SnaBI, para R1.

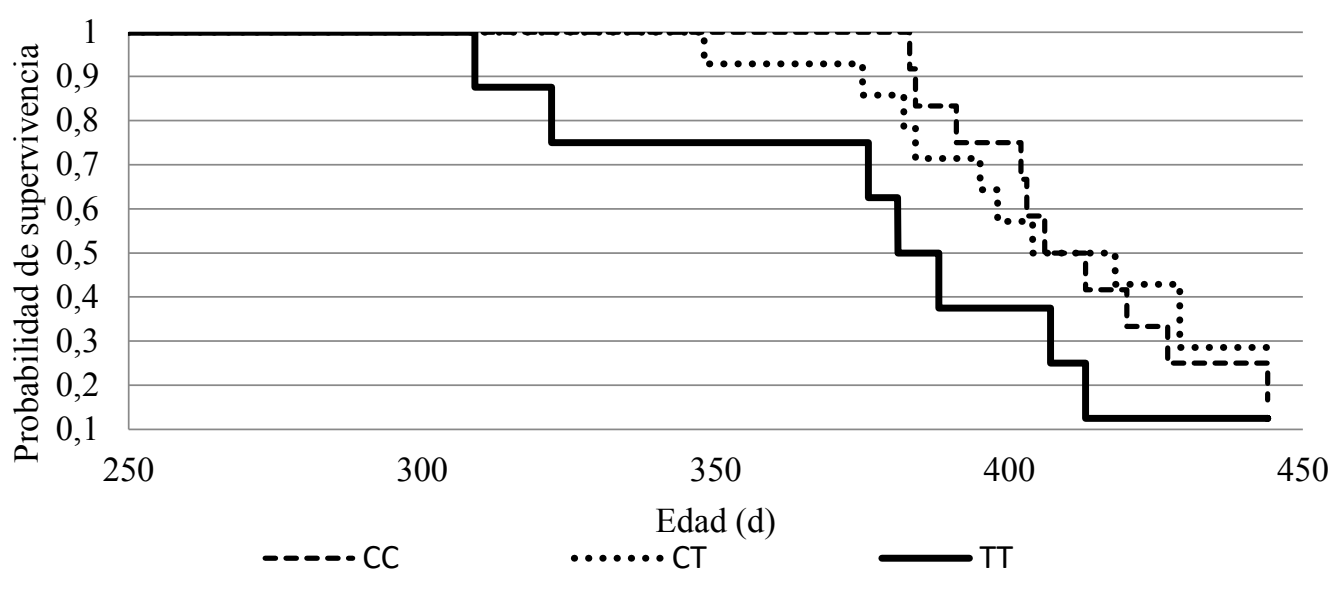

Figura 3.1.C. Curvas de supervivencia de Kaplan - Meier para los distintos genotipos del SNP IGF1-SnaBI, para R2.

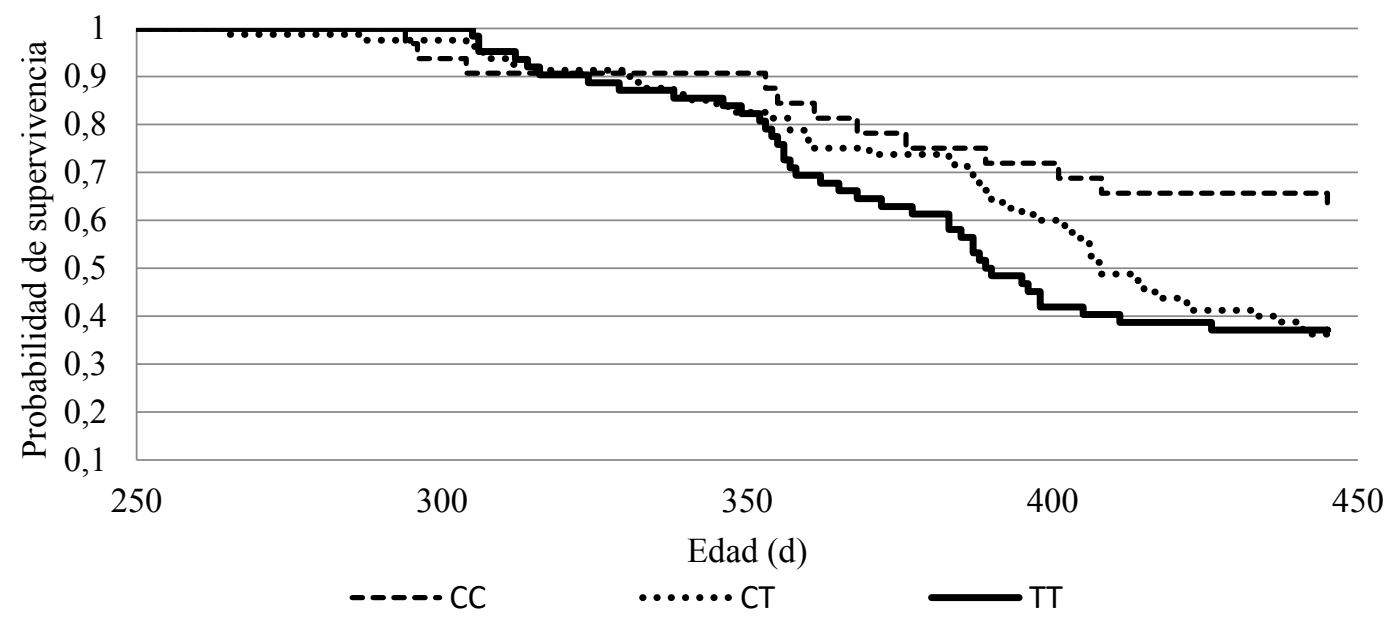

En el caso del marcador GnRHR - SNP6 los estadísticos de Log-Rank y Wilcoxon mostraron diferencias significativas en la probabilidad de supervivencia 
de ambos genotipos $(\mathrm{p}<0,05)$ en el análisis de la población completa (Figura 3.2.A), indicando un riesgo más alto de pubertad para el genotipo heterocigota.

Figura 3.2.A. Curvas de supervivencia de Kaplan - Meier para los distintos genotipos del SNP GnRHR-SNP6, para toda la población evaluada.

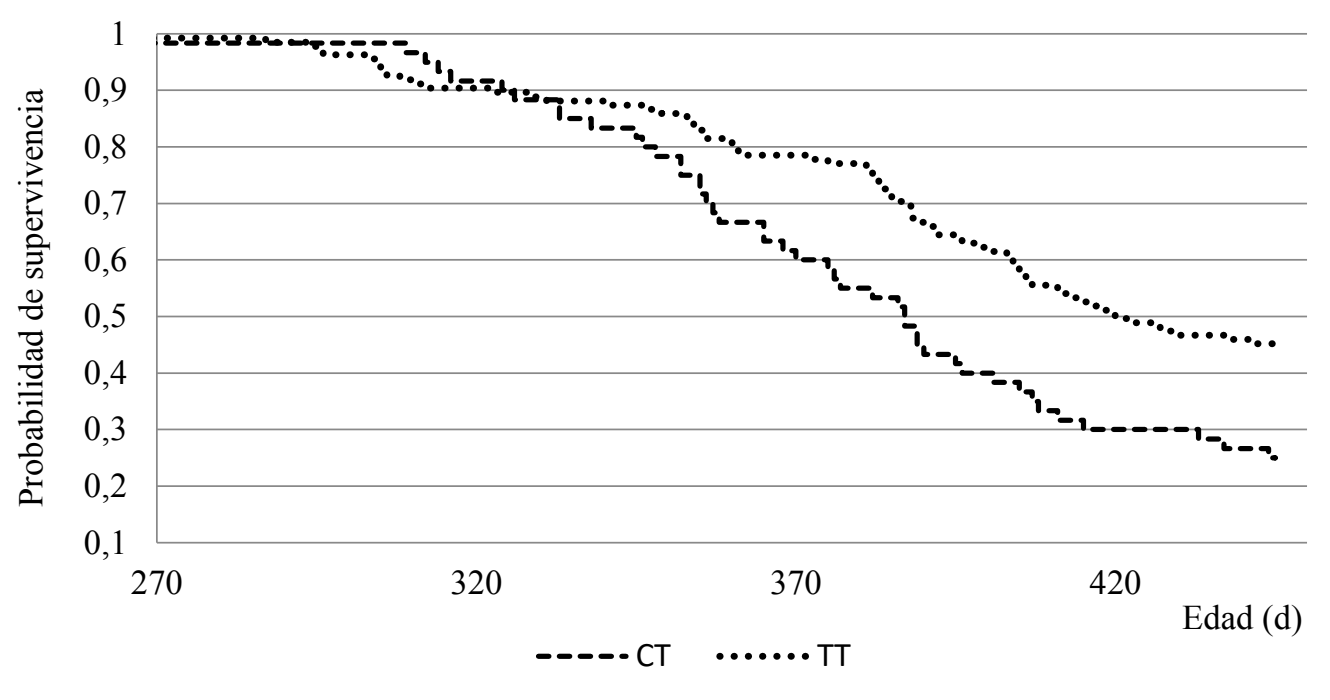

Las mismas diferencias fueron observadas en el análisis de R2, pero no para R1 si bien el estadístico de Wilcoxon muestra una tendencia $(p=0,053)$. En los 3 casos se observa una mediana de la probabilidad de supervivencia más temprana para el genotipo heterocigota respecto al homocigota, y nuevamente la mediana de la probabilidad de supervivencia se ubica a una edad más temprana en R1 que en R2 (Figura 3.2.B; Figura 3.2.C). 
Figura 3.2.B. Curvas de supervivencia de Kaplan - Meier para los distintos genotipos del SNP GnRHR-SNP6, para R1.

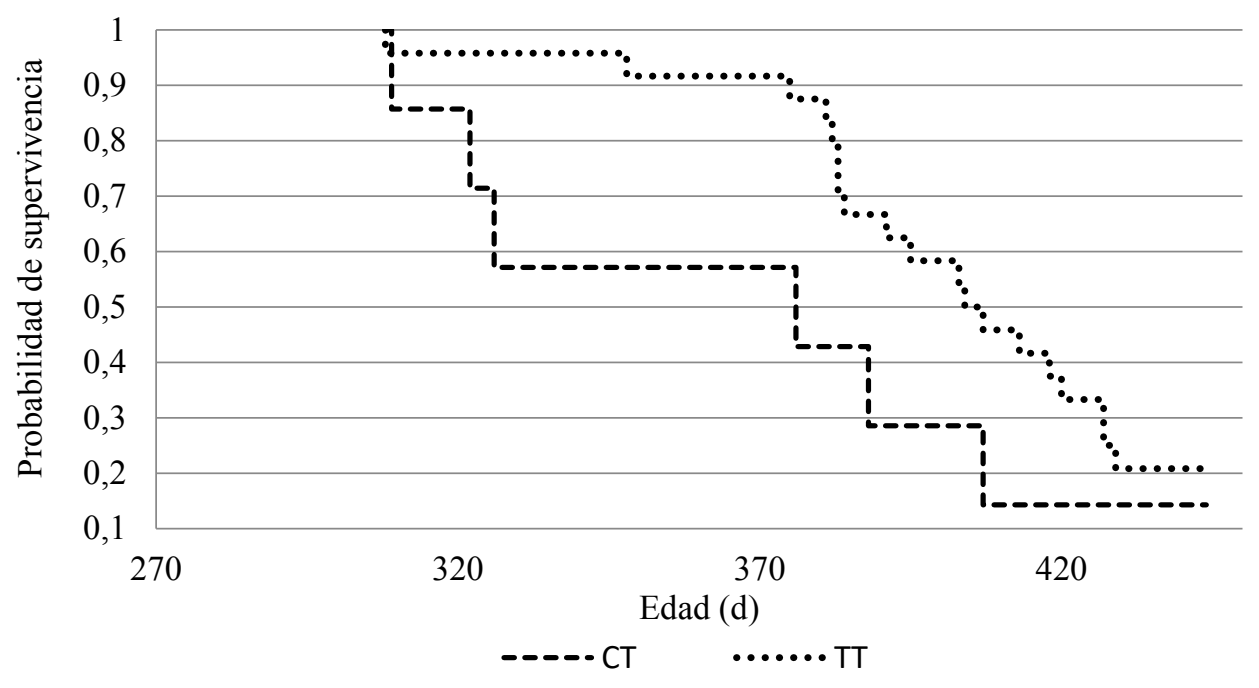

Figura 3.2.C. Curvas de supervivencia de Kaplan - Meier para los distintos genotipos del SNP GnRHR-SNP6, para R2.

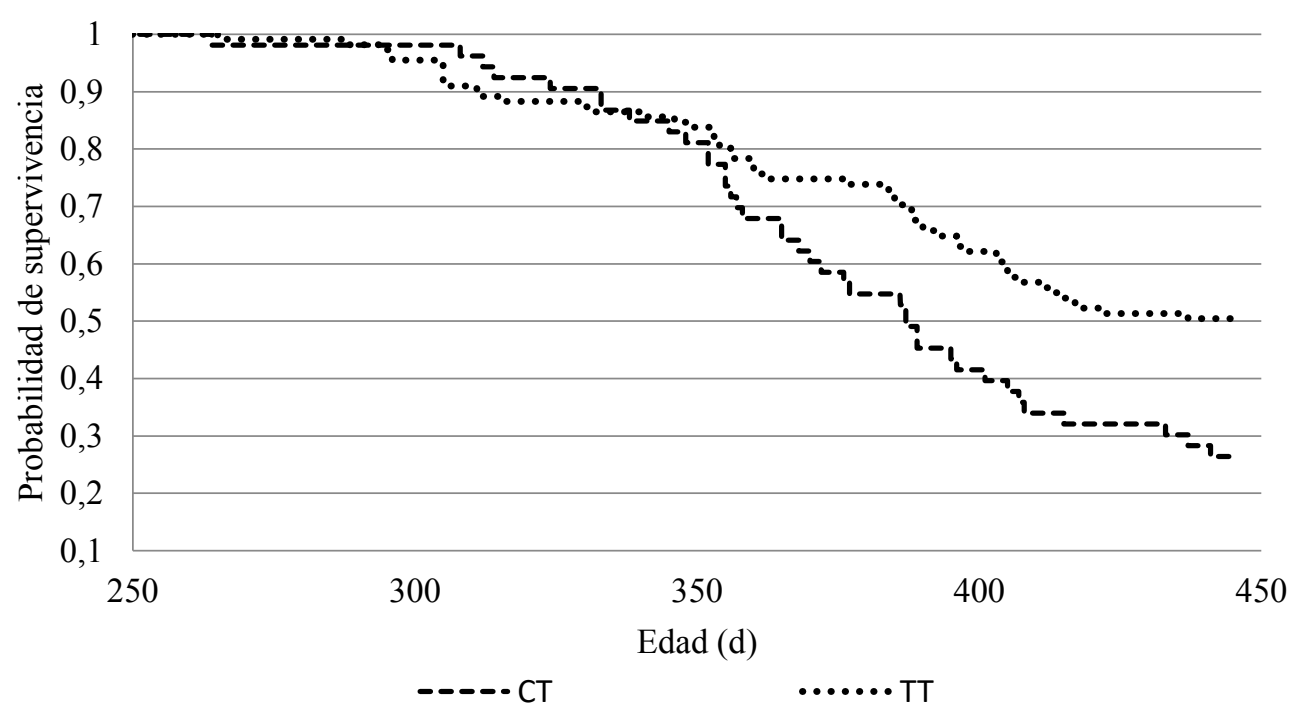

El modelo de riesgos proporcionales de COX evidenció un riesgo relativo de pubertad asociado al genotipo TT del marcador IGF1-SnaBI de más del doble respecto al genotipo $\mathrm{CC}(\mathrm{p}<0,05)$, no habiendo diferencias en el riesgo de pubertad 
entre el genotipo CT y los genotipos CC y TT (Tabla 3.4). Por otra parte, el riesgo de pubertad aumenta 3,5 puntos porcentuales por cada unidad de cambio de peso ( $p$ $<0,001$; Tabla 3.4).

Tabla 3.4. Estimadores de riesgo asociado al polimorfismo en el marcador IGF1SnaBI y el peso sin considerar al rodeo como un factor de estratificación.

\begin{tabular}{cccccc}
\hline Variables & Estimador & E.S. & $\begin{array}{c}\text { Riesgo } \\
\text { relativo }\end{array}$ & IC 95\% & Valor de P \\
\hline IGF-SnaBI CT & 0,3673 & 0,294 & $\mathbf{1 , 4 4 4}$ & $0,811-2,571$ & 0,2 \\
IGF-SnaBI TT & 0,7556 & 0,317 & $\mathbf{2 , 1 2 9}$ & $1,143-3,966$ & 0,02 \\
$\quad$ Peso & 0,0348 & 0,004 & $\mathbf{1 , 0 3 5}$ & $1,026-1,045$ & $<0,0001$ \\
\hline
\end{tabular}

Nota: el genotipo CC se estableció como nivel basal (riego relativo $=1$ ).

$\mathrm{Al}$ incorporar la estratificación por rodeo las estimaciones del riesgo relativo para el genotipo TT y CT siguen siendo mayores respecto al genotipo $\mathrm{CC}$, pero perdiendo significancia estadística (Tabla 3.5). El efecto del peso en el riesgo de pubertad aumenta levemente (Tabla 3.4; Tabla 3.5). No se observó una correlación entre los residuales de Schoenfeld y el tiempo, indicando la proporcionalidad del riesgo en el tiempo entre los distintos genotipos. El efecto de la incorporación de la estratificación por rodeos en el modelo de análisis produce un aumento del intervalo de confianza, haciendo que en el caso del genotipo CC vs TT el mismo incluya el valor 1, determinando la perdida de significancia estadística, si bien en ambos casos el genotipo TT tiene un mayor riesgo de pubertad (Tabla 3.6). 
Tabla 3.5. Estimadores de riesgo asociado al polimorfismo en el marcador IGF1SnaBI y el peso considerando al rodeo como un factor de estratificación.

\begin{tabular}{cccccc}
\hline Variables & Estimador & E.S. & $\begin{array}{c}\text { Riesgo } \\
\text { relativo }\end{array}$ & IC 95\% & Valor de P \\
\hline IGF1-SnaBI CT & 0,1695 & 0,296 & $\mathbf{1 , 1 8 5}$ & $0,663-2,117$ & 0,5 \\
IGF1-SnaBI TT & 0,5531 & 0,316 & $\mathbf{1 , 7 3 9}$ & $0,936-3,232$ & 0,08 \\
$\quad$ Peso & 0,0401 & 0,005 & $\mathbf{1 , 0 4 1}$ & $1,031-1,051$ & $<0,0001$ \\
\hline
\end{tabular}

Nota: el genotipo CC se estableció como nivel basal (riego relativo $=1$ )

Tabla 3.6. Estimación del riesgo relativo de pubertad entre alelos de IGF1-Sna-BI para los modelos sin estratificación por rodeo y con estratificación por rodeo

\begin{tabular}{lcccc}
\hline & \multicolumn{2}{c}{ Sin estratificación } & \multicolumn{2}{c}{ Con estratificación } \\
\cline { 2 - 5 } & Estimador & IC 95\% & Estimador & IC 95\% \\
\hline CC vs CT & 0,693 & $0,389-1,223$ & $\mathbf{0 , 8 4 4}$ & $0,472-1,509$ \\
CC vs TT & 0,470 & $0,252-0,875$ & $\mathbf{0 , 5 7 5}$ & $0,309-1,069$ \\
CT vs TT & 0,678 & $0,434-1,059$ & $\mathbf{0 , 6 8 1}$ & $0,441-1,053$ \\
\hline
\end{tabular}

Los resultados de los modelos de sensibilidad indican que la información que se pierde en la censura a la derecha propia de los datos no aportaría información suficiente para que los riesgos de pubertad se modifican de manera importante, ya que si bien todos los estimadores se volvieron no significativos los riesgos relativos no se invierten de sentido (Tablas 3.7 y 3.8 ). 
Tabla 3.7. Modelo de sensibilidad de censura S1 para el análisis de riesgo asociado al marcador IGF1-SnaBI. A. Sin considerar el efecto rodeo; B. Considerando el efecto rodeo.

\begin{tabular}{cccccc}
\hline A. & Estimador & E.S. & $\begin{array}{c}\text { Riesgo } \\
\text { relativo }\end{array}$ & IC 95\% & P valor \\
\hline IGF1-SnaBI CT & 0,060 & 0,186 & $\mathbf{1 , 0 6 2}$ & $0,738-1,530$ & 0,7 \\
IGF1-SnaBI TT & 0,4079 & 0,198 & $\mathbf{1 , 5 0 4}$ & $1,018-2,221$ & 0,04 \\
Peso & 0,0219 & 0,002 & $\mathbf{1 , 0 2 2}$ & $1,016-1,028$ & $<0,0001$ \\
\hline \hline B. & Estimador & E.S. & $\begin{array}{c}\text { Riesgo } \\
\text { relativo }\end{array}$ & IC 95\% & P valor \\
\hline IGF1-SnaBI CT & $-0,2032$ & 0,192 & $\mathbf{0 , 8 1 6}$ & $-0,560-1,189$ & 0,3 \\
IGF1-SnaBI TT & 0,1562 & 0,205 & $\mathbf{1 , 1 6 9}$ & $0,783-1,746$ & 0,3 \\
Peso & 0,0298 & 0,003 & $\mathbf{1 , 0 3 0}$ & $1,024-1,037$ & $<0,0001$ \\
\hline
\end{tabular}

Nota: se asume que las hembras no púberes alcanzan la pubertad al momento de la censura. El genotipo CC se estableció como nivel basal (riego relativo =1)

Más específicamente se observa un descenso del riesgo relativo para los genotipos TT y CT respecto del genotipo $\mathrm{CC}$ y una disminución del riesgo de pubertad debida al aumento de peso. Cuando se considera el efecto rodeo en el modelo de sensibilidad S1 el genotipo CT actúa como un factor protector de la ocurrencia de pubertad, si bien su efecto no es marcado (Tabla 3.7).

En el análisis por separado de ambos rodeos el genotipo TT muestra un riesgo más alto y más marcado en $\mathrm{R} 1$, pero en ambos casos el riesgo para este genotipo es más del $170 \%$ respecto al homocigota $\mathrm{CC}$. Si bien este efecto no es significativo los riesgos relativos son marcadamente más altos para el genotipo TT respecto al CC. En ambos casos el único efecto que mantiene su significancia sobre la pubertad es el peso, siendo más importante para el R2. (Tablas 3.9 y 3.10). 
Tabla 3.8. Análisis de sensibilidad de censura $\mathrm{S} 2$ para el análisis de riesgo asociado al marcador IGF1-SnaBI. A. Sin considerar el efecto rodeo; B. Considerando el efecto rodeo.

\begin{tabular}{cccccc}
\hline A. & Estimador & E.S. & $\begin{array}{c}\text { Riesgo } \\
\text { relativo }\end{array}$ & IC 95\% & P valor \\
\hline IGF1-SnaBI CT & 0,2611 & 0,250 & $\mathbf{1 , 0 9 8}$ & $0,795-1,819$ & 0,3 \\
IGF1-SnaBI TT & 0,5328 & 0,263 & $\mathbf{1 , 7 0 4}$ & $1,017-2,854$ & 0,04 \\
Peso & 0,0423 & 0,004 & $\mathbf{1 , 0 4 3}$ & $1,035-1,052$ & $<0,0001$ \\
\hline \hline B. & Estimador & E.S. & $\begin{array}{c}\text { Riesgo } \\
\text { relativo }\end{array}$ & IC 95\% & P valor \\
\hline IGF1-SnaBI CT & 0,1597 & 0,256 & $\mathbf{1 , 1 7 3}$ & $0,710-1,939$ & 0,5 \\
IGF1-SnaBI TT & 0,4450 & 0,271 & $\mathbf{1 , 5 6 0}$ & $0,917-2,655$ & 0,1 \\
Peso & 0,0436 & 0,004 & $\mathbf{1 , 0 4 5}$ & $1,036-1,054$ & $<0,001$ \\
\hline
\end{tabular}

Nota: se asume que las hembras no púberes alcanzan la pubertad a la edad de un día más tarde de la hembra más tardía. El genotipo CC se estableció como nivel basal (riego relativo = $1)$.

Tabla 3.9. Análisis de riesgo asociado al polimorfismo en el marcador IGF1-SnaBI y el peso para $\mathrm{R} 1$.

\begin{tabular}{cccccc}
\hline Variable & Estimador & E.S. & $\begin{array}{c}\text { Riesgo } \\
\text { relativo }\end{array}$ & IC 95\% & $\begin{array}{c}\text { valor de } \\
\text { P }\end{array}$ \\
\hline IGF1-SnaBI CT & $-0,1646$ & 0,432 & $\mathbf{0 , 8 4 8}$ & $0,364-1,979$ & 0,7 \\
IGF1-SnaBI TT & 0,6527 & 0,522 & $\mathbf{1 , 9 2 1}$ & $0,690-5,346$ & 0,2 \\
$\quad$ Peso & 0,0208 & 0,007 & $\mathbf{1 , 0 2 1}$ & $1,006-1,037$ & 0,007 \\
\hline
\end{tabular}

Nota: el genotipo CC se estableció como nivel basal (riego relativo = 1)

Tabla 3.10. Análisis de riesgo asociado al polimorfismo en el marcador IGF1SnaBI y el peso para R2.

\begin{tabular}{cccccc}
\hline Variable & $\begin{array}{c}\text { Estimador del } \\
\text { parámetro }\end{array}$ & E.S. & $\begin{array}{c}\text { Riesgo } \\
\text { relativo }\end{array}$ & IC 95\% & valor de P \\
\hline IGF1-SnaBI CT & 0,2452 & 0,378 & $\mathbf{1 , 2 7 8}$ & $0,609-2,681$ & 0,5 \\
IGF1-SnaBI TT & 0,5672 & 0,392 & $\mathbf{1 , 7 6 3}$ & $0,817-3,805$ & 0,1 \\
Peso & 0,0440 & 0,005 & $\mathbf{1 , 0 4 5}$ & $1,034-1,056$ & $<0,0001$ \\
\hline
\end{tabular}

Nota: el genotipo CC se estableció como nivel basal (riego relativo $=1$ ) 
El modelo de riesgos proporcionales de COX para el marcador GnRHR-SNP6 no demostró diferencias significativas en el riesgo relativo de pubertad para el genotipo heterocigota respecto del homocigota para el alelo T. El efecto del peso en el riesgo de pubertad resultó estadísticamente significativo, y su magnitud se encuentra en valores similares que los observados en el análisis de IGF-SnaBI (Tabla 3.11). En el análisis por separado de los rodeos en R1 se observa una tendencia de un mayor riesgo de pubertad del genotipo heterocigota respecto al genotipo TT ( $p=0,095$; Tabla 3.12).

Tabla 3.11. Estimadores de riesgo asociado al polimorfismo en el marcador GnRHR - SNP6 y el peso sin considerar al rodeo como un factor de estratificación y considerando al rodeo como un factor de estratificación para toda la población evaluada.

\begin{tabular}{ccccccc}
\hline Variables & Estimador & E.S. & \multicolumn{1}{c}{ Riesgo } \\
relativo & IC 95\% & Valor de P \\
\hline \multirow{7}{*}{ Sin estratificación por rodeo } \\
GnRHR-SNP6 TT & -0.2161 & 0,222 & $\mathbf{0 . 8 0 6}$ & $0,522-1.244$ & 0,3 \\
Peso & 0,0343 & 0,005 & $\mathbf{1 , 0 3 5}$ & $1,025-1,045$ & $<0,0001$ \\
\hline \hline \multirow{8}{*}{ Con estratificación por rodeo } \\
GnRHR-SNP6 TT & -0.0455 & 0,227 & $\mathbf{0 . 9 5 6}$ & $0,612-1.491$ & 0,8 \\
Peso & 0,0396 & 0,005 & $\mathbf{1 , 0 4 0}$ & $1,030-1,051$ & $<0,0001$ \\
\hline
\end{tabular}

Nota: El genotipo CT se estableció como nivel de riesgo basal (riesgo relativo $=1$ ). 
Tabla 3.12. Estimadores de riesgo de pubertad asociado al SNP GnRHR - SNP6 y el peso para los dos rodeos evaluados.

\begin{tabular}{ccccccc}
\hline & Variables & Estimador & E.S. & $\begin{array}{c}\text { Riesgo } \\
\text { relativo }\end{array}$ & IC 95\% & $\begin{array}{c}\text { Valor de } \\
\text { P }\end{array}$ \\
\hline \multirow{2}{*}{ R1 } & GnRHR-SNP6 TT & $-0,9348$ & 0,560 & $\mathbf{0 , 3 9 3}$ & $0,131-1,177$ & 0,09 \\
& Peso & 0,0223 & 0,008 & $\mathbf{1 , 0 2 3}$ & $1,006-1,039$ & 0,006 \\
\hline \multirow{2}{*}{ R2 } & GnRHR-SNP6 TT & 0,1177 & 0,241 & $\mathbf{1 , 1 2 5}$ & $0,701-1,804$ & 0,6 \\
& Peso & 0,0436 & 0,006 & $\mathbf{1 , 0 4 5}$ & $1,033-1,056$ & $<0,0001$ \\
\hline
\end{tabular}

Nota: El genotipo CT se estableció como nivel de riesgo basal (riesgo relativo $=1$ ).

Los análisis de sensibilidad muestran que la censura genera una pérdida importante de información, el riesgo de pubertad para el modelo S1 (pubertad al momento de la censura) para el genotipo TT tiende a ser superior respecto al CT (p $=0.06$; Tabla 3.13), mientras que en el modelo $\mathrm{S} 2$ el genotipo que tiende a asociarse a un mayor riesgo de pubertad es el genotipo CT $(\mathrm{p}=0.07$; Tabla 3.13).

Tabla 3.13. Análisis de sensibilidad de censura para el análisis de riesgo asociado al marcador GnRHR-SNP6.

\begin{tabular}{ccccccc}
\hline & Variables & Estimador & E.S. & $\begin{array}{c}\text { Riesgo } \\
\text { relativo }\end{array}$ & IC 95\% & Valor de P \\
\hline \multirow{2}{*}{ S1 } & GnRHR-SNP6 TT & 0,3057 & 0,166 & $\mathbf{1 , 3 5 8}$ & $0,979-1,882$ & 0,06 \\
& Peso & 0,0292 & 0,003 & $\mathbf{1 , 0 3 0}$ & $1,023-1,036$ & $<0,0001$ \\
\hline \multirow{2}{*}{ S2 } & GnRHR-SNP6 TT & $-0,3609$ & 0,201 & $\mathbf{0 , 6 9 7}$ & $0,470-1,034$ & 0,07 \\
& Peso & 0,0430 & 0,004 & $\mathbf{1 , 0 4 4}$ & $1,035-1,053$ & $<0,0001$ \\
\hline
\end{tabular}

Nota: en S1 se asume que las hembras no púberes alcanzan la pubertad al momento de la censura. En S2 se asume a todas las hembras púberes a la edad de la hembra mas tardía detectada. El genotipo CC se estableció como nivel basal (riego relativo $=1$ ) 
El análisis de las curvas de crecimiento de ambos rodeos demuestra que la forma de las curvas es inversa de un rodeo respecto a otro, evidenciado por la inversión de los signos de los parámetros de los términos lineal y cuadrático de la misma (Tabla 3.14).

Tabla 3.14. Estimación de parámetros de las curvas de crecimiento entre los distintos genotipos de IGF-SnaBI.

\begin{tabular}{cccccccc}
\hline & & $\mathbf{R 1}$ & & & \multicolumn{3}{c}{$\mathbf{R 2}$} \\
& $\mathbf{C C}$ & $\mathbf{C T}$ & $\mathbf{T T}$ & & $\mathbf{C C}$ & $\mathbf{C T}$ & $\mathbf{T T}$ \\
\hline$\alpha_{0}$ & $-2,07^{* *}$ & $-32,90^{*}$ & $-101,00^{* *}$ & & 179,09 & 194,46 & 202,18 \\
$\alpha_{1}$ & $0,68^{* *}$ & $0,85^{* *}$ & $1,37^{* *}$ & & $-0,3897^{* *}$ & $-0,3748^{* *}$ & $-0,4559^{*}$ \\
$\alpha_{2}$ & $-0,0001$ & $-0,0003$ & $-0,0011^{* *}$ & & $0,0013^{* *}$ & $0,0012^{* *}$ & $0,0014^{* *}$ \\
\hline
\end{tabular}

Nota: $* * \mathrm{P}<0,01 ; * \mathrm{P}<0,05$.

Además, en R2, si se compara la forma de la curva de crecimiento con una curva patrón (similar a la observada en R1) se observa una restricción del crecimiento potencial en los primeros meses posdestete, y una suerte de crecimiento compensatorio sobre el final de la recría (Figura 3.3 y 3.4), si bien los animales de R2 no llegaron a alcanzar el peso de las vaquillonas de R1.

Las estimaciones de peso no mostraron diferencias significativas entre las curvas a ninguna edad. Por su parte, se observa en R2 que el genotipo CT parece ser quien lleva un peso superior durante toda la recría, con estimaciones de peso significativamente diferentes $(\mathrm{p}<0,05)$ respecto al genotipo $\mathrm{CC}$ hasta los 343 días de edad. Las diferencias en el crecimiento de los rodeos se vuelven más evidentes 
si se observa que la primera derivada de la curva de peso, la pendiente de ésta se invierte en un rodeo respecto del otro (Figura 3.3 y3.4).

Figura 3.3 Curva de crecimiento y aumento de peso derivado (APd) para los distintos polimorfismos del marcador IFG-SnaBI en el rodeo R1.

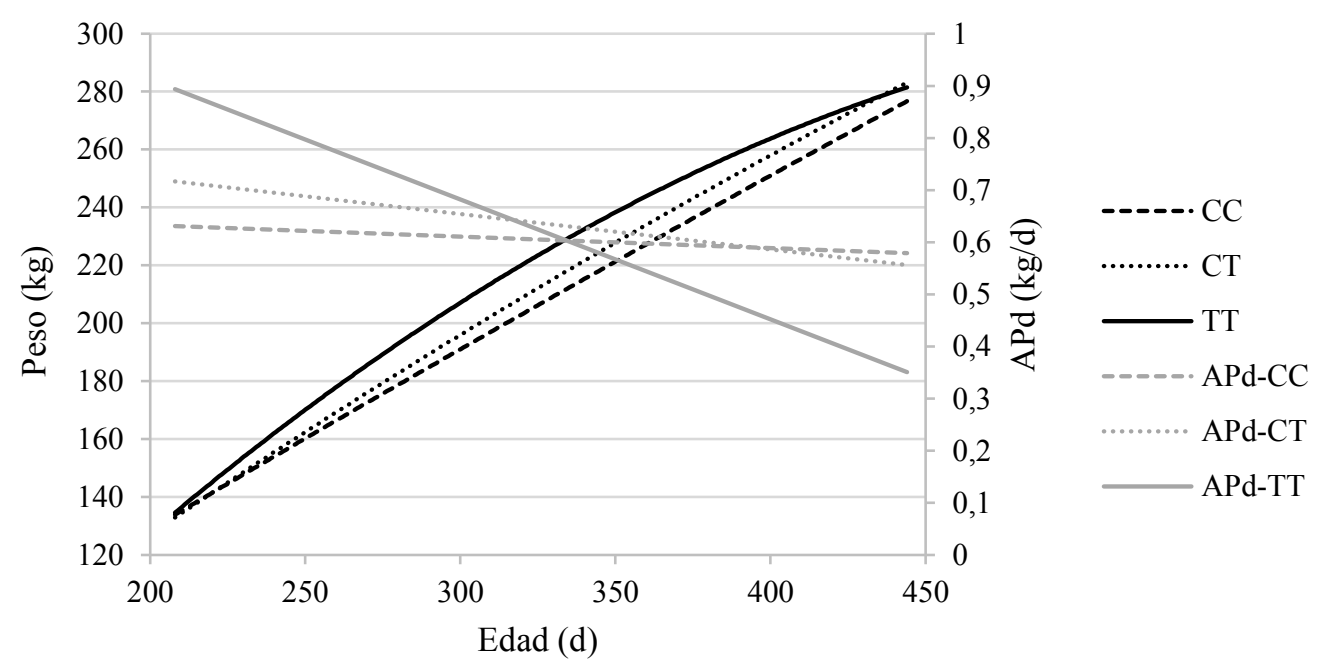

Nota: El APd fue calculado como la primera derivada de la curva de peso

Figura 3.4. Curva de crecimiento y aumento de peso derivado (APd) para los distintos polimorfismos del marcador IFG1-SnaBI en el rodeo R2.

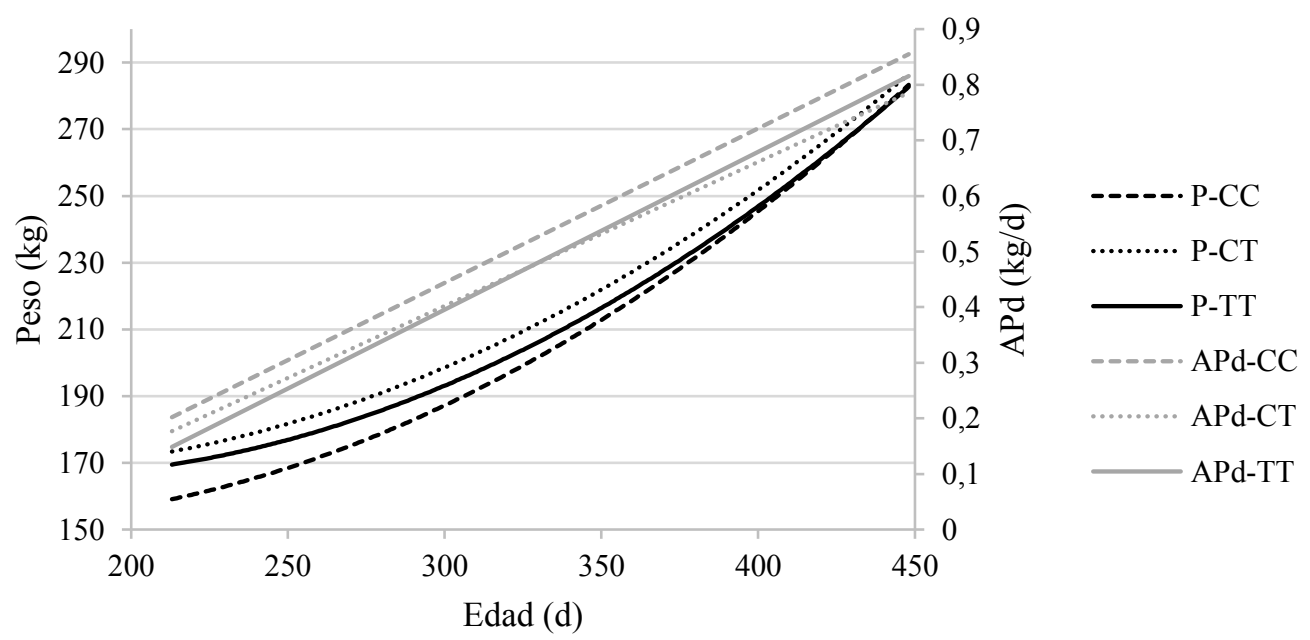

Nota: El APd fue calculado como la primera derivada de la curva de peso 
El análisis de las estimaciones para la curva de aumento de peso derivado (APd) muestra para el R1, (quien demuestra una curva de crecimiento más parecida a una curva objetivo para esa edad), diferencias entre los genotipos CC y TT hasta los 286 días y luego desde los 400 días, y entre los genotipos TT y CT hasta los 222 días y luego desde los 396 días. Por el contrario, en R2 no se observaron diferencias en las estimaciones de APd.

\subsection{DISCUSIÓN}

Tradicionalmente, los trabajos sobre precocidad sexual suelen ser evaluados con modelos lineales (Honaramooz y col., 1999; Luna-Pinto y Cronjé, 2000; Gasser y col., 2006; Johnston y col., 2009; Fortes y col., 2010). Sin embargo, para poder tener estimaciones ciertas de la edad a la pubertad en las hembras, la determinación del evento pubertad debe realizarse diariamente (Mialon y col., 2000) o a intervalos muy cortos de tiempo (Honaramooz y col., 2004) de manera de evitar la censura en el intervalo originada por determinar a todas las hembras como púberes en un mismo momento.

Los análisis de supervivencia son de amplia difusión en estudios epidemiológicos, ya que no incorporan el tiempo a un evento como su edad, sino que observan un evento y determina su ocurrencia en una ventana de riesgo. Si se determinan intervalos de tiempo ya sea regulares o irregulares, el evento se define dentro de esa ventana (Allison, 2010). Sumado a esto, la información de los animales que no sufren el evento puede incorporarse al análisis, lo cual otorga mucha plasticidad en los muestreos en condiciones productivas, donde 
generalmente el diseño de los muestreos está condicionado por las tareas programadas por el establecimiento.

Por otro lado, este tipo de análisis fueron inicialmente desarrollados para el estudio de asociación del riesgo de enfermar, o morir ante determinadas situaciones que se incorporan como variables explicatorias, en este sentido el uso de estos modelos para el estudio de eventos que son beneficiosos requiere un esfuerzo de interpretación. En este trabajo el mayor riesgo constituye una ventaja productiva y la supervivencia por contrario no, ya que el objetivo productivo es sufrir el evento lo más anticipadamente posible.

En el presente trabajo de Tesis Doctoral, los muestreos debieron finalizar previo al inicio del servicio, cuando no todas las vaquillonas habían alcanzado la pubertad. Si el modelo de análisis obligara a tener una medición del evento en cada animal se deberían haber descartado las mediciones de 79 y 76 vaquillonas para los análisis de asociación con los marcadores IGF1-SnaBI y GnRHR-SNP6, respectivamente (Tabla 3.3), por no tener determinada una edad a la pubertad, y con esto estaría perdiendo la información de las hembras menos precoces del rodeo, o bien de las más jóvenes de edad, pudiendo sobre o subestimar los efectos de las distintas variables evaluadas.

El análisis de sensibilidad de la censura permite evaluar cuan informativa es la censura en la variable. Esto es, si los animales censurados tienen un sesgo común, es decir que tienen un riesgo superior o inferior sistemático respecto a los no censurados, pudiendo modificar los parámetros evaluados (Allison, 2010). Los análisis de sensibilidad en la asociación entre el riesgo de pubertad y el 
polimorfismo en el marcador IGF1-SnaBI en este trabajo no invierten los parámetros, ni tampoco modifican en gran magnitud las estimaciones de los riesgos relativos, si bien algunos de los efectos pierden significancia estadística, particularmente en R1, pudiendo ser consecuencia del impacto del bajo número de hembras evaluadas.

En los análisis de sensibilidad de la asociación con el marcador GnRHR SNP6 se observa que el riesgo de pubertad para el genotipo TT respecto al CC se invierte entre S1 y S2 (Tabla 3.13) y entre S1 y los modelos de análisis (Tablas 3.13 y 3.11), esto podría ser explicado en parte por la desproporción encontrada en las frecuencias genotípicas por un lado (Tabla 3.2) y la fuerte censura observada para el genotipo TT, donde cerca del $45 \%$ de los animales no sufrieron el evento pubertad (Tabla 3.3). Frecuencias genotípicas similares para el genotipo CC fueron reportadas por Lirón y col (2012) en machos Angus.

Lo anterior sumado a la restricción del crecimiento observada en R2 (Figura 3.3), donde además el efecto del peso en el riesgo de pubertad es mayor respecto a R1 (Tabla 3.12), genera una gran dificultad a la hora de intentar sacar conclusiones del comportamiento de la pubertad y su asociación con los distintos polimorfismos del marcador.

Según los resultados obtenidos en el análisis de los riesgos proporcionales de Cox, el genotipo TT del marcador IGF1-SnaBI podría incrementar el riesgo de pubertad, si bien este efecto desaparece al incorporar al rodeo como estrato, pero si se evalúan los dos rodeos por separado (Tabla 3.4 y 3.5) el riesgo relativo para este genotipo continúa siendo más de un $60 \%$ más alto que para el homocigota $\mathrm{CC}$. El 
mismo genotipo fue asociado con una menor edad a la pubertad, definida como la edad a los $28 \mathrm{~cm}$ de circunferencia escrotal, en toros Angus de la Provincia de Buenos Aires (Lirón y col., 2012). Los cambios en las estimaciones al incorporar efecto rodeo, podrían ser explicados en parte por la diferencia de animales evaluados, la diferente proporción de animales censurados para uno y otro rodeo, pudiendo esto último estar asociado a las diferencias observadas en el crecimiento.

El genotipo TT del marcador IGF1-SnaBI ha sido también asociado con el reinicio de la actividad ovárica postparto en vacas Holstein (Nicolini y col., 2013; Silveira y col., 2015). Si tenemos en cuenta los mecanismos fisiológicos que regulan el reinicio de la actividad posparto, estos son muy similares a los que dan inicio de la actividad reproductiva en hembras prepúberes (Lauderdale, 1986).

Mialon y col. (2000), reportaron una correlación genética entre la edad a la pubertad y el reinicio de la actividad ovárica posparto de entre 0,45 y 0,7, dependiendo si la determinación de la actividad ovárica fue realizada a través de medición de progesterona o detección de celo. En contraposición a esto, existen evidencias de una correlación fenotípica negativa entre la edad a la pubertad y el largo del anestro postparto (Patterson y col., 1992), sin embargo, al no poder despejar el efecto ambiental, estos resultados podrían estar influenciados por la nutrición posparto de los animales que paren más temprano, y por lo tanto suelen afrontar las lactancias con forrajes de menor calidad. Por el contrario, aquellas hembras presumiblemente menos precoces, tienden a parir hacia el final de la estación de partos, con disponibilidad de pastos de primavera. 
El peso en el tiempo demostró ser el efecto que más impacto tiene en el riesgo de pubertad (Tablas $3.4 ; 3.5 ; 3.11 ; 3.12$ ), lo cual ha sido ampliamente reportado previamente (Arije y Wiltbank, 1971; Buttram y Willham, 1989; Gasser y col., 2006a; Gasser y col., 2006d). Pero al analizar el peso de manera separada en ambos rodeos, se observa que las curvas de crecimiento tienen una forma inversa, en la tabla 3.14 puede observarse que los parámetros lineal y cuadrático para los distintos rodeos tienen el signo invertido. La curva para el R1 es la que más se adecua a una curva patrón para animales en crecimiento (Figura 3.3), mientras que la curva de crecimiento para $\mathrm{R} 2$ en cambio muestra una fuerte restricción en el aumento de peso durante los primeros meses posdestete (Figura 3.4). Esta restricción podría estar afectando el momento de la pubertad (Gasser y col., 2006a; Funston y col., 2012a), ya que, si bien las ganancias de peso posteriores parecieran buscar un crecimiento compensatorio, no lo logran, a ello debe sumarse el efecto que podría haber ocasionado la restricción temprana per se en la pubertad. En este sentido parte de la explicación del fuerte efecto rodeo encontrado en los análisis de riesgos proporcionales podría originarse aquí.

los animales con diferentes genotipos del gen IGF1-SnaBI, tienen un crecimiento diferente según el rodeo, y esto podría estar relacionado con la nutrición diferente entre los mismos. En el análisis de riesgos proporcionales para ambos marcadores el impacto del peso en el riesgo de pubertad fue mayor para R2 (Tablas 3.9, 3.10 y 3.12), parece evidente que el efecto de la restricción del crecimiento es quien limita la aparición de la pubertad, estableciendo una suerte de umbral de crecimiento que debe ser superado para iniciar la actividad reproductiva. 
Los trabajos que informan sobre los efectos de la IGF-1 en la reproducción son controversiales. Algunos trabajos han encontrado una asociación entre el nivel de IGF-1 y una menor edad a la pubertad (Hopper y col., 1993), mientras que otros no lograron detectar este efecto (Hall y col., 1993). En este sentido el estudio realizado por Yilmaz y col., (2006) no encontró una asociación entre la edad a la pubertad y el nivel de IGF-1, sobre la evaluación de un rodeo seleccionado durante 12 años de forma divergente según los niveles de IGF1, si bien reportan una tendencia a que las vacas de altos niveles plasmáticos de IGF1 tienden a parir antes.

El análisis de las curvas de crecimiento para los distintos genotipos de IGF1SnaBI, demuestra que la forma de las curvas entre los establecimientos es diferente. también se observaron diferencias en el comportamiento de los genotipos, siendo el genotipo TT el que mejor se comporta en R1, mientras que el genotipo heterocigota $\mathrm{CT}$ es el que se comporta mejor en R2. Si bien en ambos casos el genotipo homocigota para el alelo $\mathrm{C}$ es quien reporta un peso inferior, teniendo en cuenta que no hubo diferencias en los estimadores de las curvas, pero si lo hubo para el aumento de peso, estimado como la primera derivada de la curva de crecimiento. En el análisis realizado por Rogberg-Muñoz y col. (2013) con el mismo marcador para evaluar curvas de crecimiento en toritos Angus demostró un peso mayor en el genotipo CC. Estas diferencias podrían radicar en que parece muy ambicioso explicar el crecimiento solo por las variaciones de un SNP, siendo el crecimiento un carácter influenciado por un gran número de genes, sumado a un importante efecto ambiental y a la interacción de este con el genotipo. 


\subsection{CONCLUSIONES}

Para el análisis del arribo a la pubertad en hembras bovinas en condiciones extensivas, podría ser más apropiado el uso de modelos que permitan manejar la censura en el intervalo y evaluar la perdida de información que se produce por excluir las colas de las distribuciones. En este sentido los modelos de supervivencia son una alternativa que permite incorporar variables explicatorias tanto continuas como categóricas, modelando el efecto del tiempo, como así también de covariables tiempo dependientes.

En este trabajo se observó un mayor riesgo de pubertad para el genotipo TT del marcador IGF1-SnaBI, y no pudieron ser detectadas diferencias entre los polimorfismos del marcador GnRHR-SNP6. El peso fue en todos los análisis el principal factor de riesgo para una pubertad más temprana, observándose un importante efecto de rodeo, en principio determinado por un patrón de crecimiento diferente durante el período de muestreo. 


\section{CAPITULO IV}

\section{CORRELACIONES GENÉTICAS ENTRE LA PRECOCIDAD SEXUAL \\ EN LAS HEMBRAS Y LA CIRCUNFERENCIA ESCROTAL EN LOS \\ MACHOS A DIFERENTES EDADES EN UN RODEO ANGUS.}

\subsection{INTRODUCCIÓN}

Las categorías de hembras en los rodeos de cría son las más numerosas y como tal son responsables de la mayor proporción de los costos y de las ganancias. En general la condición para que una vaca se mantenga productiva en el rodeo es que ésta destete una cría por año (Carrillo, 1997). A este objetivo debe de sumarse el hecho de que esa cría sea lo más pesada posible. En cualquier rodeo de cría, los terneros nacidos más tempranamente son más pesados por el simple hecho de haber nacido antes (Perry y Cushman, 2013), independientemente de la selección genética por un mayor peso al destete o una mayor producción de leche.

Dado que la gestación es de una duración estable (283 \pm 5 días), los partos tempranos son el resultado de concepciones más tempranas en el servicio anterior. A su vez, preñeces tempranas son más probables en vacas que tuvieron un puerperio más largo (Short y col., 1990; Perry y Cushman, 2013), lo cual depende de cuan temprano fue su parto en la temporada de parición anterior, y en última instancia, de que tan anticipadamente ocurrió su primer parto como una vaquillona. En efecto, las vaquillonas que paren más temprano en la primera estación reproductiva tienden a parir antes en los partos sucesivos durante toda su vida productiva (Leismeister y col, 1973), y suelen ser más longevas en el rodeo (Cushman y col., 2013). 
El razonamiento entonces para sistemas con servicio estacionado y restringido es el siguiente: un primer parto temprano en las vaquillonas, y por lo tanto un puerperio más largo, aumenta la probabilidad de una próxima preñez y su parto subsecuente más temprano. Iniciando así un círculo virtuoso que aumenta los $\mathrm{kg}$ de ternero destetado en los partos sucesivos, de forma que la edad en que la vaquillona alcanza su primer parto configura su productividad futura (Day y Nogueira, 2013). Además, las preñeces tempranas en las vaquillonas reducen la diferencia en el peso al destete respecto de las vacas, produciendo terneros más pesados (Cushman y col., 2013; Patterson y col., 2013).

La primera condición que debe cumplir una vaquillona para poder preñarse es estar ciclando antes que se inicie la temporada de servicios, es así como la edad a la pubertad juega un rol primordial en el momento de la preñez, considerando además que los primeros tres celos son infértiles o subfértiles. Si bien la pubertad es una condición cualitativa (con valores sí/no), el tiempo hasta el evento tiene una base genética cuantitativa y por lo tanto es adecuada para incorporar en programas de mejoramiento genético. (Morris y Wilson, 1997).

Sin embargo, la edad a la pubertad es difícil de medir directamente, ya que para su determinación se debe evaluar la actividad ovárica o bien, medir los niveles séricos de P4 de las hembras en repetidas ocasiones durante un largo período (Mialon y col., 2000; Honaramooz y col., 2004; Johnston y col., 2009). Estas dificultades indujeron la búsqueda de otras características, tales como la edad al primer parto (EPP), días al parto (DAP) (Bourdon y Brinks, 1983), o fecha de primer parto (FPP) (Cammack y col., 2009). Esto resulta en una forma indirecta de medir la precocidad sexual, más sencilla de registrar, ya que sólo se necesita 
registrar los nacimientos en el establecimiento, y que por otro lado refleja lo que verdaderamente impacta en el resultado económico del sistema. Una medición de cualquiera de estas características abarcan la pubertad, capacidad de concebir gestar y parir un ternero, pero suelen estar limitada por la temporada de servicios (Bormann y Wilson, 2010).

La fecha de parto (FP) evalúa el tiempo transcurrido desde el parto de la primera vaca del grupo de contemporáneos hasta el momento del parto de cualquier otra hembra (Bourdon y Brinks, 1983), a diferencia de DAP esta característica no considera el tiempo de gestación por lo tanto no existe necesidad de denunciar el inicio del servicio, pero ambas características evalúan lo mismo: la capacidad de una vaca de preñarse/parir antes que otra (Urioste y col., 2007).

La selección por fertilidad en las hembras suele estar limitada por la naturaleza binaria de la característica, y por la baja $\mathrm{h}^{2}$ reportada, sin embargo el rango de $\mathrm{h}^{2}$ reportadas para estas características es amplio, tal es así como la edad al primer parto presenta reportes que van desde 0,08 a 0,23 (Gutiérrez y col., 2002; Martinez-Velazquez y col., 2003) y para días al parto desde 0,03 a 0,30 (Buddenberg y col., 1990; MacNeil y Newman, 1994).

Por otro lado, el crecimiento y el desarrollo reproductivo en el macho y la hembra comparten vías metabólicas comunes, con algunas diferencias específicas, principalmente en el control gonadal del eje hipotálamo-hipofisiario-gonadal (Evans y Rawlings, 2010). Por ejemplo, en ambos sexos ha sido definida la importancia de un pico temprano de LH (Evans y col., 1994a; Madgwick y col., 2005), el establecimiento de un feedback negativo entre el principal producto de las 
gónadas (estradiol o testosterona) sobre la secreción de gonadotrofinas durante el periodo prepuberal y el establecimiento de similares sinapsis inhibidoras a nivel central sobre la secreción de GnRH.

El crecimiento testicular sigue una función sigmoidea con una fase de crecimiento más lento inicial, seguida de una fase conocida como desarrollo puberal desde las 25 semanas aproximadamente hasta la pubertad, caracterizada por un crecimiento muy acelerado del testículo (Rawlings y col., 2008) logrado a expensas de un aumento de tejido parenquimatoso, que luego desacelera alcanzando un plateau más o menos estable alrededor de los 3 años de edad (Coulter y col., 1975).

El tamaño testicular suele ser medido por los productores de toros, donde uno de los objetivos de selección suele ser una mayor circunferencia escrotal (CE) en jóvenes y adultos. En estas categorías la CE fue positivamente correlacionada tanto fenotípica como genéticamente con el porcentaje de espermatozoides vivos por eyaculado, como así también con motilidad y concentración (Glaze, 2011; Corbet y col., 2013). Siendo además un carácter con una heredabilidad reportada de alrededor de 0,5 con rangos entre 0,3 a 0,78 (Martinez-Velazquez y col., 2003; Corbet y col., 2009; Johnston y col., 2009; Fortes y col., 2012) volviéndolo un carácter ideal para seleccionar, ya que es sencillo de medir, tiene importancia económica y se puede esperar una satisfactoria respuesta a la selección.

La CE presenta una correlación genética con la edad a la pubertad en toros de alrededor de -0,65 (Lunstra y Cundiff, 2003), incluso una de las definiciones de pubertad en machos, de mucha practicidad a campo, establece que un macho es púber cuando supera un umbral de 27,9 cm de CE (Lunstra y col., 1978). Tal es así 
que puede esperarse que animales que tengan un crecimiento testicular más acelerado sean más precoces que aquellos que tengan un crecimiento de las gónadas más lento.

Por otra parte, existen reportes de una correlación genética negativa entre CE y la edad al primer parto $(-0,35)$ de sus medio hermanas (Toelle y Robison, 1985). Esto permite seleccionar caracteres en las hembras a través de los machos lo cual facilita presionar la selección en los rodeos.

La circunferencia escrotal en las evaluaciones genéticas es evaluada como un único carácter en animales de un año de edad [Breedplan Angus Argentino (http://angusargentino.com/wp-content/uploads/2016/12/Midiendo-

Circunferencia-Escrotal-para-BREEDPLAN.pdf); BIF guidelines 2010], o a los 18 meses en la mayoría de las evaluaciones genéticas oficiales en Argentina (FAGB, 2010), ajustadas por edad a la medición como una covariable lineal.

El mejoramiento genético animal tiene como principal herramienta las evaluaciones genéticas, y los DEPs que con estas se estiman, siendo el principal efector del mejoramiento genético en los últimos 40 años, a partir de estos los animales con mayor mérito genético para las distintas características evaluadas son apareados, de modo de obtener una próxima generación superior que la progenitora. Por otra parte haciendo uso de las correlaciones genéticas pueden seleccionarse características que no son evaluadas directamente por la prueba.

En los rodeos bovinos la presión de selección que puede ejercerse en las hembras es mucho menor que en los machos (Schaeffer, 2006). Además, la reposición de hembras suele realizarse con hembras recriadas de propia producción, 
los machos en cambio suelen ser comprados a establecimientos especializados en la producción de toros. De tal manera que el mejoramiento genético que puede lograrse en rodeos comerciales a través de machos de compra evaluados para precocidad sexual es muy alto, y esta característica puede multiplicarse y seleccionarse en el propio establecimiento en las hembras de reposición.

Esto implica que a la hora de incorporar un reproductor debe pensarse no solo en los destetes que se obtendrán de los hijos de ese toro, sino también de los hijos de las hijas de ese toro, por lo que el impacto de la incorporación de un toro supera su vida útil, alcanzando a través de sus hijas muchos años más. Por esto, también debemos evaluar al toro como el padre de las hembras que formaran nuestro pie de cría, no solo como el padre de un producto que se transfiere al destete a otra explotación. Por otro lado, es en lo toros padres de toros donde más se ejerce intensidad de selección (Schaeffer 2006).

El objetivo del presente trabajo fue estimar los componentes de varianza para la edad al primer parto (EPP), fecha de primer parto (FPP) y de la circunferencia escrotal a los 300 (CE300), 400 (CE400) y 630 (CE630) días de edad, como también las relaciones genéticas entre estas características, en búsqueda de una alternativa para mejorar la eficiencia de las hembras a través de la selección de machos.

\subsection{MATERIALES Y MÉTODOS.}

\subsubsection{Manejo del rodeo}


Para este análisis se utilizaron los registros históricos de los animales nacidos entre los años 2004 y 2013 del establecimiento Flores Chicas, ubicado en el partido de Lobería (58 $28^{\prime}$ W; $38^{\circ} 06^{\prime}$ S), en el sudeste de la provincia de Buenos Aires. El programa de mejoramiento genético del establecimiento prioriza un biotipo Angus funcional de tamaño moderado, la fertilidad y la precocidad sexual desde el año 2002.

El servicio de los vientres adultos se realiza en los meses de noviembre, diciembre y enero, por lo que las pariciones ocurren entre los meses de agosto y octubre. Los terneros permanecen junto a sus madres hasta los 6 meses aproximadamente alternando pastizales naturales y pasturas templadas, para luego del destete pasar a una recría pastoril basada en el pastoreo directo de avena (Avena sativa) y rye grass (Lollium multiflorum).

El plan sanitario del rodeo incluye las vacunaciones contra fiebre aftosa, carbunclo bacteridiano, mancha y gangrena gaseosa y brucelosis en las hembras, sumado al uso de desparasitaciones estratégicas contra nematodos gastrointestinales.

Específicamente el programa de mejoramiento genético por precocidad sexual incluye mediciones de calidad seminal a partir de los 12 meses de edad, de modo de determinar los toritos más precoces dentro del grupo de contemporáneos. Las hembras por su parte inician su primer servicio a principios de septiembre con una edad promedio de 375 días, sin el uso de protocolos hormonales, con toros de su misma edad. Pasados los 60 días de finalizado el servicio, se realiza el diagnóstico de preñez por tacto rectal, descartando las hembras no gestantes. Una 
vez lograda la primera cría, las hembras reciben su próximo servicio entre los meses de noviembre y enero.

\subsubsection{Mediciones y armado de archivos de datos.}

Para la estimación de parámetros de varianza se definieron tres características de circunferencia escrotal según la edad de su medición: 1.Circunferencia escrotal a los 300 días (CE300): incluye las mediciones de CE realizadas entre los 250 y 349 días de edad; 2.- Circunferencia escrotal a los 400 días (CE400): registrando las mediciones de CE entre los 370 y 430 días de edad; 3.- Circunferencia escrotal a los 630 días (CE630): incluyendo las mediciones de CE realizadas entre los 580 y 679 días de edad. Cada registro de medición de CE incluyó el número de identificación del animal, el año de nacimiento, y la edad a la medición En caso de existir dos mediciones para un mismo animal en el intervalo evaluado, se conservó la más cercana a la edad de referencia.

En las hembras se registró el número de identificación de la vaquillona, el año de nacimiento, y se calculó la edad al primer parto (EPP), sustrayendo la fecha de nacimiento a la fecha de parto, y la fecha de primer parto (FPP) como la diferencia en días entre la fecha de parto de la primera vaquillona en la estación de partos, y la fecha de parto de vaquillona a evaluar.

Del total de registros obtenidos se eliminaron aquellos animales que no tuvieran registro de padres. Posteriormente se eliminaron aquellos registros que excedieran en más o menos los 3 desvíos estándar $( \pm 3 \mathrm{DE})$ respecto de la media para el grupo de contemporáneos, constituido por todos los animales nacidos en un 
mismo año. La normalidad de los datos dentro de los grupos de contemporáneos se confirmó a través de gráficos de densidad y Q-Q plot.

La base de datos para el análisis quedó conformada por 2.476 mediciones de CE300, 2.120 mediciones de CE400 y 2.066 mediciones de CE630, los registros de las hembras quedaron definidos por 2.463 registros de EPP y FPP. Para cada característica evaluada, los grupos de contemporáneos fueron definidos según el año de nacimiento. Complementariamente se conformó el pedigrí de los animales evaluados con los registros de identificación individual, padre y/o madre hasta 3 generaciones. La conformación de las bases de datos fue realizada utilizando el software Microsoft Access y R (R core Team).

\subsubsection{Análisis estadístico}

El análisis de datos se realizó ajustando un modelo animal multicaracter (Mrode, 2005) y los parámetros genéticos fueron estimados a través de un algoritmo de máxima verosimilitud restricta (REML, Searle y col., 2006), implementado a través del software AIREMLF90 del paquete BLUPF90 (Misztal y col., 2002). Las ecuaciones del modelo se presentan a continuación en notación matricial:

$$
\left[\begin{array}{c}
y_{E P P} \\
y_{C E 300} \\
y_{C E 400} \\
y_{C E 630}
\end{array}\right]=\left[\begin{array}{cccc}
X_{1} & 0 & 0 & 0 \\
0 & X_{2} & 0 & 0 \\
0 & 0 & X_{3} & 0 \\
0 & 0 & 0 & X_{4}
\end{array}\right]\left[\begin{array}{l}
b_{1} \\
b_{2} \\
b_{3} \\
b_{4}
\end{array}\right]+\left[\begin{array}{cccc}
z_{1} & 0 & 0 & 0 \\
0 & Z_{2} & 0 & 0 \\
0 & 0 & Z_{3} & 0 \\
0 & 0 & 0 & z_{4}
\end{array}\right]\left[\begin{array}{c}
a_{E P P} \\
a_{C E 300} \\
a_{C E 400} \\
a_{C E 630}
\end{array}\right]+\left[\begin{array}{l}
e_{1} \\
e_{2} \\
e_{3} \\
e_{4}
\end{array}\right],
$$

donde el vector $\boldsymbol{y}_{\boldsymbol{i}}$ contiene los registros para cada característica, $\boldsymbol{b}_{\boldsymbol{i}}(i$ asigna el conjunto \{EPP; CE300; CE400; CE630\}) es el vector de efectos fijos para la característica correspondiente, que incluye el año de nacimiento como grupo de contemporáneos (GC) y la edad a la medición de CE y solo el GC para las mediciones de EPP, $\boldsymbol{a}_{\boldsymbol{i}}$ es el vector de los valores de cría y $\boldsymbol{e}_{\boldsymbol{i}}$ es el vector de errores 
del modelo $i$. Las matrices $\boldsymbol{X}_{\boldsymbol{i}}$ y $\boldsymbol{Z}_{\boldsymbol{i}}$ contienen los efectos fijos y aleatorios del modelo respectivamente.

El modelo se complementa con la siguiente definición de la estructura de covarianza para los efectos aleatorios:

$$
\operatorname{Cov}\left[\begin{array}{c}
a_{E P P} \\
a_{C E 300} \\
a_{C E 400} \\
a_{C E 630}
\end{array}\right]=G_{0} \otimes A
$$

donde $\mathbf{G}_{0}$ es la matriz de covarianza genética aditiva,

$$
\mathbf{G}_{0}=\left[\begin{array}{cccc}
\sigma_{a E P P}^{2} & \sigma_{E P P, C E 300} & \sigma_{E P P, C E 400} & \sigma_{E P P, C E 630} \\
& \sigma_{a C E 300}^{2} & \sigma_{C E 300, C E 400} & \sigma_{C E 300, C E 630} \\
& & \sigma_{a C E 400}^{2} & \sigma_{C E 400, C E 630} \\
s y m & & & \sigma_{a C E 630}^{2}
\end{array}\right],
$$

A es el numerador de la matriz de relaciones de parentesco y $\bigotimes$ es el operador de kronecker. A su vez,

$$
\operatorname{Cov}\left[\begin{array}{l}
e_{1} \\
e_{2} \\
e_{3} \\
e_{4}
\end{array}\right]=\left[\begin{array}{cc}
\sigma_{e 1}^{2} I & \mathbf{0} \\
\mathbf{0} & \mathbf{R}_{0} \otimes I
\end{array}\right]
$$

Donde $\mathbf{R}_{0}$ es

$$
\mathbf{R}_{0}=\left[\begin{array}{ccc}
\sigma_{e 2}^{2} & \sigma_{e_{2}, e_{3}} & \sigma_{e_{2}, e_{4}} \\
& \sigma_{e 3}^{2} & \sigma_{e_{3}, e_{4}} \\
s y m & & \sigma_{e 4}^{2}
\end{array}\right] .
$$

aquí, la diagonal corresponde a la varianza del error para CE y fuera de la diagonal a la covarianza del error entre las mediciones de CE. Esta estructura particular de la covarianza del error se origina en que EPP solo es medida en las hembras, por lo 
tanto, no hay covarianza del error entre CE y EPP (Schaeffer y col., 1978). La notación $\mathbf{R}_{0} \otimes \boldsymbol{I}$ es una simplificación que simplifica el entendimiento de la estructura de covarianza del error del modelo, estrictamente esta notación aplica solo si los toros son evaluados para todas las características.

Un segundo modelo fue ajustado reemplazando EPP por FPP.

La correlación genética entre caracteres fue calculada como:

$$
r_{G(i, j)}=\frac{\hat{\sigma}_{i, j}}{\sqrt{\hat{\sigma}_{a i}^{2} \times \hat{\sigma}_{a j}^{2}}}
$$

donde $r_{G(i, j)}$ es la covarianza genética entre la característica i y la característica j, $\hat{\sigma}_{i, j}$ es la covarianza aditiva entre ellas $\mathrm{y}, \hat{\sigma}_{a i}^{2} \mathrm{y} \hat{\sigma}_{a j}^{2}$ son las varianzas aditivas para una y otra característica.

Las heredabilidades fueron calculadas como el cociente entre la varianza genética aditiva y la varianza fenotípica. Los errores estándar asintóticos para las estimaciones se obtuvieron a través del mismo análisis a través del software (Misztal y col., 2002).

Finalmente se obtuvieron los valores de cría para todos los animales evaluados para cada característica, y se calculó la precisión de la estimación a través del error de predicción a través de la siguiente ecuación:

$$
\operatorname{Prec}_{i, j}=\sqrt{1-\frac{e_{i, j}^{2}}{\hat{\sigma}_{a i}^{2}}}
$$


donde $\operatorname{Prec}_{i, j}$ es la precisión de la estimación de la característica $i$ para el animal $j, e_{i, j}$ es el desvío del valor de cría estimado para la característica $i$, en el animal $j$, y $\hat{\sigma}_{a i}^{2}$ es la varianza aditiva para la característica $i$.

Los toros fueron rankeados según sus valores de cría y luego se calcularon las correlaciones de Spearman entre los rankings de toros utilizando el software R, como el coeficiente de correlación de Pearson entre variables ordenadas, donde los valores de cría $X_{i}, Y_{i}$ son transformados a su valor de posición ordenada $\operatorname{rg} X_{i}, \operatorname{rg} Y_{i}$ y su correlación $r_{s}$ fue calculada como:

$$
r_{s}=\rho_{r g_{x}, r g_{y}}=\frac{\operatorname{cov}\left(r g_{x}, r g_{y}\right)}{\sigma_{r g_{x}} \sigma_{r g_{y}}}
$$

donde $\rho$ es el coeficiente de correlación de Pearson aplicado a variables de orden, $\operatorname{cov}\left(r g_{x}, r g_{y}\right)$ es la covarianza de las variables ordenadas y $\sigma_{r g_{x}} \sigma_{r g_{y}}$ son los desvíos estándar de las variables ordenadas.

\subsection{RESULTADOS}

La distribución de la totalidad de registros de circunferencia escrotal realizadas en el establecimiento muestra 3 momentos de muestreo bastante diferenciados. El primero de ellos situado entre los 200 y los 380 días de edad aproximadamente, un segundo momento de muestreo entre los 400 y 500 días de edad, y un tercer muestreo a partir de los 600 días, lo que determinó las edades de muestreo consideradas en el análisis (Figura 4.1).

La cantidad de mediciones utilizadas en el análisis muestran una variabilidad entre diferentes años de muestreo, como así también entre las características para un mismo grupo de año de nacimiento (Tabla 4.1; Figura 4.2). 
Tabla 4.1. Medias fenotípicas para las características evaluadas en machos y hembras

\begin{tabular}{|c|c|c|c|c|c|c|c|c|c|}
\hline \multirow[t]{2}{*}{$\mathrm{GC}$} & \multicolumn{3}{|c|}{ CE300 } & \multicolumn{3}{|c|}{ CE400 } & \multicolumn{3}{|c|}{ CE360 } \\
\hline & $\mathrm{n}$ & $\mathrm{CE}$ & Edad & $\mathrm{n}$ & $\mathrm{CE}$ & Edad & $\mathrm{n}$ & $\mathrm{CE}$ & Edad \\
\hline 2004 & 214 & $25,95 \pm 1,99$ & $282,15 \pm 19,43$ & 108 & $32,19 \pm 2,64$ & $406,03 \pm 18,92$ & 11 & $38,14 \pm 1,82$ & $669,82 \pm 10,44$ \\
\hline 2005 & 212 & $26,45 \pm 3,23$ & $284,36 \pm 36,66$ & 241 & $32,61 \pm 2,24$ & $396,51 \pm 13,06$ & 221 & $36,27 \pm 2,17$ & $616,00 \pm 17,82$ \\
\hline 2006 & 334 & $27,08 \pm 2,23$ & $284,36 \pm 19,84$ & 46 & $33,15 \pm 3,57$ & $415,87 \pm 14,99$ & 233 & $36,14 \pm 1,95$ & $650,39 \pm 23,86$ \\
\hline 2007 & 239 & $26,66 \pm 2,70$ & $285,95 \pm 33,71$ & 105 & $32,49 \pm 1,90$ & $415,24 \pm 10,03$ & 258 & $35,57 \pm 1,98$ & $612,35 \pm 14,38$ \\
\hline 2008 & 304 & $27,74 \pm 2,90$ & $286,21 \pm 26,08$ & 189 & $33,29 \pm 2,28$ & $412,46 \pm 13,20$ & 219 & $37,55 \pm 1,98$ & $630,65 \pm 24,32$ \\
\hline 2009 & 205 & $27,24 \pm 2,35$ & $272,82 \pm 18,23$ & 296 & $32,62 \pm 2,27$ & $400,81 \pm 14,95$ & 230 & $38,49 \pm 2,30$ & $632,49 \pm 17,79$ \\
\hline 2010 & 332 & $27,29 \pm 2,52$ & $281,69 \pm 28,83$ & 259 & $34,26 \pm 2,21$ & $389,38 \pm 12,52$ & 198 & $37,24 \pm 2,05$ & $606,87 \pm 23,94$ \\
\hline 2011 & 177 & $25,87 \pm 2,28$ & $276,36 \pm 27,10$ & 279 & $32,37 \pm 2,14$ & $396,38 \pm 14,08$ & 291 & $36,22 \pm 2,13$ & $615,37 \pm 21,96$ \\
\hline 2012 & 186 & $25,50 \pm 2,22$ & $272,12 \pm 23,83$ & 241 & $32,44 \pm 2,04$ & $409,00 \pm 14,77$ & 218 & $37,64 \pm 1,93$ & $658,03 \pm 15,77$ \\
\hline 2013 & 364 & $25,41 \pm 2,12$ & $273,48 \pm 19,51$ & 356 & $32,02 \pm 2,09$ & $405,34 \pm 13,39$ & 187 & $35,56 \pm 2,02$ & $598,58 \pm 17,68$ \\
\hline Total & 2476 & $26,58 \pm 2,57$ & $280,13 \pm 25,66$ & 2120 & $32,71 \pm 2,32$ & $402,38 \pm 15,86$ & 2066 & $36,72 \pm 2,27$ & $624,99 \pm 27,21$ \\
\hline
\end{tabular}

\begin{tabular}{cccccc}
\hline \multirow{2}{*}{ GC } & \multicolumn{3}{c}{ EPP } & & \multicolumn{2}{c}{ FPP } \\
\cline { 2 - 3 } \cline { 5 - 6 } & $\mathrm{n}$ & EPP & & $\mathrm{n}$ & FPP \\
\hline 2004 & 184 & $698,05 \pm 34,45$ & & 184 & $29,59 \pm 19,87$ \\
2005 & 179 & $674,10 \pm 20,56$ & & 179 & $37,29 \pm 20,63$ \\
2006 & 288 & $685,92 \pm 30,17$ & & 288 & $33,16 \pm 14,37$ \\
2007 & 90 & $684,37 \pm 19,13$ & & 90 & $24,31 \pm 20,21$ \\
2008 & 319 & $696,95 \pm 30,36$ & & 319 & $34,70 \pm 19,16$ \\
2009 & 288 & $695,76 \pm 30,11$ & & 288 & $40,60 \pm 25,80$ \\
2010 & 255 & $690,30 \pm 31,73$ & & 255 & $21,81 \pm 17,10$ \\
2011 & 263 & $696,71 \pm 29,43$ & & 263 & $25,13 \pm 18,19$ \\
2012 & 276 & $698,46 \pm 28,96$ & & 276 & $34,28 \pm 16,51$ \\
2013 & 321 & $706,17 \pm 26,44$ & & 321 & $37,77 \pm 18,85$ \\
\hline Total & 2463 & $694,14 \pm 30,16$ & & 2463 & $32,63 \pm 20,01$ \\
\hline
\end{tabular}


Figura 4.1. Mediciones y edad a la medición de la circunferencia escrotal en el establecimiento

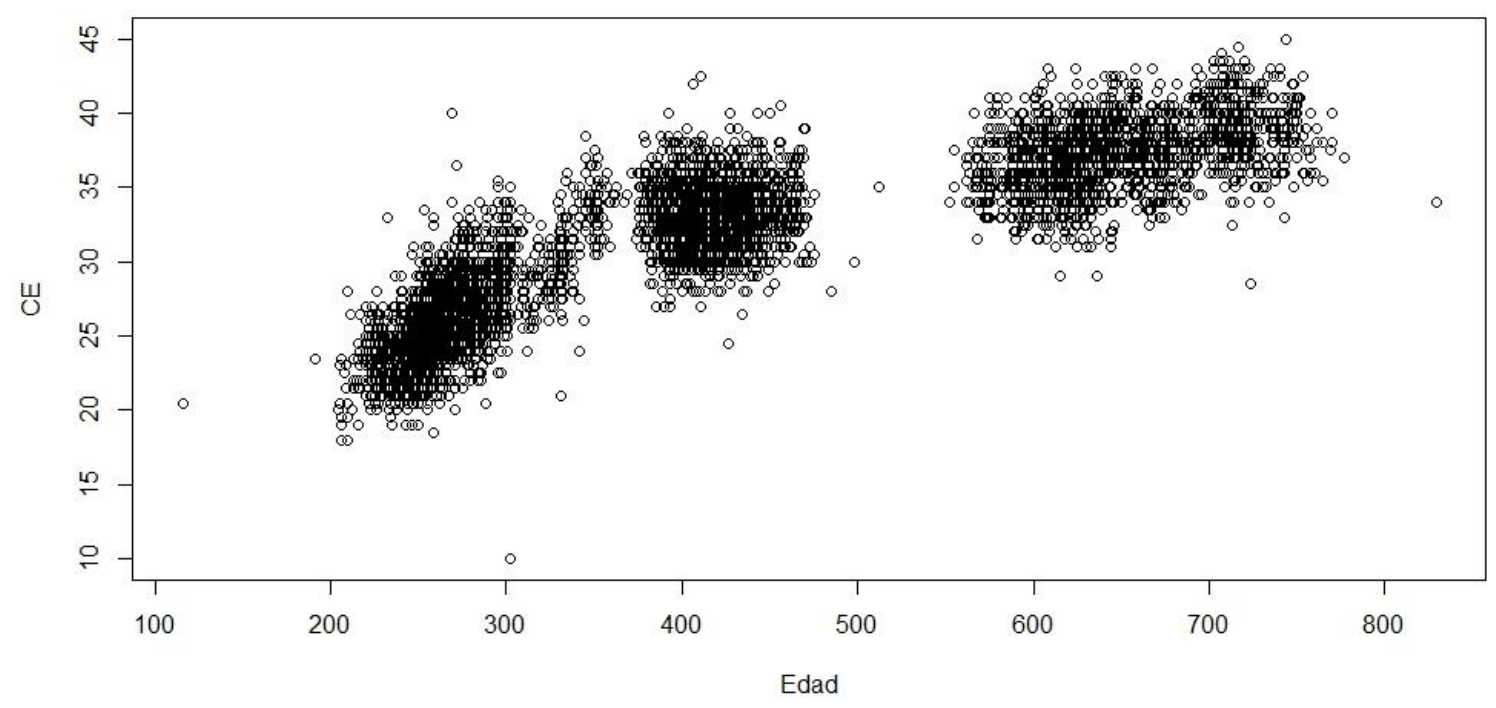

Esto responde a la cantidad de toros que son recriados en diferentes años y a que el momento de los muestreos puede sufrir variaciones entre años, determinando que en algunos momentos (como en el caso de CE630 para el año 2004, o de CE400 para el año 2006) no se disponga de un gran número de mediciones. Por otro lado, pasados los 700 días los animales comienzan a ser comercializados, lo que determina que no existan registros de mediciones posteriores.

Todos los caracteres evaluados demostraron tener variabilidad genética y $\mathrm{h}^{2}$ suficiente (Tabla 4.2; Tabla 4.3) como para responder en programas de selección. La CE400 fue la que presentó mayor $\mathrm{h}^{2}$ (de alrededor del 70\%), siendo esta característica, además, la que mayor variabilidad fenotípica presenta de las CE evaluadas. 
Figura 4.2. Gráficos de caja y bigotes describiendo las medidas de circunferencia escrotal ajustada por edad (encima) y los registros de parto de las hembras (debajo) en los distintos grupos de contemporáneos.
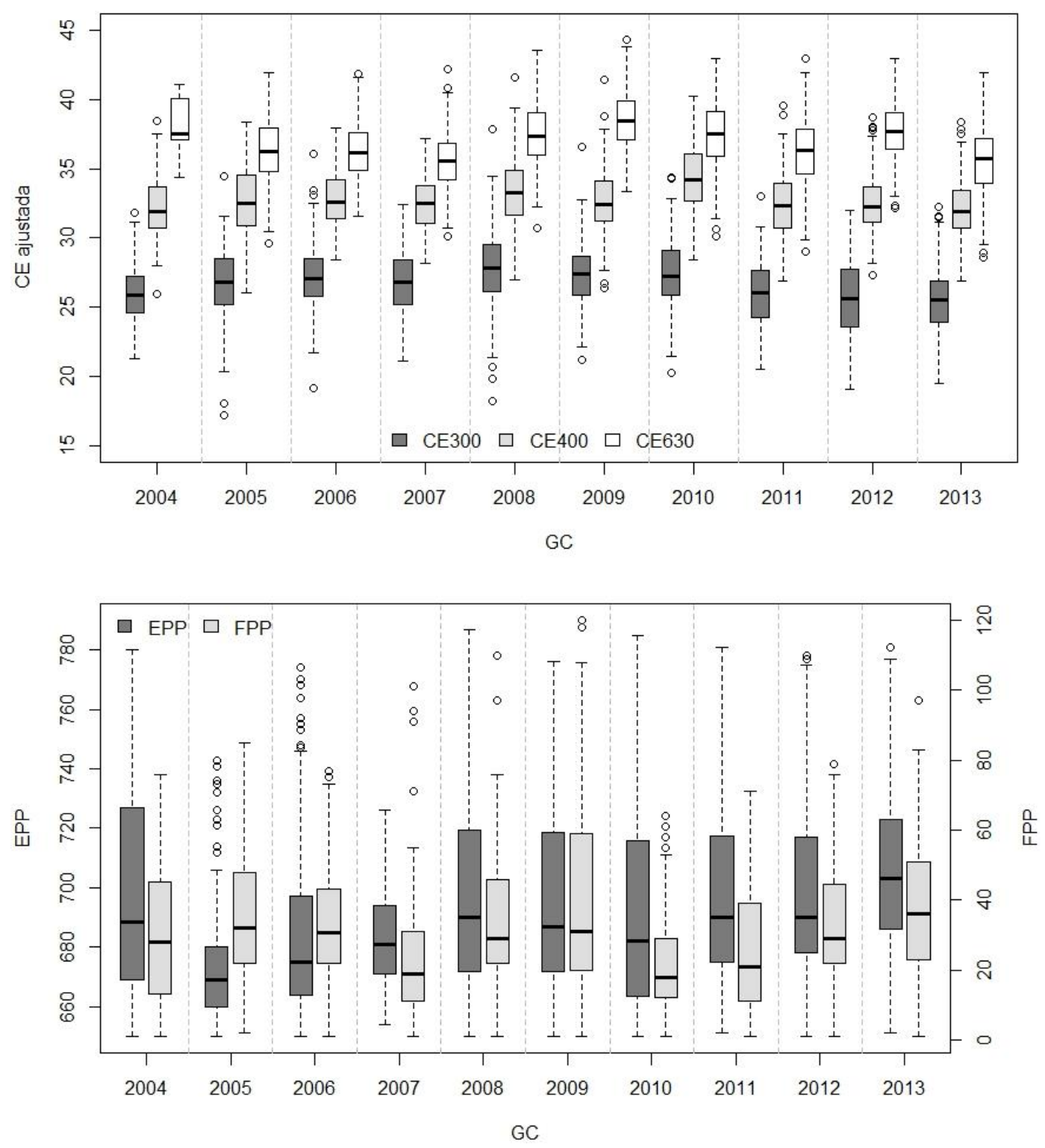

Referencias: CE300: Circunferencia escrotal a los 300 días de edad; CE400: Circunferencia escrotal ajustada a los 400 días de edad; CE630: Circunferencia escrotal ajustada a los 630 días de edad; EPP: edad al primer parto; FPP: fecha de primer parto; GC: Grupo de contemporáneos.

Las correlaciones genéticas por su parte resultaron negativas entre las mediciones de precocidad en la hembra y la CE evaluada en todas las edades, con una correlación más importante con la $\mathrm{CE}$ evaluada más tempranamente, y 
diluyéndose a medida que la evaluación de la CE es más tardía (Tabla 4.3). Si bien ambas características de precocidad en la hembra muestran un comportamiento similar, EPP tiene un componente genético más importante, demostrando una mayor $\mathrm{h}^{2}$ y correlaciones genéticas más favorables con las medidas evaluadas en los machos.

Por su parte las correlaciones genéticas entre las mediciones de CE resultaron altas, con valores superiores para mediciones más cercanas entre sí. A medida que las mediciones son más tardías, las CE se correlacionan más aun, posiblemente por el menor impacto de la edad a medida que la curva de crecimiento testicular se acerca a su fase asintótica (Tabla 4.3).

Tabla 4.2. Descomposición de la varianza total para Edad al primer parto (EPP), fecha de primer parto (FPP) y Circunferencia escrotal (CE) a los 300, 400 y 630 días de edad.

\begin{tabular}{ccc}
\hline & $\sigma_{a}^{2} \pm \mathrm{SD}$ & $\sigma_{e}^{2} \pm \mathrm{SD}$ \\
\hline EPP & $316,53 \pm 46,64$ & $536,15 \pm 41,623$ \\
DAP & $71,36 \pm 19,12$ & $299,78 \pm 18,10$ \\
CE300 & $1,994 \pm 0,342$ & $2,649 \pm 0,288$ \\
CE400 & $3,416 \pm 0,423$ & $1,436 \pm 0,337$ \\
CE630 & $2,560 \pm 0,384$ & $1,886 \pm 0,318$ \\
\hline
\end{tabular}


Tabla 4.3. Correlaciones genéticas (encima de la diagonal), fenotípicas (debajo de la diagonal) y heredabilidad (en la diagonal principal) para para Edad al primer parto (EPP; A), fecha de primer parto (FPP; B) y Circunferencia escrotal (CE) a los 300, 400 y 630 días de edad.

\begin{tabular}{ccccc}
\hline $\mathbf{A}$ & EPP & CE300 & CE400 & CE630 \\
\hline EPP & $\mathbf{0 , 3 7 1} \pm \mathbf{0 , 0 5}$ & $-0,478 \pm 0,13$ & $-0,244 \pm 0,11$ & $-0,152 \pm 0,12$ \\
CE300 & $-0,191 \pm 0,14$ & $\mathbf{0 , 4 2 9} \pm \mathbf{0 , 0 7}$ & $0,770 \pm 0,07$ & $0,737 \pm 0,08$ \\
CE400 & $-0,125 \pm 0,13$ & $0,524 \pm 0,09$ & $\mathbf{0 , 7 0 4} \pm \mathbf{0 , 0 7}$ & $0,983 \pm 0,02$ \\
CE630 & $-0,070 \pm 0,15$ & $0,466 \pm 0,08$ & $0,726 \pm 0,05$ & $\mathbf{0 , 5 7 6} \pm \mathbf{0 , 0 8}$ \\
\hline & & & & \\
\hline B & FPP & CE300 & CE400 & CE630 \\
\hline FPP & $\mathbf{0 , 1 9 2} \pm \mathbf{0 , 0 5}$ & $-0,331 \pm 0,16$ & $-0,258 \pm 0,14$ & $-0,128 \pm 0,16$ \\
CE300 & $-0,099 \pm 0,12$ & $\mathbf{0 , 4 7 2} \pm \mathbf{0 , 0 5}$ & $0,759 \pm 0,07$ & $0,725 \pm 0,08$ \\
CE400 & $-0,095 \pm 0,11$ & $0,524 \pm 0,08$ & $\mathbf{0 , 7 1 3} \pm \mathbf{0 , 0 7}$ & $0,980 \pm 0,02$ \\
CE630 & $-0,102 \pm 0,13$ & $0,467 \pm 0,09$ & $0,726 \pm 0,05$ & $\mathbf{0 , 5 8 2} \pm \mathbf{0 , 0 8}$ \\
\hline
\end{tabular}

Las correlaciones fenotípicas por su parte son considerablemente menores, de manera que el papel del componente ambiental no sería tan importante como la relación genética entre estas características.

Las soluciones para los efectos fijos del BLUP Modelo Animal, muestran una gran homogeneidad de los grupos de contemporáneos para todas las características. Además, puede observarse que el efecto de la edad sobre la circunferencia escrotal disminuye a medida que la medición es más tardía (Tabla 4.4). 
Tabla 4.4. Soluciones de los efectos fijos para cada una de las estimaciones de los valores de cría para edad al primer parto (EPP), fecha de primer parto (FPP) y Circunferencia escrotal (CE) a los 300, 400 y 630 días de edad.

\begin{tabular}{|c|c|c|c|c|c|c|}
\hline & Efecto & EPP & FPP & CE300 & CE400 & CE630 \\
\hline \multirow{11}{*}{$\mathrm{GC}$} & 2004 & $701,80 \pm 2,10$ & $29,43 \pm 2,10$ & $11,14 \pm 0,55$ & $19,83 \pm 1,54$ & $31,65 \pm 1,60$ \\
\hline & 2005 & $683,35 \pm 2,34$ & $40,55 \pm 2,33$ & $11,70 \pm 0,58$ & $20,42 \pm 1,47$ & $30,61 \pm 1,57$ \\
\hline & 2006 & $692,16 \pm 1,74$ & $33,48 \pm 1,74$ & $12,23 \pm 0,55$ & $20,59 \pm 1,59$ & $30,14 \pm 1,65$ \\
\hline & 2007 & $692,15 \pm 2,90$ & $25,67 \pm 2,90$ & $11,69 \pm 0,57$ & $19,83 \pm 1,56$ & $29,95 \pm 1,56$ \\
\hline & 2008 & $704,43 \pm 1,71$ & $35,77 \pm 1,71$ & $12,67 \pm 0,55$ & $20,42 \pm 1,54$ & $31,41 \pm 1,60$ \\
\hline & 2009 & $701,31 \pm 2,04$ & $40,57 \pm 2,04$ & $12,75 \pm 0,54$ & $20,21 \pm 1,48$ & $32,40 \pm 1,61$ \\
\hline & 2010 & $698,06 \pm 1,92$ & $23,99 \pm 1,92$ & $12,40 \pm 0,55$ & $22,09 \pm 1,44$ & $31,43 \pm 1,55$ \\
\hline & 2011 & $703,56 \pm 1,82$ & $26,99 \pm 1,82$ & $11,24 \pm 0,55$ & $20,10 \pm 1,47$ & $30,49 \pm 1,57$ \\
\hline & 2012 & $708,11 \pm 1,99$ & $36,50 \pm 1,99$ & $11,20 \pm 0,56$ & $19,76 \pm 1,51$ & $31,36 \pm 1,68$ \\
\hline & 2013 & $718,05 \pm 2,10$ & $38,78 \pm 2,10$ & $10,68 \pm 0,55$ & $19,04 \pm 1,49$ & $30,05 \pm 1,53$ \\
\hline & Edad & --- & --- & $0,052 \pm 0,002$ & $0,031 \pm 0,003$ & $0,009 \pm 0,002$ \\
\hline
\end{tabular}

Los rankings de toros realizados con sus valores de cría para cada una de las características evaluadas (Tabla 4.5) muestran una correlación negativa entre los rankings para CE y la EPP, con excepción de CE630 quien no mostró una correlación entre los rankings de toros para una y otra característica (Tabla 4.6). Si bien estas correlaciones resultaron menores de los esperado constituyen una herramienta de selección útil para los productores, respaldado por las correlaciones genéticas entre los caracteres. 
Tabla 4.5. Extracto del ranking de toros para las características evaluadas.

\begin{tabular}{|c|c|c|c|c|c|c|c|c|c|c|}
\hline \multirow{2}{*}{ Toro } & \multicolumn{2}{|c|}{ CE300 } & \multicolumn{2}{|c|}{ CE400 } & \multicolumn{2}{|c|}{ CE630 } & \multicolumn{2}{|c|}{ EPP } & \multicolumn{2}{|c|}{ FPP } \\
\hline & $\mathrm{VC}$ & Ord & $\mathrm{VC}$ & Ord & $\mathrm{VC}$ & Ord & $\mathrm{VC}$ & Ord & $\mathrm{VC}$ & Ord \\
\hline 1 & 0.01 & 12 & -1.54 & 15 & -1.19 & 14 & -25.17 & 8 & -1.88 & 10 \\
\hline 2 & 0.23 & 11 & 1.41 & 4 & 0.42 & 7 & -20.24 & 12 & 0.08 & 13 \\
\hline 3 & 0.79 & 9 & 0.70 & 5 & 0.07 & 10 & -15.32 & 14 & 0.26 & 14 \\
\hline 4 & -0.02 & 13 & -0.21 & 13 & -0.09 & 11 & -29.37 & 4 & -7.57 & 4 \\
\hline 5 & -0.38 & 15 & -0.15 & 12 & 0.23 & 9 & -6.55 & 15 & -0.95 & 12 \\
\hline 6 & -0.24 & 14 & 0.40 & 7 & 0.81 & 4 & -20.98 & 11 & 6.62 & 15 \\
\hline 7 & 1.53 & 5 & 0.68 & 6 & 0.71 & 5 & -39.05 & 1 & -6.89 & 5 \\
\hline 8 & 1.96 & 2 & 2.12 & 3 & 2.48 & 2 & -21.14 & 10 & -5.79 & 6 \\
\hline 9 & 0.32 & 10 & -0.54 & 14 & -0.60 & 13 & -26.68 & 6 & -4.14 & 7 \\
\hline 10 & 1.73 & 3 & 2.44 & 2 & 0.99 & 3 & -20.13 & 13 & -2.75 & 9 \\
\hline 11 & 2.01 & 1 & 0.07 & 9 & 0.57 & 6 & -24.41 & 9 & -3.30 & 8 \\
\hline 12 & 1.19 & 6 & 2.46 & 1 & 2.57 & 1 & -26.26 & 7 & -9.57 & 2 \\
\hline 13 & 1.69 & 4 & 0.16 & 8 & -0.58 & 12 & -27.20 & 5 & -1.51 & 11 \\
\hline 14 & 0.95 & 8 & 0.02 & 10 & -1.59 & 15 & -33.03 & 3 & -15.24 & 1 \\
\hline 15 & 1.06 & 7 & -0.05 & 11 & 0.33 & 8 & -33.66 & 2 & -8.81 & 3 \\
\hline
\end{tabular}

Nota: Se seleccionaron 15 toros con una precisión por encima de 0,6 para todas las características.

Referencias: CE300: Circunferencia escrotal a los 300 días de edad; CE400:

Circunferencia escrotal a los 400 días de edad; CE630: Circunferencia escrotal a los 630 días de edad; EPP: edad al primer parto; FPP: Fecha de primer parto

Las correlaciones de Spearman para los rankings de toros para las características de CE mostraron correlaciones positivas entre ellas, con valores más altos para medidas próximas entre sí, que con medidas más alejadas (Tabla 4.6). En cuanto a la precisión de las estimaciones para CE630 un 99\% y un $41,5 \%$ estuvieron por encima de 0,6 y 0,9 respectivamente, cuando el resto de las predicciones mostraron precisiones más bajas, siendo $40,7 \%$ y $79,3 \%$ de las predicciones de CE300 y CE400 con precisiones por encima de 0,6 , y 20,8\% y $56,6 \%$ por encima de 0,9 . 
Tabla 4.6. Correlaciones de orden entre los rankings de toros para edad al primer parto (EPP), fecha de primer parto (FPP) y Circunferencia escrotal (CE) a los 300, 400 y 630 días de edad.

\begin{tabular}{cccccc}
\hline & EPP & FPP & CE300 & CE400 & CE630 \\
\hline EPP & --- & 0,3867 & $-0,2428$ & $-0,1091$ & $-0,0282$ \\
FPP & $<0,0001$ & --- & $-0,1370$ & $-0,0734$ & 0,0171 \\
CE300 & $<0,0001$ & $<0,0001$ & --- & 0,4175 & 0,2911 \\
CE400 & $<0,0001$ & $<0,05$ & $<0,0001$ & --- & 0,5215 \\
CE630 & 0,1 & NS & $<0,0001$ & $<0,0001$ & ---
\end{tabular}

Nota: Las correlaciones se muestran por encima de la diagonal, por debajo de la diagonal se encuentran los p-valores para cada correlación.

\subsection{DISCUSIÓN}

En este estudio se estimaron conjuntamente los parámetros genéticos para EPP y FPP, como estimadores de la precocidad sexual en hembras y la circunferencia escrotal medida a diferentes edades, utilizando un modelo multi característica. La idea original que sustenta este trabajo es que mediciones de $\mathrm{CE}$ más tempranas, cuando los testículos comienzan a crecer exponencialmente, logran capturar mejor el mérito genético de la precocidad sexual en los toros. Esto refleja el control genético sobre el inicio temprano de la señalización endocrina que desencadena la función reproductiva y análogamente impacta también en la precocidad de las hembras. Si bien esto no está siendo testeado como una hipótesis de trabajo, ya que no se está determinando directamente. En cambio, se intenta sostener esta idea a través de inferencia mediante correlaciones genéticas. De hecho, se utilizan EPP y FPP en las hembras y CE en machos a diferentes edades como estimadores de la precocidad sexual. Este concepto puede ser muy importante 
por la implicancia del momento de medición de la CE en las evaluaciones genéticas bovinas.

La edad al primer parto es una característica económicamente relevante, generalmente presenta heredabilidades más altas que otras características indicativas de fertilidad en las hembras (Cammack y col, 2009). La heredabilidad reportada en esta tesis para EPP es similar a la reportada por Borman y Wilson (2010), pero mayor a otros reportes (Gutierrez y col., 2002; Martinez-Velazquez y col., 2003). Las heredabilidades reportadas para FPP en este trabajo resultaron mayores que las informadas en razas británicas (Meyer y col., 1990; Johnston y Bunter, 1996) e índicas (Meyer y col., 1990; Forni y Albuquerque, 2005). En este sentido la heredabilidad es un parámetro poblacional y su estimación varía entre estudios, tanto como la población utilizada para su determinación. El manejo más homogéneo, puede inducir a una disminución de las varianzas ambientales y por lo tanto a aumentar las heredabilidades (Bourdon, 2000).

Sin embargo, tal como otras características reproductivas en las hembras EPP y FPP son difíciles de manejar en las evaluaciones genéticas (Rust y Groenveld, 2001). Generalmente, al inicio del servicio la mayoría de las vaquillonas deberían estar ciclando (BIF, 2010, p. 86), por lo que resulta complicado determinar diferencias en la precocidad de las hembras. Además, como las vaquillonas presentan mayor fertilidad que las vacas multíparas, esta categoría suele ser incluida en programas de IATF. En ese caso, el protocolo de sincronización de celos induce ciclicidad en vaquillonas que naturalmente tardarían más en preñarse (Short y col., 1976; Lucy y col., 2001), generando un dato erróneo. 
Un aspecto a destacar de los datos utilizados en este análisis, radica en que los registros de las hembras provienen vaquillonas que inician la temporada de servicios con 375 días en promedio por servicio natural. Este manejo diferencial genera que la medicion de EPP y FPP reflejen mas certeramente al arribo a la pubertad de las hembras en el momento en que las mismas se preñan.

Tanto EPP como FPP obligan a manejar las hembras no paridas, una de las formas de hacerlo consiste en excluir a las mismas del análisis (Forni y Albuquerque, 2005). En caso de incluirlas puede asignarse un valor fijo de penalización (Johnston y Bunter, 1996), asumir una distribución normal truncada y modelar aleatoriamente la censura para asignar un registro a las mismas o bien ajustar un modelo lineal con umbrales incluyendo el evento parto como característica binaria (Urioste y col., 2007). Estas correcciones contribuirían a no sobreestimar o subestimar parámetros.

En este trabajo las hembras no paridas no fueron tenidas en cuenta ya que no se disponía de información sobre las hembras que iniciaron el servicio cada año. Según los resultados de Forni y Albuquerque (2005), la incorporación de las hembras no paridas no mejora la identificación de diferencias genéticas entre animales.

En las evaluaciones genéticas la CE suele utilizarse tambien como una forma de seleccionar hembras mas precoces. En este trabajo CE400 presento mayor heredabilidad que la CE medida a otras edades (Tabala 4.3), resultados similares fueron reportados por Corbet y col (2013), mientras que CE300 y CE630 presentan heredabilidades mas proximas a 0,5 . Estos resultados difieren con los resultados de 
Morris y col. (1992), quien describe una reducción de la heredabilidad a medida que la CE es medida mas tardiamente entre los 8 y 11 meses.

Las correlaciones geneticas entre EPP/FPP y CE resultaron negativas en todos los casos y mayores cuando la CE es medida mas tempranamente. Ademas las correlaciones de los ranking de toros muestran la misma relación. Estos resultados soportan la idea original de qué mediciones tempranas de la CE reflejan mejor la precocidad sexual. Sin embargo basados en las correlaciones de los ranking de toros, los mejores toros para mejorar la $\mathrm{CE}$ a edades tempranas no son los que tienen mayor merito genetico para EPP. Las correlaciones aquí reportadas difieren de publicadas en el trabajo referido previamente (Morris y col., 1992), quienes reportan un aumento de la correlación genética entre la edad al primer celo y la CE cuando esta es medida mas tardíamente a los 8, 11 y 13 meses. Las diferencias en los resultados pueden basarse en las poblaciones utilizadas, los datos de precocidad de las hembras utilizados y el modelo de analisis por lo que la comparación es dificil. Sin duda es importante realizar investigaciones con un diseño experimental adecuado para comprender los mecanismos que subyacen a estas relaciones genéticas.

Basados en los resultados de este trabajo, la edad en la que se mide la CE es un aspecto importante para tener en cuenta cuando se busca el mejoramiento de la precocidad sexual, tanto en los machos, donde altas CE a edades tempranas son un indicador de la pubertad (Lunstra y col., 1978) como en las hembras, a partir de la relacion entre los mecanismos fisiologicos en ambos sexos. En este punto vale reforzar que el manejo del rodeo genera un dato de EPP que esta mucho mas relacionado con la edad a la pubertad respecto a la mayoria de los establecimientos 
comerciales, de manera que el refleja mucho mejor la asociación genetica entre la precocidad sexual del macho y de la hembra.

En Argentina ninguna de las evaluaciones genéticas disponibles incluye características de precocidad sexual en las hembras, y la mayoría evalúa al CE a los 18 meses de edad, de manera que la precisión con la que los rodeos de hembras son seleccionados es relativamente baja. La incorporación de una medición de CE más temprana permitiría implementar una nueva herramienta para seleccionar vaquillonas que se preñen más tempranamente, sin mayores problemas, ya que es una característica que las cabañas acostumbran medir, y no suele presentar mayores problemas de estimación de valores de cría. La incorporación de mediciones directamente sobre la hembra, tal como EPP, mejorarían la precisión de la selección, pero implica definir una estrategia sobre el registro y la denuncia de los datos para lograr una estimación precisa. Estas herramientas sumadas a una correcta recría y mediciones del GDR permitirían mejorar la eficiencia de las vaquillonas y de los rodeos de hembras, aumentando la productividad de los sistemas.

\subsection{CONCLUSIONES}

La incorporación de características que permitan seleccionar hembras más precoces en las evaluaciones genéticas constituye una herramienta importante para mejorar la rentabilidad de los sistemas de cría. Actualmente sólo se dispone de mediciones de CE a los 15 o 18 meses según la evaluación, la cual presenta una correlación baja con la precocidad sexual en la hembra La incorporación de una medición más temprana de la CE permitiría mejorar la precisión de los programas 
de mejoramiento de la característica tanto en machos como en hembras, a través de su correlación genética. Además, EPP es de fácil registro y presenta una heredabilidad que permitiría una adecuada respuesta, facilitando la selección de machos con el objetivo de mejorar la precocidad sexual de los planteles de hembras. 


\section{CAPITULO V}

\section{CONCLUSIONES GENERALES}

La planificación nutricional de las recrías pastoriles para entore a de vaquillonas a 15 meses es un punto de inflexión en la eficiencia reproductiva de la hembra en su primer servicio. Según los resultados expuestos en el capítulo 2 de esta tesis la limitación del crecimiento durante el inicio de la recría y una restricción puntual y durante un corto período alrededor de los 360 días pudieron haber demorado el arribo a la pubertad de las vaquillonas. Además, se observó que ADP de 0,75 ó 0,65 en las etapas pre y post destete son fueron condición suficiente para alcanzar la pubertad durante la recría siempre que el ADP mínimo en el periodo no evaluado este por encima de $0,4 \mathrm{~kg} / \mathrm{d}$ y que un umbral del $65 \%$ del peso vivo adulto determinó la ciclicidad del 90\% de las hembras.

Por otra parte, se evidencia la mayor potencia de los modelos de análisis longitudinales de datos respecto a los análisis transversales para trabajar con medidas repetidas en un bajo número de animales.

En el capítulo 3 de este trabajo se evaluó el efecto de dos marcadores genéticos en el riesgo de pubertad: IGF1-SnaBI y GnRHR-SNP6, mediante el uso de modelos de supervivencia. La primera diferencia respecto al enfoque tradicional de asociación con marcadores genéticos a través de modelos de efectos mixtos radica en la posibilidad de trabajar con datos que tienen censura en sus registros, logrando incorporar información que de otra manera hubiese sido descartada. Mediante esta modalidad de análisis se encontró un riesgo de pubertad de más del doble $(2,129)$ para el genotipo TT del marcador IGF1-SnaBI respecto al genotipo 
$\mathrm{CC}$, estas diferencias se volvieron no significativas al incorporar el rodeo al análisis. Este nuevo resultado puede estar originado en la diferencia en el crecimiento durante la recría, donde se observa que las curvas de crecimiento en uno y otro rodeo son estadísticamente significativas, soportado además en que el peso es el factor que tiene asociado un riesgo de pubertad más alto, con alrededor de un $4 \%$ de riesgo de pubertad por cada unidad de cambio de peso.

Los análisis de riesgo de pubertad asociado a las variaciones en el marcador GnRH-SNP6 son poco concluyentes, debido a que la censura propia de los dados sesgada hacia uno de los genotipos genera una sensible perdida de información.

En el capítulo 4 de este trabajo se estimó la correlación genética entre la circunferencia escrotal a diferentes edades con la edad al primer parto (EPP) y la fecha de primer parto (FPP), con el objetivo de evaluar el mejoramiento genético de la precocidad sexual de las hembras a través de la línea macho. Los resultados encontrados indican que la FPP presenta una mayor heredabilidad que la FPP, siendo $0.37 \pm 0.05$ y $0.192 \pm 0.05$, respectivamente. Además, se encontró una correlación genética de $-0,478 \pm 0,13$ entre la circunferencia escrotal a los 300 días de edad (CE300), siendo de más del doble que para mediciones de CE más tardías. La correlación entre los rankings de toros para las distintas CE y para EPP demostró resultados similares, pero en menor magnitud que las correlaciones genéticas. Estos resultados indican que la selección de toros a través de evaluaciones de CE a edades tempranas constituye una mejor herramienta para disminuir la EPP de las hembras, si bien los toros líderes para una característica no son los lideres para la otra. 


\section{BIBLIOGRAFÍA}

1. Adams GP, Evans ACO, Rawlings NC. Follicular waves and circulating gonadotrophins in 8 month old prepubertal heifers. J. Reprod. Fertil. 1994. 100:27-33.

2. Adams GP, Kot K, Smith CA, Ginther OJ. Selection of a dominant follicle and suppression of follicular growth in heifers. Anim. Reprod. Sci. 1993. 30:259-271. doi:10.1016/0378-4320(93)90076-4.

3. Albuquerque LG, Baldi F. Seleção para precocidade sexual de zebuínos: situação atual e perspectivas. In: VII Simpósio de Produção de Gado de Corte. 2011. Viçosa, Brasil. p. 299-323.

4. Allen CC, Alves BRC, Li X, Tedeschi LO, Zhou H, Paschal JC, Riggs PK, Braga-Neto UM, Keisler DH, Williams GL, Amstalden M. Gene expression in the arcuate nucleus of heifers is affected by controlled intake of high- and low-concentrate diets. J. Anim. Sci. 2012. 90:2222-2232. doi:10.2527/jas.2011-4684.

5. Allison P. 2010. Survival models using SAS. A practical guide. second edi. SAS Institute Inc., North Carolina USA.

6. Amstalden M, Cardoso RC, Alves BRC, Williams GL. Reproduction Symposium: Hypothalamic neuropeptides and the nutritional programming of puberty in heifers. J. Anim. Sci. 2014. 92:3211-3222. doi:10.2527/jas2014-7808.

7. Anderson WJ, Forrest DW, Goff BA, Shaikh AA, Harms PG. Ontogeny of ovarian inhibition of pulsatile luteinizing hormone secretion in posnatal holstein heifers. Domest. Anim. 1986. E. 3:107-116.

8. Arije GF, Wiltbank JN. Age and weight at puberty in hereford heifers. J. Anim. Sci. 1971. 33:401-406.

9. Atkins JA, Pohler KG, Smith MF.. Physiology and endocrinology of puberty in heifers. Vet. Clin. North Am. - Food Anim. Pract. 2013 29:479-492. doi:10.1016/j.cvfa.2013.07.008.

10. Barcellos JOJ, Pereira GR, Dias EA, McManus C, Canellas L, Bernardi ML, Tarouco A, Prates ÊR. Higher feeding diets effects on age and liveweight gain at puberty in crossbred Nelore x Hereford heifers. Trop. Anim. Health Prod. 
2014. 46:953-960. doi:10.1007/s11250-014-0593-6.

11. Bishop D. Exogenous Estradiol Reduces Inhibition Estradiol in Prepubertal of Luteinizing Hormone by in ewe lambs. Biol. Reprod. 1990. 761:755-761.

12. Bo GA, Alonso A, Caccia M, Carcedo J, Cutaia L, Moreno D, Martinez M, Baruselli PS. Fisiología de la reproduccion de la vaca. 2007.IRAC. Córdoba, Córdoba, Argentina.

13. Bourdon RM. Understanding animal breeding. $2^{\text {nd }}$ edition. Prentice Hall, inc. New Jersey. USA. 2000. Capitulo 9.

14. Bourdon RM, Brinks JS. Calving date versus calving interval as a reproductive measure in beef cattle. J. Anim. Sci. 1983. 57:1412-1417.

15. Buddenberg BJ, Brown CJ, Brown AH. Heritability estimates of calving date in Hereford cattle maintained on range under natural mating. J. Anim. Sci. 1990. 68:70-74. doi:10.2527/1990.68170x.

16. Buttram ST, Willham RL. Size and management effects on reproduction in first-, second- and third-parity beef cows. J. Anim. Sci. 1989. 67:2191-2196.

17. Buxton DR, Mertens DR, Moore KJ. Forage quality for ruminants: plant and animal considerations. Prof. Anim. Sci. 1995. 11:121-131. doi:10.15232/S1080-7446(15)32575-4.

18. Byerley DJ, Staigmiller RB, Berardinelli JG, Short RE. Pregnancy rates of beef heifers bred either on puberal or third estrus. J. Anim. Sci. 1987. 65:645650. doi:10.2527/jas1987.653645x.

19. Cammack KM, Thomas MG, Enns RM. Review: Reproductive traits and their heritabilities in beef cattle. Prof. Anim. Sci. 2009. 25:517-528.

20. Cantet RJC, García-Baccino C, Rogberg-Muñoz A, Forneris NS, Munilla S. Beyond genomic selection: The animal model strikes back (one generation)! J. Anim. Breed. Genet. 2017. 134:224-231. doi:10.1111/jbg.12271.

21. Carrillo J. Manejo de un rodeo de cria. 2nd ed. Editorial Centro Regional Buenos Aires Sur, Balcarce, Argentina. 1997.

22. Casaro G., Mihura H. Selección de vaquillonas de reposición en rodeos de cria. Taurus. 1999. 4:34-39.

23. Caton JS, Dhuyvetter DV. Influence of Energy Supplementation on Grazing Ruminants: Requirements and Responses. J. Anim. Sci. 1997. 75:533-542. 
24. Chelikani PK, Ambrose JD, Kennelly JJ. Effect of dietary energy and protein density on body composition, attainment of puberty, and ovarian follicular dynamics in dairy heifers. Theriogenology. 2003. 60:707-725. doi:10.1016/S0093-691X(03)00088-8.

25. Chilibroste P. Fuentes comunes de error en la alimentación del ganado lechero en pastoreo: I . Predicción del consumo. 1998. Disponible en: http:/www.spluy.com/documentos/difusion/conferencias/fuentes1.pdf

26. Corbet NJ, Burns BM, Corbet SH, Johnston DJ, Crisp JM, McGowan MR, Prayaga KC, Venus BK, Holroyd RG. Genetic variation in growth, hormonal and seminal traits of young tropically adapted bulls. En: Advanced of Animal Breeding and Genetics. 2009. p. 121-124.

27. Corbet NJ, Burns BM, Johnston DJ, Wolcott ML, Corbet DH, Venus BK, Li Y, McGowan MR, Holroyd RG. Male traits and herd reproductive capability in tropical beef cattle. 2. Genetic parameters of bull traits. Anim. Prod. Sci. 2013. 53:101-113. doi:10.1071/AN12163.

28. Coulter GH, Larson LL, Foote RH. Effect of age on testicular growth and consistency of Holstein and Angus bulls. J. Anim. Sci. 1975. 41:1383-1389.

29. Cundiff LV, Van Vleck LD, Hohenboken WD. Uniform guidelines for beef improvement programs. 2010. 182. Available from: http://beefimprovement.org/content/uploads/2015/08/REVISED-MasterEdBIF-GuidelinesFinal-08-2015.pdf

30. Cushman RA, Kill LK, Funston RN, Mousel EM, Perry GA. Heifer calving date positively influences calf weaning weights through six parturitions. J. Anim. Sci. 2010. 91:4486-4491. doi:10.2527/jas2013-6465.

31. Daftary SS, Gore A. IGF-1 in the brain as a regulator of reproductive neuroendocrine function. Exp. Biol. Med. 2005. 230:292-306.

32. Dassonneville R, Brøndum RF, Druet T, Fritz S, Guillaume F, Guldbrandtsen B, Lund MS, Ducrocq V, Su G. Effect of imputing markers from a lowdensity chip on the reliability of genomic breeding values in Holstein populations. J. Dairy Sci. 2005. 94:3679-3686. doi:10.3168/jds.2011-4299.

33. Day ML, Anderson LH. Current Concepts on the Control of Puberty in Cattle. J. Anim. Sci. 1998. 76:1-15. doi:/1998.76suppl_31x. 
34. Day ML, Imakawa K, Garcia-Winder M, Zalesky DD, Schanbacher BD, Kittok RJ, Kinder JE. Endocrine mechanisms of puberty in heifers: estradiol negative feedback regulation of luteinizing hormone secretion. Biol. Reprod. 1984. 31:332-341. doi:10.1095/biolreprod31.2.332.

35. Day ML, Nogueira GP. Management of age at puberty in beef heifers to optimize efficiency of beef production. Anim. Front. 2013. 3:6-11. doi:10.2527/af.2013-0027. Decruyenaere V, Buldgen A, Stilmant D. Factors affecting intake by grazing ruminants and related quantification methods: a review. Biotechnol. Agron. Soc. Environ. 2009. 13:559-573. doi:/1995.7392774x.

36. Dekkers JCM. Commercial application of marker- and gene-assisted selection in livestock: Strategies and lessons. J. Anim. Sci. 2004. 82:E313E328. doi:82/13_suppl/E313 [pii].

37. Desjardins C, Hafs HD. Maturation of bovine female genitalia from birth through puberty. J. Anim. Sci. 1969. 28:502-507.

38. Dieleman SJ, Bevers MM, Van Tol HTM, Willemse AH. 1986. Peripheral plasma concentrations of oestradiol, progesterone, cortisol, LH and prolactin during the oestrous cycle in the cow, with emphasis on the peri-oestrous period. Anim. Reprod. Sci. 10:275-292. doi:10.1016/0378-4320(86)900035.

39. Dodson SE, McLeod BJ, Haresign W, Peters AR, Lamming GE. Endocrine changes from birth to puberty in the heifer. J. Reprod. Fertil. 1988. 82:527538. doi:10.1530/jrf.0.0820527.

40. Duittoz AH, Tillet Y, Le Bourhis D, Schibler L. The timing of puberty (oocyte quality and management). Anim. Reprod. 2016. 13:313-333. doi:10.21451/1984-3143-AR874.

41. Estill CT. Initiation of Puberty in Heifers. En: Hopper RM. Bovine Reproduction. 2014. Vol. 9781118470. p. 195-202.

42. Evans ACO. Characteristics of ovarian follicle development in domestic animals. Reprod. Domest. Anim. 2003. 38:240-246. doi:10.1046/j.14390531.2003.00439.x.

43. Evans ACO, Adams GP, Rawlings NC. Follicular and hormonal development 
in prepubertal heifers from 2 to 36 weeks of age. J. Reprod. Fertil. 1994a. 102:463-470.

44. Evans ACO, Adams GP, Rawlings NC. Endocrine and ovarian follicular changes leading up to the first ovulation in prepubertal heifers. J. Reprod. Fertil. 1994b. 100:187-194. doi:10.1530/jrf.0.1000187.

45. Evans ACO, Currie WD, Rawlings NC. Effects of naloxone on circulating gonadotrophin concentrations in prepubertal heifers. J. Reprod. Fertil. 1992. 96:847-55.

46. Evans ACO, Rawlings NC. Fisiología de la pubertad de terneros y terneras. Taurus. 2010. 12:11-23.

47. Ferrell CL Effects of postweaning rate of gain on onset of puberty and productive performance of heifers of different breeds. J. Anim. Sci. 1982. $55: 1272-1283$.

48. Fitz T, Mayan M, Sawyer HR, Niswender GD. Characterization of two steroidogenic cell types in the ovine corpus luteum. Biol. Reprod. 1982. 27:703-711. doi:10.1095/biolreprod27.3.703.

49. Forni S, Albuquerque LG. Estimates of genetic correlations between days to calving and reproductive and weight traits in Nelore cattle. J. Anim. Sci. 2005. 83:1511-1515.

50. Fortes MRS, Lehnert SA, Bolormaa S, Reich C, Fordyce G, Corbet NJ, Whan V, Hawken RJ, Reverter A. Finding genes for economically important traits: Brahman cattle puberty. Anim. Prod. Sci. 2012. 52:143-150. doi:10.1071/AN11165.

51. Fortes MRS, Reverter A, Zhang Y, Collis E, Nagaraj SH, Jonsson NN, Prayaga KC, Barris W, Hawken RJ. Association weight matrix for the genetic dissection of puberty in beef cattle. PNAS. 2010. 107:1-6. doi:10.1073/pnas.1002044107/-/DCSupplemental.

52. Fortune JE. Ovarian follicular growth and development in mammals. 1994. Biol. Reprod. 50:225-232.

53. Franceschini I, Lomet D, Cateau M, Delsol G, Tillet Y, Caraty A. Kisspeptin immunoreactive cells of the ovine preoptic area and arcuate nucleus coexpress estrogen receptor alpha. Neurosci. Lett. 2006. 401:225-230. 
doi:10.1016/j.neulet.2006.03.039.

54. Freetly HC, Cundiff LV. Postweaning Growth and Reproduction Characteristics of Heifers Sired by Bulls of Seven Breeds and Raised on Different Levels of Nutrition. J. Anim. Sci. 1997. 75:2841-2851.

55. Freetly HC, Ferrell CL, Jenkins TG. Production performance of beef cows raised on three different nutritionally controlled heifer development programs. J. Anim. Sci. 2001. 79:819-826.

56. Freetly HC, Kuehn LA, Cundiff LV. Growth curves of crossbred cows sired by hereford, angus, belgian blue, brahman, boran, and tuli bulls, and the fraction of mature body weight and height at puberty. J. Anim. Sci. 2011. 89:2373-2379. doi:10.2527/jas.2011-3847.

57. Funston RN, Deutscher GH. Comparison of target breeding weight and breeding date for replacement beef heifers and effects on subsequent reproduction and calf performance. J. Anim. Sci. 2004. 82:3094-3099.

58. Funston RN, Martin JL, Larson DM, Roberts J. Physiology and endocrinology symposium: Nutritional aspects of developing replacement heifers. J. Anim. Sci. 2012a. 90:1166-1171. doi:10.2527/jas.2011-4569.

59. Funston RN, Summers AF, Roberts AJ. Alpharma beef cattle nutrition symposium: Implications of nutritional management for beef cow-calf systems 1. 2012b. 2301-2307. doi:10.2527/jas2011-4568.

60. Garcia MR, Amstalden M, Williams SW, Stanko RL, Morrison CD, Keisler DH, Nizielski SE, Williams GL. Serum leptin and its adipose gene expression during pubertal development, the estrous cycle, and different seasons in cattle. J. Anim. Sci. 1998. 80: 2158-2167.

61. Gasser CL, Behlke EJ, Grum DE, Day ML. Effect of timing of feeding a highconcentrate diet on growth and attainment of puberty in early-weaned heifers. J. Anim. Sci. 2006a. 84:3118-3122. doi:10.2527/jas.2005-676.

62. Gasser CL, Bridges GA, Mussard ML, Grum DE, Kinder JE, Day ML. Induction of precocious puberty in heifers III: Hastened reduction of estradiol negative feedback on secretion of luteinizing hormone. J. Anim. Sci. 2006 b. 84:2050-2056. doi:10.2527/jas.2005-638.

63. Gasser CL, Burke CR, Mussard ML, Behlke EJ, Grum DE, Kinder JE, Day 
ML. Induction of precocious puberty in heifers II: Advanced ovarian follicular development. J. Anim. Sci. 2006c. 84:2042-2049. doi:10.2527/jas.2005-637.

64. Gasser CL, Grum DE, Mussard ML, Fluharty FL, Kinder JE, Day ML. Induction of precocious puberty in heifers I: Enhanced secretion of luteinizing hormone. J. Anim. Sci. 2006d. 84:2035-2041. doi:10.2527/jas.2005-636.

65. Ge W, Davis ME, Hines HC, Irvin KM, Simmen RCM. Association of a genetic marker with blood serum insulin-like growth factor-I concentration and growth traits in Angus cattle. J Anim Sci. 2001. 79:1757-1762.

66. Gibbons JR, Wiltbank MC, Ginther OJ. Functional interrelationships between follicles greater than $4 \mathrm{~mm}$ and the follicle-stimulating hormone surge in heifers. Biol. $\quad$ Reprod. $1997.1066-1073$. doi:10.1095/biolreprod57.5.1066.

67. Ginther OJ. Selection of the dominant follicle in cattle and horses. Anim. Reprod. Sci. 2000. 60-61:61-79. doi:10.1016/S0378-4320(00)00083-X.

68. Ginther OJ. The theory of follicle selection in cattle. Domest. Anim. Endocrinol. 2016. 57:85-99. doi:10.1016/j.domaniend.2016.06.002.

69. Ginther OJ, Kastelic JP, Knopf L. Composition and characteristics of follicular waves during the bovine estrous cycle. Anim. Reprod. Sci. 1989. 20:187-200. doi:10.1016/0378-4320(89)90084-5.

70. Glaze JB. Genetic selection for fertility and performance. Appl. Reprod. Strateg. Beef Cattle Proc. 2011. 255-262.

71. Gonzalez-Padilla E, Ruiz R, LeFever D, Denham A, Wiltblank JN. Puberty in beef heifers III. Induction of fertile estrus. J. Anim. Sci. 1975. 40:11101118.

72. Gregory KE., Laster DB, Cundiff LV, Smith GM, Koch RM. Characterization of biological types of cattle-cycle III: II. Growth rate and puberty in females. J. Anim. Sci. 1979. 49:461-471.

73. Guaita MS, Fernandez HH. Tablas de composición química de los alimentos para rumiantes. Área de investigación en producción animal INTA, EEA Balcarce. Ediciones INTA, Publicaciones regionales. 2011. Pag 60.

74. Gutiérrez JP, Alvarez I, Fernández I, Royo LJ, Díez J, Goyache F. Genetic 
relationships between calving date, calving interval, age at first calving and type traits in beef cattle. Livest. Prod. Sci. 2002. 78:215-222. doi:10.1016/S0301-6226(02)00100-8.

75. Habier D, Fernando RL, Dekkers JCM. Genomic selection using low-density marker panels. $\quad$ Genetics. 2009. 182:343-353. doi:10.1534/genetics.108.100289.

76. Hall JB. Nutritional development and the target weight debate. Vet. Clin. North Am. - Food Anim. Pract. 2013. 29:537-554. doi:10.1016/j.cvfa.2013.07.015.

77. Hall JB, Staigmiller RB, Bellows RA, Short RE, Moseley WM, Bellows SE, Al HET. Body Composition and Metabolic Profiles Associated with Puberty in Beef Heifers. J. Anim. Sci. 1995. 73:3409-3420.

78. Haydock KP, Shaw NH. The comparitive yield method for estimating dry matter yield of pasture. Aust. J. Exp. Agric. Anim. Husb. 1975. 15:663-670.

79. Hedeker D, Gibbons RD. 2006. Longitudinal data analysis. John Wiley \& Sons, editor.

80. Holm DE, Nielen M, Jorritsma R, Irons PC, Thompson PN. Evaluation of pre-breeding reproductive tract scoring as a predictor of long term reproductive performance in beef heifers. Prev. Vet. Med. 2015. 118:56-63. doi:10.1016/j.prevetmed.2014.10.016.

81. Honaramooz A, Aravindakshan J, Chandolia RK, Beard AP, Bartlewski PM, Pierson RA, Rawlings NC. Ultrasonographic evaluation of the pre-pubertal development of the reproductive tract in beef heifers. Anim. Reprod. Sci. 2004. 80:15-29. doi:10.1016/S0378-4320(03)00136-2.

82. Honaramooz A, Chandolia RK, Beard AP, Rawlings NC. Effects of season of birth on the prepubertal pattern of gonadotropin secretion and age at puberty in beef heifers. Theriogenology. 1999. 52:67-79. doi:10.1016/S0093-691X(99)00110-7

83. Hopper HW, Williams SE, Byerley DJ, Rollosson MM, Ahmed PO, Kiser TE. Effect of prepubertal body weight gain and breed on carcass composition at puberty in beef heifers. J. Anim. Sci. 1993. 71:1104-1111. doi:/1993.7151104x. 
84. Houseknecht KL, Baile CA, Matteri RL, Spurlock ME. The biology of leptin : a review . J. Anim. Sci. 1998. 76:1405-1420.

85. Hughes H. Raised replacement heifers: Some economic considerations. Vet. Clin. North Am. - Food Anim. Pract. 2013. 29:643-652. doi:10.1016/j.cvfa.2013.07.013.

86. Hurnik JF. Sexual behavior of female domestic mammals. Vet. Clin. North Am. Food Anim. Pract. 1987. 3:423-461. doi:10.1016/S07490720(15)31162-2

87. I'Anson H, Manning JM, Herbosa CG, Pelt J, Friedman CR, Wood RI, Bucholtz DC, Foster DL. Central Inhibition of Gonadotropin-Releasing Hormone Secretion in the Growth-Restricted Hypogonadotropic Female Sheep. Endocrinology. 2000. 141:520-527.

88. Johnston DJ, Barwick SA, Corbet NJ, Fordyce G, Holroyd RG, Williams PJ, Burrow HM. Genetics of heifer puberty in two tropical beef genotypes in northern Australia and associations with heifer- and steer-production traits. Anim. Prod. Sci. 2009. 49:399-412. doi:10.1071/EA08276.

89. Johnston DJ, Bunter KL. Days to calving in Angus cattle: Genetic and environmental effects, and covariances with other traits. Livest. Prod. Sci. 1996. 45:13-22. doi:10.1016/0301-6226(95)00088-7.

90. Jones JE, Armstrong JD, Harvey RW. Changes in metabolites, metabolic hormones, and luteinizing hormone before puberty in Angus, Braford, Charolais , and Simmental heifers. J. Anim. Sci. 2014. 64:1607-1615.

91. Kashi Y, Hallerman E, Soller M. Marker-assisted selection of candidate bulls for progeny testing programmes. Anim. Sci. 1990. 51:63-74.

92. Kassari TH, Wikse SE, Jones R. Use of yearling bulls in beef cattle operations. Part I. Economic analysis and fertility assessment. Compend Contin Educ Pr. Vet. 1996. 18:1244-1253.

93. Kesner JS, Convey EM, Anderson CR. Evidence that estradiol induces the preovulatory LH surge in cattle by increasing pituitary sensitivity to LHRH and then increasing LHRH release. Endocrinology. 1981. 108:1386-1391. doi:10.1210/endo-108-4-1386.

94. Kinder JE, Bergfeld ME, Wehrman ME, Peters KE, Kojima FN. Endocrine 
basis for puberty in heifers and ewes. J. Reprod. Fertil. 1995. 49:393-407.

95. Kinder JE, Day ML, Kittok RJ. Endocrine regulation of puberty in cows and ewes. J. Reprod. Fertil. 1987. 34:167-186.

96. Kinder JE, Garcia-Winder M, Imakawa K, Day ML, Zalesky DD, D’Occhio ML, Stumpf TT, Kittok RJ, Schanbacher BD. Circulating concentrations of 17-estradiol influence pattern of LH in circulation of cows. Domest. Anim. Endocrinol. 1991. 8:463-469. doi:10.1016/0739-7240(91)90015-C.

97. Knickerbocker JJ, Wiltbank MC, Niswender GD. Mechanisms of luteolysis in domestic livestock. Domest. Anim. Endocrinol. 1988. 5:91-107. doi:10.1016/0739-7240(88)90011-2.

98. Knol EF, Nielsen B, Knap PW. Genomic selection in commercial pig breeding. Anim. Front. 2016. 6:15. doi:10.2527/af.2016-0003.

99. Lamb GC. Criteria for selecting replacements at weaning, before breeding, and after breeding. Vet. Clin. North Am. - Food Anim. Pract. 2013. 29:567578. doi:10.1016/j.cvfa.2013.07.003.

100. Larson RL, White BJ, Laflin S. Beef Heifer Development. Vet. Clin. North Am. - Food Anim. Pract. 2016. 32:285-302. doi:10.1016/j.cvfa.2016.01.003.

101. Lauderdale JW. A review of patterns of change in luteal function. J. Anim. Sci. 1986. 62:79-91. doi:10.1093/ansci/62.2.79.

102. Legarra A, Christensen OF, Aguilar I, Misztal I. Single Step, a general approach for genomic selection. Livest. Sci. 2014. 166:54-65. doi:10.1016/j.livsci.2014.04.029.

103. Lesmeister LJ, Burfening PJ, Blackwell RL. Date of First Calving in Beef Cows and Subsequent Calf Production. J. Anim. Sci. 2014. 36:1-6.

104. Lirón JP, Prando AJ, Fernández ME, Ripoli MV, Rogberg-Muñoz A, Goszczynski DE, Posik DM, Peral-García P, Baldo A, Giovambattista G. Association between GNRHR, LHR and IGF1 polymorphisms and timing of puberty in male Angus cattle. BMC Genet. 2012. 13:26. doi:10.1186/14712156-13-26.

105. Lirón JP, Prando A, Ripoli MV, Rogberg-Muñoz A, Posik DM, Baldo A, Peral-García P, Giovambattista G. Characterization and validation of bovine Gonadotripin releasing hormone receptor (GNRHR) polymorphisms. Res. 
Vet. Sci. 2011. 91:391-396. doi:10.1016/j.rvsc.2010.09.024.

106. Lomniczi A, Loche A, Castellano JM, Ronnekleiv OK, Bosch M, Kaidar G, Knoll JG, Wright H, Pfeifer GP, Ojeda SR. Epigenetic control of female puberty. Nat. Publ. Gr. 2013a. 16:281-289. doi:10.1038/nn.3319.

107. Lomniczi A, Wright H, Castellano JM, Sonmez K, Ojeda SR. A system biology approach to identify regulatory pathways underlying the neuroendocrine control of female puberty in rats and nonhuman primates. Horm. Behav. 2013b. 64:175-186. doi:10.1016/j.yhbeh.2012.09.013.

108. Lomniczi A, Wright H, Ojeda SR. Epigenetic regulation of female puberty. Front. Neuroendocrinol. 2015. 36:90-107. doi:10.1016/j.yfrne.2014.08.003.

109. Lozano J. Propuesta para optimizar la eficiencia del stock bovino de carne, mediante el incremento de las tasas de destete y de extracción. Tesis MSc en direccion de empresas. Instituto de Ciencias de la Administracion. Córdoba. Argentina. 2011

110. Lucy MC, Billings HJ, Butler WR, Ehnis LR, Fields MJ, Kesler DJ, Kinder JE, Mattos RC, Short RE, Thatcher WW, Wettemann RP, Yelich JV, Hafs HD. Efficacy of an intravaginal progesterone insert and an injection of $\mathrm{PGF}_{2 \alpha}$ for synchronizing estrus and shortening the interval to pregnancy in postpartum beef cows, peripubertal beefs heifers, and dairy heifers. J. Anim. Sci. 2001. 79:982-995.

111. Luna-Pinto G, Cronjé PB. The roles of the insulin-like growth factor system and leptin as possible mediators of the effects of nutritional restriction on age at puberty and compensatory growth in dairy heifers. South African J. Anim. Sci. 2000. 30:155-163. doi:10.4314/sajas.v30i2.3865.

112. Lunstra DD, Cundiff LV. Growth and pubertal development in Brahman-, Boran-, Tuli-, Belgian Blue-, Hereford- and Angus-sired F1 bulls. J. Anim. Sci. 2003. 81:1414-1426. doi:10.2527/2003.8161414x.

113. Lunstra DD, Ford JJ, Echternkamp SE. Puberty in beef bulls: hormone concentrations, growth, testicular development, sperm production and sexual aggressiveness in bulls of different breeds. J. Anim. Sci. 1978. 46:1054-1062.

114. MacNeil MD, Newman S. Genetic analysis of calving date in Miles City Line 1 Hereford cattle. J. Anim. Sci. 1994. 72:3073-3079. 
115. Madgwick S, Evans ACO, Beard AP. Treating heifers with GnRH from 4 to 8 weeks of age advanced growth and the age at puberty. Theriogenology. 2005. 63:2323-2333. doi:10.1016/j.theriogenology.2004.10.011.

116. Maj A, Snochowski M, Siadkowska E, Rowińiska B, Lisowski P, Robakowska-Hyzgorek D, Oprzadek J, Grochowska R, Kochman K, Zwierzchowski L. Polymorphism in genes of growth hormone receptor (GHR) and insulin-like growth factor-1 (IGF1) and its association with both the IGF1 expression in liver and its level in blood in Polish Holstein-Friesian cattle. Neuroendocrinol. Lett. 2008. 29:981-989. doi:NEL290608A11 [pii].

117. Martin LC, Brinks JS, Bourdont RM, Cundiff LV. Genetic effects on beef heifer puberty and subsequent reproduction. J. Anim. Sci. 1992. 70:40064017.

118. Martin TL, Fogwell RL, Ireland JJ. Concentrations of Inhibins and Steroids in Follicular-Fluid During Development of Dominant Follicles in Heifers. Biol. Reprod. 1991. 44:693-700. doi:10.1095/biolreprod44.4.693.

119. Martinez-Velazquez G, Gregory KE, Bennett GL, Van Vleck LD. Genetic relationships between scrotal circumference and female reproductive traits. J. Anim. Sci. 2003. 81:395-401. doi:10.1111/j.1439-0531.2008.01186.x.

120. Messager S. Kisspeptin and its receptor: new gatekeepers of puberty. Neuroendocrinology. 2005. 17:687-688. doi:JNE1357 [pii] \r10.1111/j.13652826.2005.01357.x

121. Meuwissen THE, Hayes BJ, Goddard ME. Prediction of Total Genetic Value Using Genome-Wide Dense Marker Maps. Genetics. 2001. 157:1819-1829.

122. Meuwissen THE, Hayes BJ, Goddard ME. Genomic selection: A paradigm shift in animal breeding. Anim. Front. 2016. 6:6. doi:10.2527/af.2016-0002

123. Meyer K, Hammond K, Parnell PF, MacKinnon MJ, Sivarajasingam S. Estimates of heritability and repeatability for reproductive traits in Australian beef cattle. Livest. Prod. Sci. 1990. 25:15-30. doi:10.1016/03016226(90)90038-8.

124. Mialon MM, Renand G, Krauss D, Menissier F. Genetic variability of the length of postpartum anoestrus in Charolais cows and its relationship with age at puberty. Genet. Sel. Evol. 2000. 32:403-414. doi:10.1051/gse:2000127 
g320405 [pii].

125. Bormann MJ, Wilson DE. Calving day and age at first calving in angus heifers. J. Anim. Sci. 2010. 88:1947-1956. doi:10.2527/jas.2009-2249.

126. Misztal I, Tsuruta S, Strabel T, Auvray B, Druet T, Lee DH. BLUPF90 and related programs (BGF90). Proc. 7th World Congr. Genet. Appl. to Livest. Prod. 2002. 28:21-22. doi:9782738010520.

127. Moran C, Quirke JF, Roche JF. Puberty in heifers: a review. Anim. Prod. Sci. 1989. 18:167-182.

128. Morris CA, Baker RL, Cullen NG. Genetic correlations between pubertal traits in bulls and heifers. Livest. Prod. Sci. 1992. 31:221-234. doi:10.1016/0301-6226(92)90019-Z.

129. Morris CA, Wilson JA. Progress with selection to change age at puberty and reproductive rate in Angus cattle. Proc. New Zeal. Soc. Anim. Prod. 1997. 57:9-11.

130. Morris CA, Wilson JA, Bennett GL, Cullen NG, Hickey SM, Hunter JC. Genetic parameters for growth, puberty, and beef cow reproductive traits in a puberty selection experiment. New Zeal. J. Agric. Res. 2000. 43:83-91. doi:10.1080/00288233.2000.9513411.

131. Mrode R, Thompson R. Linear models for the prediction of animal breeding vales. 2nd Ed. CABI publishing, Oxfordshire, UK. 2005.

132. National Research Council. Nutrient requirements of beef cattle. Seventh. Washington, DC. 2000.

133. Nelsen TC, Short RE, Phelps DA, Staigmiller RB. Nonpuberal Estrus and Mature Cow Influences on Growth and Puberty in Heifers. J. Anim. Sci. 1985. 61:470-473.

134. Nicolini P, Carriquiry M, Meikle A. A polymorphism in the insulin-like growth factor 1 gene is associated with postpartum resumption of ovarian cyclicity in Holstein-Friesian cows under grazing conditions. Acta Vet. Scand. 2013. 55:11. doi:10.1186/1751-0147-55-11.

135. Ojeda SR, Dubay C, Lomniczi A, Kaidar G, Matagne V, Sandau US, Dissen GA. Gene networks and the neuroendocrine regulation of puberty. Mol. Cell. Endocrinol. 2010. 324:3-11. doi:10.1016/j.mce.2009.12.003. 
136. Ojeda SR, Lomniczi A. Unravelling the mystery of puberty. Nat. Rev. Endocrinol. 2014. 10:67-9. doi:10.1038/nrendo.2013.233.

137. Ojeda SR, Lomniczi A, Mastronardi C, Heger S, Roth C, Parent AS, Matagne $\mathrm{V}$, Mungenast AE. Minireview: The neuroendocrine regulation of puberty: Is the time ripe for a systems biology approach? Endocrinology. 2006. 147:1166-1174. doi:10.1210/en.2005-1136.

138. Patterson DJ, Brown DS, Sexten WJ, Decker JE, Poock SE. Management strategies for adding value to replacement beef heifers: A working model. Vet. Clin. North Am. - Food Anim. Pract. 2013. 29:653-666. doi:10.1016/j.cvfa.2013.07.005.

139. Patterson DJ, Corah LR, Brethour JR, Higgins JJ, Kiracofe GH, Stevenson JS. Evaluation of reproductive traits in Bos taurus and Bos indicus crossbred heifers: relationship of age at puberty to length of the postpartum interval to estrus. J. Anim. Sci. 1992. 70:1994-1999.

140. Patterson DJ, Perry RC, Kiracofe H, Bellows RA, Staigmiller RB, Corah LR, Management Considerations in Heifer Development and Puberty. J. Anim. Sci. 1992. 70:4018-4035.

141. Pereira Gomes de Freitas S. Desmpenho de novilhas expostas à reprodução aos 14/15 meses de idade. Tesis Doctoral. Universidade Federal do Rio Grande do Sul. 2005.

142. Perry GA, Cushman R. Effect of age at puberty/conception date on cow longevity. Vet. Clin. North Am. - Food Anim. Pract. 2013. 29:579-590. doi:10.1016/j.cvfa.2013.07.011.

143. Perry RC, Corah LR, Kiracofe GH, Stevenson JS, Beal WE. Endocrine changes and ultrasonography of ovaries in suckled beef cows during resumption of postpartum estrous cycles. J. Anim. Sci. 1991. 69:2548-2555.

144. Prando AJ. Estudio de asociacion entre marcadores genéticos y precocidad sexual en el macho bovino. Tesis Doctoral. Universidad Nacional de La Plata 2015.

145. Van Raden PM. Efficient methods to compute genomic predictions. J. Anim. Sci. 2008. 91:4414-4423.

146. R Development Core Team (2008). R: A language and environment for 
statistical computing. R Foundation for Statistical Computing, Vienna, Austria. ISBN 3-900051-07-0, URL http://www.R-project.org.

147. Ramaley JA. Development of gonadotropin regulation in the prepubertal mammal. Biol. Reprod. 1979. 20:1-31.

148. Rawlings NC, Bartlewski PM, Aravindakshan J, Cook SJ. The relationship between secretory patterns of gonadotrophic hormones and the attainment of puberty in bull and heifer calves born early or late during the spring calving season. Anim. Reprod. Sci. $2005 . \quad 86: 175-186$. doi:10.1016/j.anireprosci.2004.07.006.

149. Rawlings N, Evans ACO, Chandolia RK, Bagu ET. Sexual Maturation in the Bull. Reprod. Domest. Anim. 2008. 43:295-301. doi:10.1111/j.14390531.2008.01177.x.

150. Rearte, D. Documento programa nacional de carnes. Perfil de las cadenas: bovina, aves, cerdos, ovinos y caprinos. Inta. 2010. 1-57.

151. Rearte, D. Situación actual y prospectivas de la ganaderia argentina, enfoque regional. Arch. Latinoam. Prod. Anim. 2011. 19:46-49.

152. Roa J, García-Galiano D, Castellano JM, Gaytan F, Pinilla L, Tena-Sempere M. Molecular and Cellular Endocrinology Metabolic control of puberty onset : New players, new mechanisms. Mol. Cell. Endocrinol. 2010. 324:8794. doi:10.1016/j.mce.2009.12.018.

153. Roberts AJ, Geary TW, Grings EE, Waterman RC, Macneil MD. Reproductive performance of heifers offered ad libitum or restricted access to feed for a one hundred forty-day period after weaning. J. Anim. Sci. 2009. 87:3043-3052. doi:10.2527/jas.2008-1476.

154. Rodrigues ADP, Peres RFG, Lemes AP, Martins T, Pereira MCH, Day ML, Vasconcelos JLM. Theriogenology Progesterone-based strategies to induce ovulation in prepubertal Nellore heifers. Theriogenology. 2013. 79:135-141. doi:10.1016/j.theriogenology.2012.09.018.

155. Rogberg-Muñoz A, Cantet RJC, Fernández ME, Lirón JP, Prando A, Birchmeier AN, Ripoli MV, Giovambattista G. Longitudinal analysis of the effects of IGF1-SnaBI genotypes on the growth curve of Angus bull calves. Livest. Sci. 2013. 154:55-59. doi:10.1016/j.livsci.2013.03.016. 
156. Rothschild MF, Soller M. Candidate gene analysis to detect genes controlling traits of economic importance in domestic livestock. Probe (Lond). 1997. 8:13-20.

157. Russo A. Fundamentos de la regulación neuroendocrina, paracrina y autocrina del ciclo estral en la hembra bovina. Dillon. Banfield, Buenos Aires, Argentina. 2011.

158. Rust T, Groeneveld E. Variance component estimation on female fertility traits in beef cattle. South African J. Anim. Sci. 2001. 31:131-141. doi:10.4314/sajas.v31i3.3793.

159. Schaeffer LR. Strategy for applying genome-wide selection in dairy cattle. J. Anim. Breed. Genet. 2006. 123:218-223.

160. Schaeffer LR, Wilton JW, Thompson R. Simultaneous estimation of variance and covariance components from multivarite mixed model equations. Biometrics. 1978. 34:199-208.

161. Schams D. Luteal peptides and intercellular communication. J. Reprod. Fertil. 1987. 34:87-99.

162. Schams D, Schallenberger E, Gombe S, Karg H. Endocrine patterns associated with puberty in male and female cattle. J. Reprod. Fertil. 1981. 30:103-110.

163. Schoenemann HM, Humphrey WD, Crowder ME, Nett TM, Reeves JJ. Pituitary luteinizing hormone-releasing hormone receptors in ovariectomized cows after challenge with ovarian steroids. Biol. Reprod. 1985. 32:574-583. doi:10.1095/biolreprod32.3.574.

164. Searle SR, Casella G, McCulloch CE. Variance Components. 2nd ed. John Wiley \& Sons, Inc. 2006.

165. Short RE, Bellows RA. Relationships among Weight Gains, Age at Puberty and Reproductive Performance in Heifers. J. Anim. Sci. 1971. 32:127-131. doi:10.2134/jas1971.321127x.

166. Short RE, Bellows RA, Carr JB, Staigmiller RB, Randel RD. Induced or synchronized puberty in heifers. J. Anim. Aci. 1976. 43: 1254-1258.

167. Short RE, Bellows RA, Staigmiller RB, Berardinelli JG, Custer EE. Physiological mechanisms controlling anestrus and infertility in postpartum 
beef cattle. J. Anim. Sci. 1990. 68:799-816.

168. Silveira PAS, Pegoraro LMC, Butler WR, Correa MN, Schneider A. Effect of IGF-1 SnaBI polymorphism on reproductive parameters and metabolic parameters in dairy cows. In: Proceedings of the 29th Annual Meeting of the Brazilian Embryo Technology Society (SBTE); Gramado, RS, Brazil, August 20th to 23rd, 2015, and 31st Meeting of the European Embryo Transfer Association (AETE). Ghent, Belgium. p. A046.

169. Suzuki S, Kadokawa H, Hashizume T. Direct kisspeptin-10 stimulation on luteinizing hormone secretion from bovine and porcine anterior pituitary cells. Anim. Reprod. Sci. 2008. 103:360-365. doi:10.1016/j.anireprosci.2007.05.016.

170. Toelle VD, Robison OW. Estimates of genetic correlations between testicular measurements and female reproductive traits in cattle. J. Anim. Sci. 1985. 60:89-100.

171. Trenkle A, Willham RL. 1977. Beef Production Efficiency. Sciences (New. York). 198:1009-1015.

172. Urioste JI, Misztal I, Bertrand JK. Fertility traits in spring-calving Aberdeen Angus cattle. 1. Model development and genetic parameters. J. Anim. Sci. 2007. 85:2854-2860. doi:10.2527/jas.2006-549.

173. Vraspir RA, Summers AF, Roberts AJ, Funston RN. Effect of Pubertal Status and Number of Estrous Cycles Prior to the Breeding Season on Pregnancy Rate in Beef Heifers. Nebraska beef cattle reports. 2014. 760.

174. Walters DL, Schallenberger E. Pulsatile secretion of gonadotrophins, ovarian steroids and ovarian oxytocin during the periovulatory phase of the oestrous cycle in the cow. J. Reprod. Fertil. 1984. 71:503-512. doi:10.1530/jrf.0.0710503.

175. Wehrman ME, Kojima FN, Sanchez T, Mariscal DV, Kinder JE. Incidence of precocious puberty in developing beef heifers. J. Anim. Sci. 1996. $74: 2462-2467$.

176. Williams GL, Amstalden M, Garcia MR, Stanko RL, Nizielski SE, Morrison $\mathrm{CD}$, Keisler DH. Leptin and its role in the central regulation of reproduction in cattle. Domest. Anim. Endocrinol. 2002. 23:339-349. doi:10.1016/S0739- 
7240(02)00169-8.

177. Yelich JV, Wettemann RP, Marston TT, Spicer LJ. Luteinizing hormone, growth hormone, insulin-like growth factor-I, insulin and metabolites before puberty in heifers fed to gain at two rates. Domest. Anim. Endocrinol. 1996. 13:325-338. doi:10.1016/0739-7240(96)00046-X.

178. Yilmaz A. Variance Component Estimation for Reproductive Traits and Analyses of Myofibrillar Proteins and Age At Puberty in Angus Beef Cattle Divergently Selected for Blood Serum Insulin-Like Growth Factor I Concentration. PhD Thesis. Ohio State University. 2003.

179. Yilmaz A, Davis ME, Simmen RCM. Analysis of female reproductive traits in Angus beef cattle divergently selected for blood serum insulin-like growth factor I concentration. Theriogenology. 2006. 65:1180-1190. doi:10.1016/j.theriogenology.2005.06.018.

180. Zieba DA. Regulatory Roles of Leptin at the Hypothalamic-Hypophyseal Axis Before and after Sexual Maturation in Cattle. Biol. Reprod. 2004. 71:804-812. doi:10.1095/biolreprod.104.028548.

181. Zulu VC, Nakao T, Sawamukai Y. Insulin-Like Growth Factor-I as a Possible Hormonal Mediator of Nutritional Regulation of Reproduction in Cattle. J. Vet. Med. Sci. 2002. 64:657-665. doi:10.1292/jvms.64.657. 


\section{ANEXOS}

Anexo 1. Datos utilizados en la ecuación de predicción de los requerimientos energéticos de las vaquillonas. National Research Council. NRC. 2012

\begin{tabular}{|c|c|c|}
\hline Peso (kg) & $\operatorname{ADP}(\mathrm{kg} / \mathrm{d})$ & $\begin{array}{c}\text { EM } \\
\text { (Mcal/d) }\end{array}$ \\
\hline \multirow{5}{*}{150} & 0 & 5.6 \\
\hline & 0.5 & 9.4 \\
\hline & 0.7 & 10.4 \\
\hline & 0.9 & 11.3 \\
\hline & 1.1 & 12.4 \\
\hline \multirow{6}{*}{200} & 0 & 7 \\
\hline & 0.3 & 10.8 \\
\hline & 0.5 & 12.7 \\
\hline & 0.7 & 13.8 \\
\hline & 0.9 & 14.3 \\
\hline & 1.1 & 15.4 \\
\hline \multirow{6}{*}{250} & 0 & 8.3 \\
\hline & 0.3 & 12.8 \\
\hline & 0.5 & 14.2 \\
\hline & 0.7 & 15 \\
\hline & 0.9 & 16.5 \\
\hline & 1.1 & 18.7 \\
\hline \multirow{6}{*}{300} & 0 & 9.5 \\
\hline & 0.3 & 14.5 \\
\hline & 0.5 & 16.3 \\
\hline & 0.7 & 17.1 \\
\hline & 0.9 & 19 \\
\hline & 1.1 & 21.5 \\
\hline \multirow{6}{*}{350} & 0 & 10.6 \\
\hline & 0.3 & 16.5 \\
\hline & 0.5 & 18.3 \\
\hline & 0.7 & 19.7 \\
\hline & 0.9 & 21.8 \\
\hline & 1.1 & 24 \\
\hline \multirow{5}{*}{400} & 0 & 11.8 \\
\hline & 0.3 & 18.2 \\
\hline & 0.5 & 19.5 \\
\hline & 0.7 & 21.7 \\
\hline & 0.9 & 23.5 \\
\hline
\end{tabular}


Anexo 2. Extracción orgánica de ADN total de sangre periférica.

1- Colocar una alícuota $500 \mu 1$ de una muestra de sangre en tubos de 1,5 ml.

2- Lavar con $1.000 \mu \mathrm{l}$ de agua tridestilada y centrifugar a $10.000 \mathrm{G}$ por 1 minuto.

3- Mezclar por inversión

4- Descartar el sobrenadante volcando suavemente el tubo y secar sobre papel la última gota.

5- Repetir pasos 2, 3 y 4 una vez mas o hasta que el pellet quede blanco

6- Resuspender el pellet en $400 \mu \mathrm{l}$ de buffer de extracción S (50 mM de $\mathrm{HCl}-$ Tris, $25 \mathrm{mM}$ de DTT, 2\% de N-Laurylsarcosine) y agitar en vortex

7- Agregar $10 \mu \mathrm{l}$ de proteinasa $\mathrm{K}(10 \mathrm{mg} / \mathrm{ml})$ e incubar durante $3 \mathrm{hs}$ a $55^{\circ} \mathrm{C}$ (La incubación puede durar toda la noche si las proteínas no se degradan).

8- Llevar la muestra a temperatura ambiente y agregar $400 \mu 1$ de cloroformo.

9- Mezclar por inversión

10- Centrifugar a $10.000 \mathrm{G}$ durante 1 minuto

11- Transferir la fase acuosa (superior), que contiene el ADN a un nuevo tubo y descartar la fase orgánica

12- Repetir pasos 8, 9, 10 y 11 una vez más

13- Agregar $80 \mu \mathrm{l}$ de acetato de amonio $10 \mathrm{M}$

14- Centrifugar a $10.000 \mathrm{G}$ durante 1 minuto

15- Transferir la fase acuosa a otro tubo y agregar $800 \mu \mathrm{l}$ de etanol 100\% preenfriado.

16- Mezclar suavemente, se observará la formación de hebras

17- Precipitar en el freezer toda la noche 
18- Centrifugar a $14.000 \mathrm{G}$ durante 15 minutos

19- Descartar el sobrenadante volcando suavemente y secar la boca del tubo sobre papel

20- Lavar el tubo con $250 \mu$ de etanol 70\% enfriado, haciendo girar el tubo de modo de mojar todas las pardes

21- Centrifugar 15 minutos a $14.000 \mathrm{G}$ y volver a descartar el sobrenadante

22- Secar el pellet a temperatura ambiente con los tubos abiertos boca abajo

23- Agregar 100 a $200 \mu 1$ de agua EPES e incubar toda la noche a $37^{\circ} \mathrm{C}$ para hidratar el ADN.

Anexo 4. Amplificación de IGF-SnaBI y GnRHR-SNP6 por reacción en cadena de la polimerasa (PCR) para pirosecuenciación.

1- En un tubo de $200 \mu 1$ apto para PCR realizar la solución detallada en la tabla A1. La secuencia de los primers se encuentra reportada en la tabla A2.

Tabla A.4.1. Solución para amplificar en Termociclador

\begin{tabular}{lcc}
\hline & IGF-SnaBI & GnRHR-SNP6 \\
\hline Buffer & $3 \mu \mathrm{l}$ & $3 \mu \mathrm{l}$ \\
Enhancer & $3 \mu \mathrm{l}$ & $3 \mu \mathrm{l}$ \\
$\mathrm{dNTPs}^{2+}$ & $2,4 \mu \mathrm{l}$ & $2,4 \mu \mathrm{l}$ \\
$\mathrm{Mg}^{2+}$ & $2,4 \mu \mathrm{l}$ & $2,4 \mu \mathrm{l}$ \\
Primer foward & $0,85 \mu \mathrm{l}$ & $0,6 \mu \mathrm{l}$ \\
Primer reverse & $0,85 \mu \mathrm{l}$ & $0,6 \mu \mathrm{l}$ \\
Polimerasa Taq & $0,15 \mu \mathrm{l}$ & $0,15 \mu \mathrm{l}$ \\
Solución ADN & $3 \mu \mathrm{l}$ & $3 \mu \mathrm{l}$ \\
Agua & $9,35 \mu \mathrm{l}$ & $9,85 \mu \mathrm{l}$ \\
\hline \multicolumn{1}{c}{ Total } & $25 \mu \mathrm{l}$ & $25 \mu \mathrm{l}$ \\
\hline
\end{tabular}


Tabla A.4.2. Secuencia de los primers utilizados para cada SNP y Temperatura de anealing

\begin{tabular}{cccc}
\hline SNP & Primer & Secuencia del Primer & $\begin{array}{c}\text { Temperatura } \\
\text { de anealing }\end{array}$ \\
\hline & GnRHR-SNP6-F & 5'-CAGCTGCCTC & \\
GNRHR- & ThRHR-SNP6-R & 5'-TGCCTCATAGG & 56 \\
SNP6 & (Biotinilado) & GTGATTTTGA-3' & \\
& GnRHR-SNP6- & 5'-ATGCAAA & \\
& interno & AATCATCTT-3' & \\
& IGF1-SnaBI-F & 5'-CCAGCGCTGT & \\
IGF1- & IGF1-SnaBI-R & CTTCCATTCTA-3' & \multirow{2}{*}{ 5'-TGATTAACTTT } \\
SnaBI & (Biotinilado) & CTACCGGGCG-3' & \\
& IGF1-SnaBI- & 5'-ATTCGTCGC & \\
& interno & CCATCCTC-3' & \\
\hline
\end{tabular}

2- Disponer los tubos en el ciclador y seleccionar el programa correspondiente

a. Para GnRHR-SNP6 45 ciclos donde cada ciclo consiste en: $94^{\circ} \mathrm{C}$ durante 45 segundos, $56^{\circ} \mathrm{C}$ durante 45 segundos y luego aumenta a $72^{\circ} \mathrm{C}$ durante 45 segundos y se mantiene a esa temperatura por 7 minutos.

b. Para IGF-SnaBI se utiliza el mismo programa solo que la temperatura de anealing se eleva desde $56^{\circ} \mathrm{C}$ a $60^{\circ} \mathrm{C}$.

Anexo 5. Descripción de la técnica de pirosecuenciación.

Purificación de los productos de PCR para pirosecuenciación.

Los productos amplificados contienen biotina en una de sus hebras, esta puede ser separada de su cadena complementaria no biotinilada mediante el uso de perlas de sefarosa unidas a estreptavidina. La estreptavidina se une a la biotina, por lo tanto, durante un proceso de lavado el ADN de doble cadena biotinilado 
permanece unido a las perlas, mientras el resto de los productos resultantes de la reacción de PCR son removidos. Seguidamente, el ADN es desnaturaliza mediante el uso de un álcali, y por lavado posterior se elimina la cadena no biotinilada. Esta purificación disminuye las señales de fondo mejorando la calidad de la información.

\section{Pirosecuenciación.}

La técnica se basa en la formación de pirofosfato inorgánico (PPi) como resultado de la incorporación de los dNTPs durante la polimerización del ADN. Luego de la incorporación de un dNTP conocido, la enzima ATP sulfurilasa genera adenosinatrifosfato (ATP) a partir de adenosina-5'-fosfosulfato (APS) y del PPi liberado. Este ATP liberado provee de la energía necesaria para la oxidación de luciferina a oxiluciferina por acción de la enzima luciferasa, con la consecuente formación de luz. Con cada adición de un dNTP en cada paso de la polimerización del ADN se produce un haz de luz en forma proporcional, la intensidad de la luz es leída por el equipo y presentada en formas de picos de distinta altura en un pirograma.

Al conocer la identidad de cada dNTP liberado, la secuencia molde se determina a partir de la lectura de los picos de luz durante la reacción. En cada paso de la secuenciación los dNTPs no utilizados y el exceso de ATP es degrado por la enzima apirasa, y el equipo queda preparado aguardando el próximo paso de la secuenciación. El cebador interno utilizado está diseñado de manera que el extremo 3' se hibride una a tres bases antes de la posición polimórfica de interés, y cada combinación alélica genera un patrón de picos específicos que permite distinguirlos. 